\title{
Evaluation of Work Zone Speed Reduction Measures
}

Sponsored by the Project Development Division

of the lowa Department of Transportation

CTRE Management Project 99-44

APRIL 2000

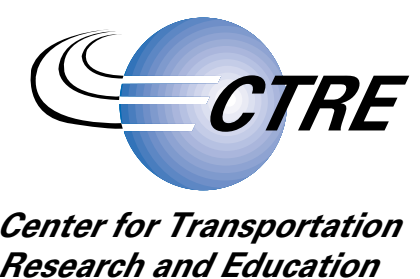

Research and Education

IOWA STATE UNIVERSITY 
The opinions, findings, and conclusions expressed in this publication are those of the authors and not necessarily those of the lowa Department of Transportation.

CTRE's mission is to develop and implement innovative methods, materials, and technologies for improving transportation efficiency, safety, and reliability, while improving the learning environment of students, faculty, and staff in transportation-related fields. 


\title{
Evaluation of W ork Zone Speed Reduction Measures
}

\author{
Principal Investigator \\ Tom Maze \\ Co-Principal Investigator \\ Ali Kamyab
}

Graduate Research Assistant

Steve Schrock

\begin{abstract}
Preparation of this report was financed in part through funds provided by the lowa Department of Transportation through its research management agreement with the Center for Transportation Research and Education, CTRE Management Project 99-44.
\end{abstract}

\author{
Center for Transportation Research and Education \\ lowa State University \\ lowa State U niversity Research Park \\ 2901 South Loop D rive, Suite 3100 \\ Ames, IA 50010-8632 \\ Telephone: $515-294-8103$ \\ Fax: 515-294-0467 \\ http://www.ctre.iastate.edu
}

April $\mathbf{2 0 0 0}$ 


\section{TABLE OF CONTENTS}

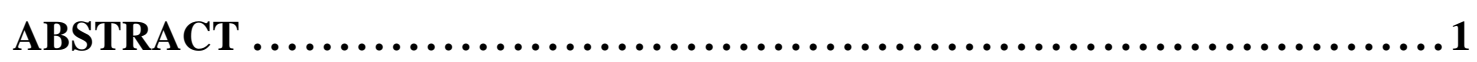

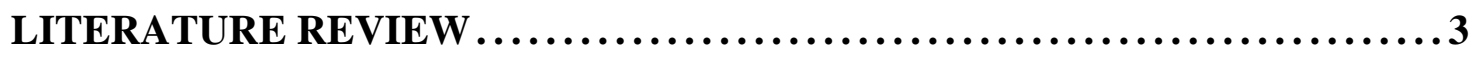

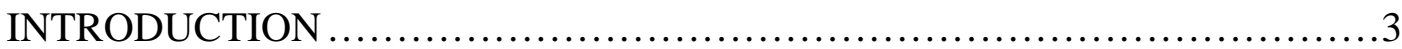

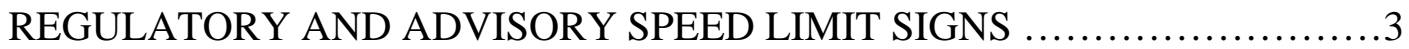

REDUCED LANE WIDTH ...............................................4

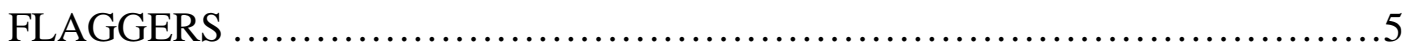

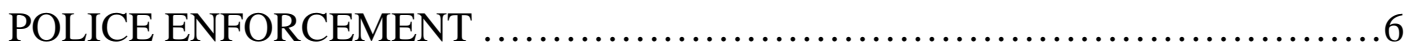

DRONE RADAR ...................................................... 8

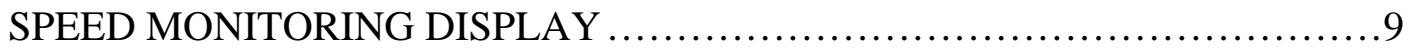

RUMBLE STRIPS..................................................... 11

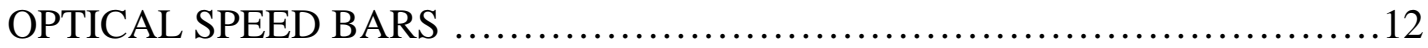

CONCLUDING REMARKS........................................... 13

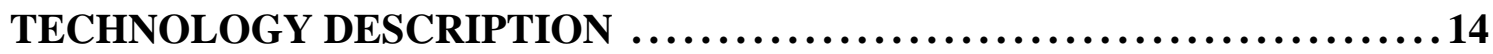

INTRODUCTION ......................................................... 14

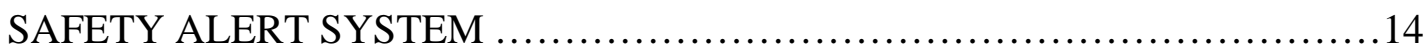

System Evaluation ................................................. 14

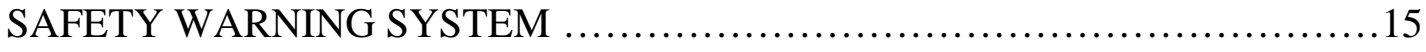

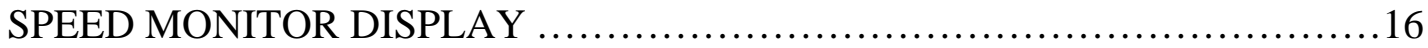

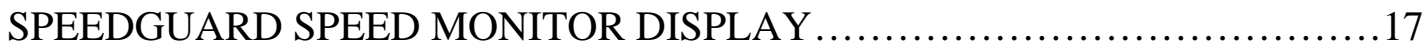

System Evaluation ................................................. 18

WIZARD WORK ZONE ALERT AND INFORMATION RADIO ...............18

REMOVABLE RUMBLE STRIPS ..................................... 18

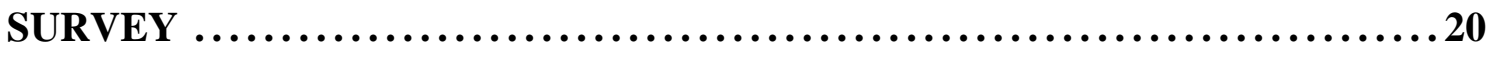

INTRODUCTION .....................................................20

QUESTION 1: WORK ZONE POLICY DESCRIPTION $\ldots \ldots \ldots \ldots \ldots \ldots \ldots \ldots \ldots . \ldots \ldots$

QUESTION 2: POLICY DEVELOPMENT PROCEDURE ......................21

QUESTION 3: SPEED LIMIT ASSIGNMENT ...............................22

Scenario 1: Mobile Maintenance Operation (Two-Lane Road) .................22

Scenario 2: Mobile Maintenance Operation (Multilane Road) .................23

Scenario 3: Lane Closure with No Concrete Barrier (Multilane Road) ...........23

Scenario 4: Lane Closure with Concrete Barrier (Multilane Road) .............24

Scenario 5: Lane Closure on a Structure with Concrete Barrier

(Multilane Road)..............................................24

Scenario 6: Lane Shift (Multilane Road) ..................................25

Scenario 7: Median Crossover (Multilane Road)...........................25

QUESTION 4: SYSTEM EFFECTIVENESS .................................26

Regulatory Speed Limit Signs..........................................27

Advisory Speed Limit Signs .............................................27

Changeable Message Signs ...............................................28

Police Enforcement ...................................................28 
Ghost Police Vehicle ..........................................................29

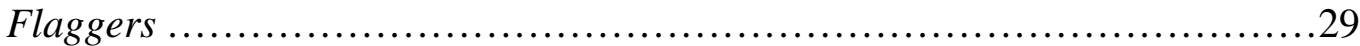

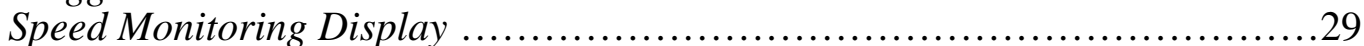

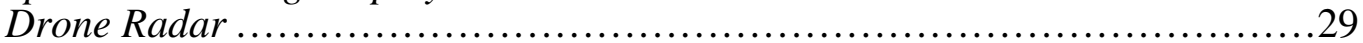

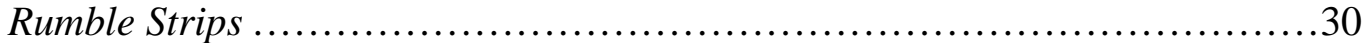

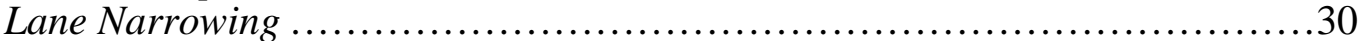

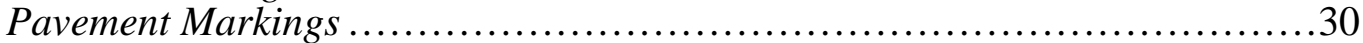

Highway Advisory Radio ................................................... 30

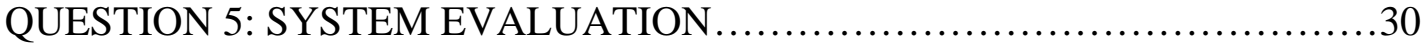

QUESTION 6: MOST EFFECTIVE SYSTEM …............................... 31

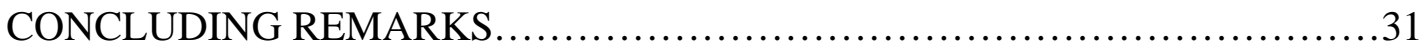

ACKNOWLEDGMENTS...........................................

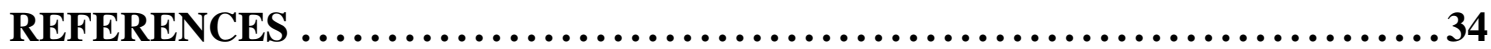

APPENDIX A-COVER LETTER AND SURVEY FORM $\ldots \ldots \ldots \ldots \ldots \ldots \ldots . \ldots, \ldots$

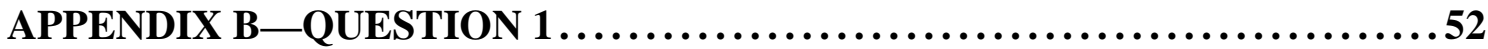

STATE AGENCIES WITH POLICIES ......................................55

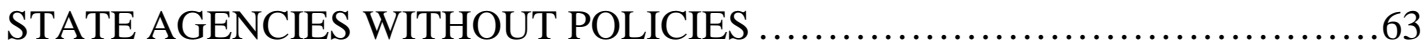

APPENDIX C-QUESTION 2 ....................................64

STATE AGENCIES WITH POLICIES .......................................64

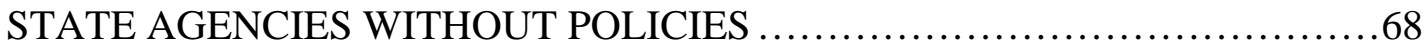

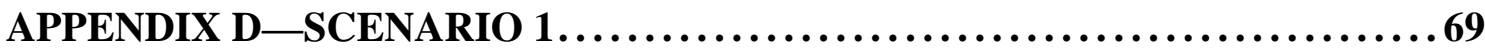

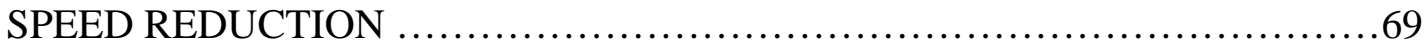

NO SPEED REDUCTION ................................................... 71

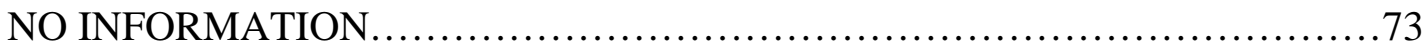

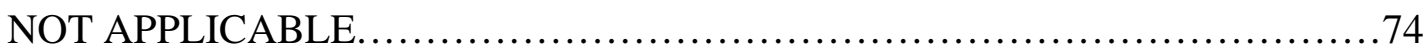

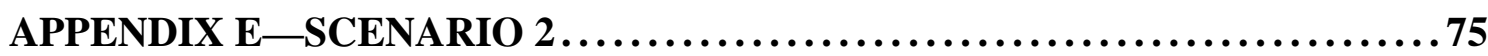

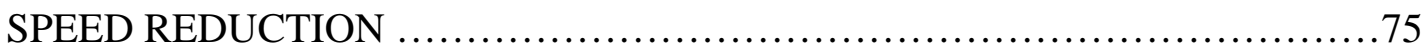

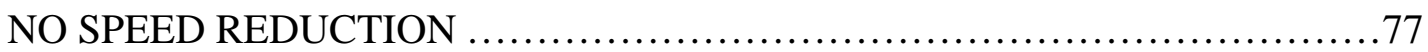

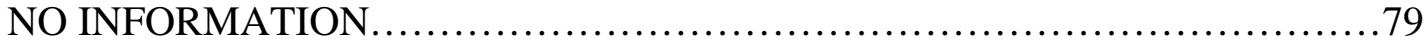

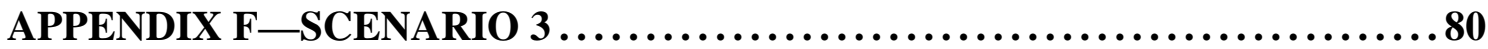

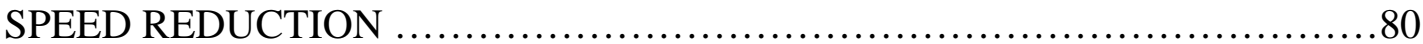

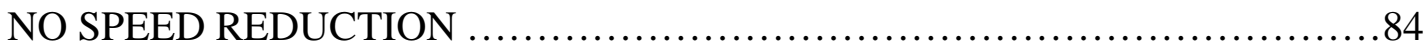

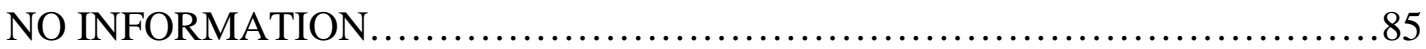

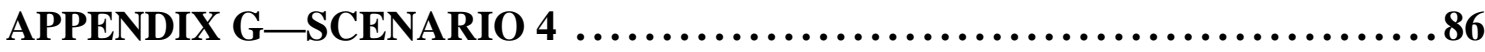

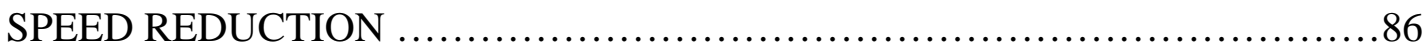

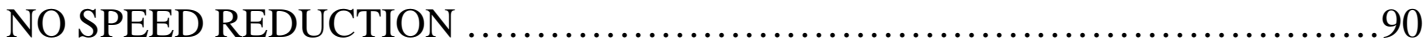

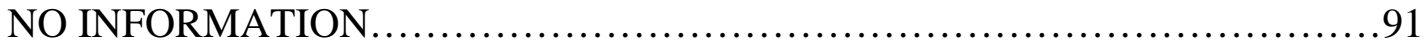

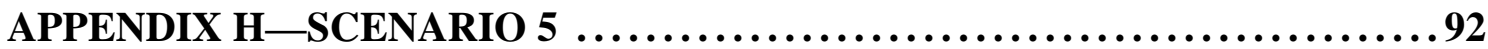

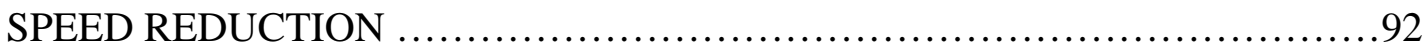

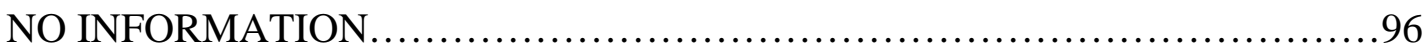




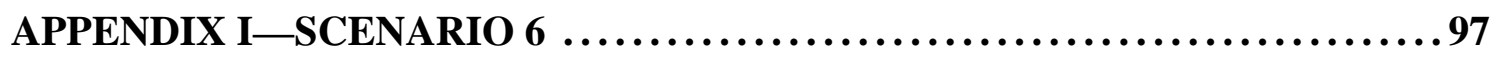

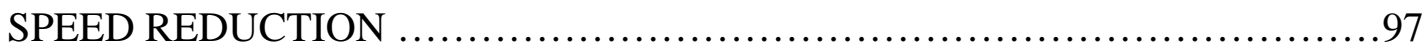

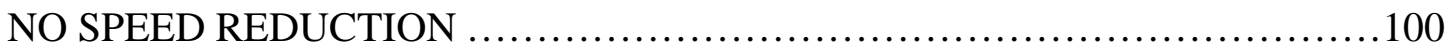

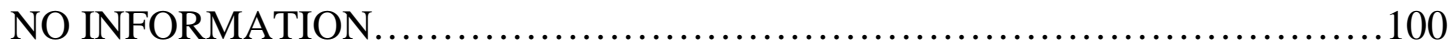

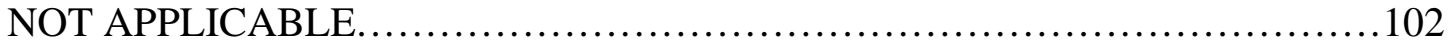

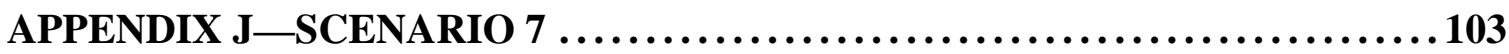

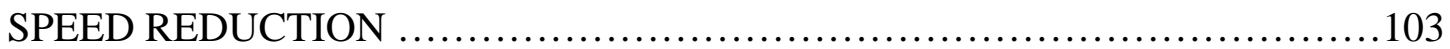

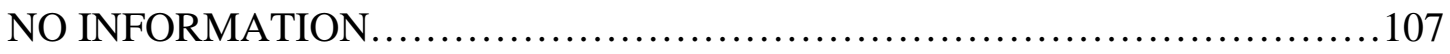

APPENDIX K-QUESTION 4 .....................................

REGULATORY SPEED LIMIT SIGNS, ADVISORY SPEED LIMIT SIGNS,

AND CHANGEABLE MESSAGE SIGNS …..........................108

POLICE ENFORCEMENT, GHOST POLICE CAR, AND FLAGGERS ..........112

SPEED MONITORING DISPLAY, DRONE RADAR, AND

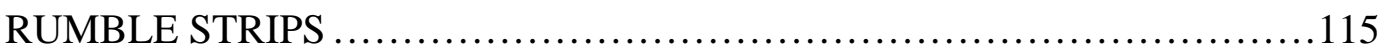

LANE NARROWING, PAVEMENT MARKINGS, AND

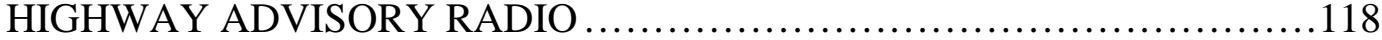

APPENDIX L-QUESTION 5: SYSTEM EVALUATION ..................121

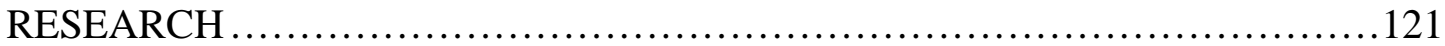

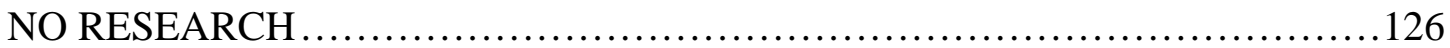

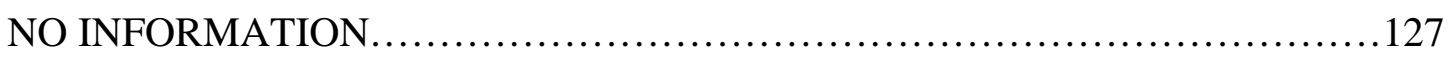

APPENDIX M-QUESTION 6: MOST EFFECTIVE SYSTEM ..............128

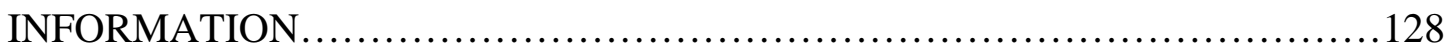

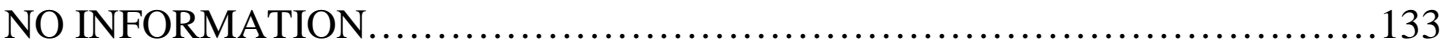




\section{LIST OF TABLES}

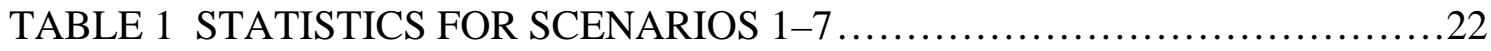
TABLE 2 QUESTION 4 SPEED REDUCTION STRATEGIES AND

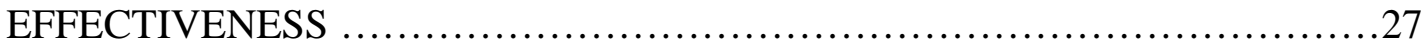




\begin{abstract}
The Iowa Department of Transportation (DOT) has made improving work zone (WZ) safety a high priority. Managing vehicle speeds through work zones is perceived to be an important factor in achieving this goal. A number of speed reduction techniques are currently used by transportation agencies throughout the country to control speeds and reduce speed variation at work zones. The purpose of this project is to study these and other applicable work zone speed reduction strategies. Furthermore, this research explores transportation agencies' policies regarding managing speeds in long-term, shortterm, and moving work zones.
\end{abstract}

This report consists of three chapters. The first chapter, "Literature Review," examines the current speed reduction practices at work zones and provides a review of the relevant literature. The speed control strategies reviewed in this chapter range from posting regulatory and advisory speed limit (SL) signs to using the latest radar technologies to reduce speeds at work zones.

The literature review chapter concludes that flagging and police enforcement speed reduction strategies have had very positive impacts in reducing work zone speeds. They are, however, labor intensive and can become costly with long-term use. Flagging by its nature is physically tiring, boring work. Moreover, due to limited resources, the use of police officers at work zones is infrequent by many agencies. The impracticality of the extensive use of law enforcement at work zones may result in a short-term impact on motorists. Replacing these strategies with innovative technologies, such as robotic flaggers and photo-radar enforcement machines, may be practical, more cost-effective solutions.

The speed reduction techniques described in the first chapter have had some success at slowing motorists through work zones. However, none of the techniques individually is capable of reducing vehicle speeds to the desired level. The most effective speed reductions will probably involve some combination of the techniques described in this literature review.

Through the literature and other referrals, several technology providers were identified. The second chapter, "Technology Description," includes a short write-up for each identified speed control technique. The write-up includes a description, the results of any field tests, the benefits, and the costs of the technology or technique.

To learn more about other state policies regarding work zone speed reduction and management, the Center for Transportation Research and Education (CTRE) conducted a survey. The survey consists of six multipart questions. The third chapter, "Survey," provides summaries of the response to each question. Copies of the survey and the cover letter are included in appendix A.

Every state DOT and a number of non-DOT transportation agencies in other states (e.g., state turnpike commissions) were contacted using Iowa DOT letterhead in the hope of improving the likelihood of a response. Surveys were sent to 63 state transportation agencies. Thirty-nine responses were received for a 62 percent response rate. Responses were entered into a database to allow queries to be conducted on each individual question. Responses, grouped under each question, are listed in detail in appendices B through $\mathrm{M}$. 
During construction activities, most participating state agencies reported reducing speed limits to $10 \mathrm{mph}$ below the normal posted speed. There are a few agencies that even consider reducing speed limits by $20 \mathrm{mph}$. Furthermore, among the 12 identified speed reduction strategies, the use of regulatory speed limit signs and police enforcement are the most common practices reported by the agencies. However, only seven percent of the participating agencies consider the use of regulatory signs to be an effective speed reduction strategy. This may be compared with 70 percent of agencies that consider engaging police enforcement to be very effective at imposing speed limit compliance at work zones.

The survey further indicates that the use of changeable message signs (CMS) by 18 out of 34 agencies might be an indication of their potential in reducing work zone speeds. A number of these agencies use CMS in conjunction with radar to detect and display speeds of approaching vehicles.

The third chapter concludes that the Iowa DOT and six other Midwest state agencies are among the small group of agencies (a total of 12) that have conducted research to study the effects of speed reduction strategies at work zones. 


\section{LITERATURE REVIEW}

\section{Introduction}

There has been a substantial increase in reconstruction and rehabilitation activities in the highway and urban street systems. The frequency of maintenance activities and the potential severity of work zone accidents have intensified the importance of safe and efficient handling of traffic in work zones.

The relationships between travel speed and accident rates indicate that accident rates increase as speed variance increases (1). A large speed variance coupled with hazardous conditions at work zones (e.g., workers' presence, lane closure, and narrow lane) may lead to higher accident rates at work zones. Therefore, it could be conjectured that by reducing the speed variance, that is, by having vehicles travel at about the average speed, accident rates would decrease at work zones.

A number of speed control techniques are currently used by state transportation agencies throughout the country. These range from posting regulatory and advisory speed limit signs to using the latest radar technologies to reduce speeds at work zones. This chapter examines the current speed reduction practices at work zones and provides a review of the relevant literature.

\section{Regulatory and Advisory Speed Limit Signs}

Posting regulatory and advisory speed limit signs is a common speed reduction practice in the United States. Regulatory signs are used to relay to motorists information about a reduced speed limit at work zones (2). These speed limit signs are enforceable by law.

Alternatively, advisory speed limit signs indicate a recommended safe speed through temporary work zones (2). Advisory speed limit signs are generally used as supplementary warnings of an approaching hazard; while enforceable by law, they do not carry the same authority as regulatory signs.

Seventy percent of state highway departments occasionally lower speed limits by 10-15 mph to reduce speeds at work zones (3). The posted speed limits on the advisory signs are even lower, especially when construction is taking place near traveling lanes.

In the past, enforcement of advisory speed limits in Minnesota required proof that exceeding them was not reasonable and prudent (4). As a result of a petition signed by 721 maintenance workers, a law was passed in 1988 allowing work zone speed limits to be marked by regulatory signs, making them enforceable by the police and the court. Under the new law, an average speed reduction of $15 \mathrm{mph}$ was recorded by the state patrol on Interstate 94 near Alexandria. This speed reduction, however, cannot be attributed to the new signs alone. Enforcement and public awareness campaigns through media made drivers aware of the lower speed.

Prescott, Hall, and Rutley attempted to determine whether saturating motorists with constant reminders of the speed limit would decrease the average traffic speed (5). No work zones were a part of the study. In this experiment, 70-mph regulatory speed limit signs were placed in the median and along the outside shoulder every mile for 20 miles along a motorway in Yorkshire, England. The experiment took place over a two-year period during normal freeway operation. This study found that the additional signing had no significant effect on the travel speed of motorists. 
A 1977 study indicated that regulatory and advisory speed limit signs had minimal impact on reducing speed at work zones in rural freeways and urban arterial roads (6). Furthermore, an Australian study concluded that lowering work zone speed limits reduced the mean traffic speed by four to five $\mathrm{mph}$, but that 80 to 95 percent of vehicles still traveled faster than the posted speed limit (7). Moreover, Sisiopiku et al. indicated that, regardless of posted work zone speed limits, motorists tended to traverse work zones at higher speeds when more lanes were open to traffic (8).

A 1981 study conducted on a two-lane rural road in central Maine indicated that the suggested Manual on Uniform Traffic Control Devices (MUTCD) warning sign sequence becomes more effective in reducing speed at work zones when augmented with flashing beacons (9). In the early 1990s, the Illinois DOT added two small strobe lights and two orange-colored plates to the signs to improve the effectiveness of regulatory $45-\mathrm{mph}$ speed limit signs (10). The orange plates indicated that when the lights were flashing the speed limit was $45 \mathrm{mph}$. The flashing lights were turned off when no crew was present at the site.

Benekohal and Shu studied the speed reduction effects of speed limit signs augmented with strobe lights (10). Their results indicated that the average speeds of cars and trucks were reduced by 1.9-7.1 and 1.3-6.0 $\mathrm{mph}$, respectively. The study concluded that, in general, the percentages of vehicles with excessive speeds at work zones decreased when strobe lights were flashing.

While important for conveying information to the public, regulatory and advisory speed limit signs alone have been shown to have minimal impact on reducing traffic speeds.

\section{Reduced Lane Width}

Narrow lane widths are, to some extent, effective in reducing traffic speeds. In general, narrower lanes leave less lateral distance between vehicles in adjacent lanes or between vehicles and shoulder obstructions, requiring more of motorists' attention and influencing motorists to reduce speeds.

The 1994 Highway Capacity Manual considers 12 feet the ideal lane width (11). In estimating free-flow speed on multilane highways, the manual suggests considering 1.9 and 6.6-mph reductions in free-flow speed when the lane widths are 11 and 10 feet, respectively.

Using a driving simulator, Van Der Horst and Hoekstra examined the impact of narrow lanes in reducing speed over a typical Netherlands rural roadway (12). The study indicated that the narrow lane width (about 18 percent narrower than the ideal width) causes drivers to reduce their speeds.

Reduced lane widths are often necessary in work zones because of a narrow right-of-way. Several studies in Texas reviewed the speed change effects of narrow lanes in Houstonarea work zones $(13,14)$. Even though the lane-width reduction was due to the constraints of the project and was not implemented to intentionally slow motorists, an overall speed reduction did result. Mean speed reductions of 3-8 mph were observed at one location. Speeds, however, were only slightly affected at the second case-study work zone. It should also be noted that other features of the work zones might have played a part in the speed reduction, as there was no effective method of isolating the impact of the narrow lanes. 
Richards, Wunderlich, and Dudek examined the effectiveness of lane-width reductions at six work zones on rural and urban freeways in Texas (15). Lane widths were reduced to 11.5 and 12.5 feet using cones. The effectiveness of the lane-width reduction treatment varied by site, from no effect at one site to a 16 percent speed reduction at another (i.e., from 0 to $8 \mathrm{mph}$ ). The study noted that more restrictive devices than cones, such as barrels and concrete barriers, would likely result in greater speed reductions.

Benekohal, Kastel, and Suhale reviewed several studies on work zone speed control techniques (16). Their review indicated that lane-width reductions have minimal effect in reducing speeds on urban and rural freeways. The study concluded that the effectiveness of lane-width reduction treatments depends significantly upon the method of reducing the lane width and the length of the narrow section.

Depending on the method used to reduce the lane width, setup and maintenance of the work zone may be time consuming. For example, if cones are used, this method may require considerable efforts to keep the cones aligned and in the correct location (17). On the other hand, reducing lane widths by installing concrete barriers would be a more reliable means of lane reduction, because the barriers will not easily be moved or displaced.

\section{Flaggers}

Flagging is a commonly used technique in work zones of all types. According to part 6 of the MUTCD, a flagger needs to be placed far enough in advance of the work space to allow motorists the opportunity to slow or stop as required (2). Several previous studies have found flaggers to be a speed control measure that can be incorporated into a work zone traffic management plan.

Benekohal and Kastel conducted a study at a rural Illinois work zone to determine the impact of flaggers on traffic speed (18). Speeds were recorded as vehicles moved through the work zone. Speed data were collected prior to and after the flaggers were given training to reinforce their knowledge of proper MUTCD flagging techniques for rural interstate work zones. This study determined that there was a speed reduction for both trucks and cars as they approached a flagger. However, the speed reduction was more pronounced after the flaggers received additional training. This training included recommendations in the MUTCD on the proper posturing, motions, and assertiveness of flaggers and of making eye contact with motorists.

This study indicated that the average speeds of cars and trucks were reduced by 11.7 and $9.1 \mathrm{mph}$, respectively, prior to flagger training sessions. The speed reductions for cars and trucks increased to 14.9 and $11.9 \mathrm{mph}$, respectively, after the training.

In a related study, an innovative flagging procedure was utilized that included more aggressive actions by the flagger (17). In addition to the procedure detailed in the MUTCD, the flagger motioned traffic to slow and pointed at a reduced speed limit sign with his free hand. This study indicated that work zone speeds were reduced by $7-13$ $\mathrm{mph}$ at rural interstates, $10-16 \mathrm{mph}$ at rural two-lane highways, $13 \mathrm{mph}$ at urban arterial roads, and $4-5 \mathrm{mph}$ at urban freeways.

A similar flagger study examined the speed reduction effects of larger flagger signs and new yellow-green flagger apparel (19). This study found that the new flagging procedure is less effective than the traditional MUTCD flagging method. The study determined that the new and traditional procedures reduced mean speeds by 9.2 and $11.1 \mathrm{mph}$, respectively. The study then concluded that the larger sign reduced the effectiveness of 
the flagger because the flagger was required to hold it with both hands to maintain control.

While flaggers can be very effective at reducing traffic speeds, there are several drawbacks associated with their use. Flagging by its very nature is labor intensive, making it costly for long-term use. Moreover, flagging is physically tiring, boring work. To maintain maximum flagger effectiveness, personnel should be properly trained and rotated on a regular basis $(3,19)$.

\section{Police Enforcement}

One of the most effective work zone speed management techniques found in the course of this literature review is police enforcement. This speed reduction strategy generally involves the use of police enforcement in two forms: stationary and mobile. A police officer stationed at one point significantly increases the speed limit compliance at that location (16). On the other hand, a circulating police car covers a larger area but is less effective at speed reduction.

Richards et al. examined the effectiveness of law enforcement under stationary as well as mobile modes at six work zones on rural and urban highways in Texas (15). The study indicated that a stationary patrol car was able to reduce mean speeds by $4-12 \mathrm{mph}$ (i.e., from 6 to 22 percent speed reduction). A circulating patrol car was found to reduce speeds by only 2-3 mph (i.e., between 3 to 5 percent speed reduction), indicating its reduced effectiveness relative to the stationary enforcement mode.

McCoy and Bonneson conducted a study of police enforcement at a work zone consisting of a single-lane closure on an urban multilane street in Sioux Falls, South Dakota (19). A police car with an officer inside was placed just downstream from a "ROAD

CONSTRUCTION AHEAD" sign with its lights flashing and its radar active. The police vehicle in this experiment remained stationary and did not attempt to stop speeding motorists.

Only free-flow vehicles were examined in this study. Free-flow vehicles were defined as those with more than four seconds of headway. Other motorists were considered to be unable to drive at their desired speed because of traffic congestion. The study concluded that average traffic speeds at the beginning of the work zone were lowered from 30 to 25 mph. These average speeds were still above the posted 20 -mph advisory speed.

Noel et al. conducted a study on a six-lane freeway in Delaware to determine the effect of the presence of law enforcement (20). Police presence was studied in two forms: (1) using a police car with flashing lights and active radar and (2) with an officer standing on the roadside motioning the traffic to slow down. The study also looked at the effect of law enforcement under one- and two-lane-closure conditions as well as at short-term (about three days) and long-term (more than 10 days) data collections.

The study found that in the short term, mean speeds were reduced by 2.4 and $5.1 \mathrm{mph}$ for one-lane closures under the first and second enforcement modes, respectively. With a two-lane-closure case study, mean speeds further reduced by $6.3 \mathrm{mph}$ under the second law enforcement mode (i.e., police controller). With a one-lane-closure case study, however, mean speeds increased by $3.6 \mathrm{mph}$ under the first enforcement mode (i.e., police radar). No explanations were provided for this speed increment.

The study indicated that the police enforcement methods were also effective in reducing speeds in the long term. Under the police radar treatment, speeds were reduced by 8.4 and 
$6.4 \mathrm{mph}$ for one- and two-lane-closure case studies, respectively. The police controller (i.e., second enforcement mode) was able to reduce mean speeds by about $3.3 \mathrm{mph}$ for both case studies. The long-term effectiveness of this speed reduction treatment was partly due to the prior existence of high-level police patrolling of the study locations.

Benekohal, Resende, and Orloski evaluated the impact of the presence, then the absence, of marked police cars on vehicle speeds at rural interstate work zones in Illinois (21). First, the study examined average traffic speeds with a marked police car circulating through the work zone for four hours. The second part of the study was to determine whether there was a lasting impact on speeds after the patrol car left at the end of four hours.

The study found that mean speeds of cars and trucks in the work zone were reduced by about 4 and $5 \mathrm{mph}$, respectively, while the police car was circulating through the work zone. The percentages of cars and trucks exceeding the speed limit through the work zone were reduced by 14 and 32 percent, respectively. One hour after the police car left the work zone, the mean speed of cars and trucks increased by about 2.5 and $0.5 \mathrm{mph}$, respectively. This study concluded that, at least for trucks, a lasting speed reduction could be obtained by periodically placing mobile police cars in a work zone.

The Minnesota DOT examined the effectiveness of police enforcement at work zones on three different sites: a rural interstate, an urban freeway, and a metro location (22). Using a laser gun, speed data were collected with and without a law enforcement vehicle presence. The patrol car was located approximately 500-600 feet upstream of the work zones, with its lights and flasher activated.

The posted speed limit on the four-lane divided interstate was $70 \mathrm{mph}$, which during the construction was reduced to $40 \mathrm{mph}$ at the work zone area. The study found that the 85th percentile speed was reduced from 51 to $43 \mathrm{mph}$ when the police vehicle was placed upstream of the work zone. Similarly, for the urban freeway with a posted speed limit of $55 \mathrm{mph}$ and for the metro location with a posted speed limit of $50 \mathrm{mph}$, the 85th percentile speeds were reduced from 66 to $58 \mathrm{mph}$ and from 58 to $47 \mathrm{mph}$, respectively. The study confirmed that the presence of law enforcement results in considerably improved compliance with posted speed limits.

Police enforcement relies on observation assisted by technology. Jones and Lacey conducted a study in Iowa to determine the effectiveness of laser-based speed enforcement programs relative to radar-based programs (23). Radar and laser speed measurement devices were used for the entire communities in the cities of Dubuque and Council Bluffs, respectively. Both cities increased their speed enforcement activity during the study periods by increasing the public awareness of the risk of being cited for speeding violations. Speed data were collected once each week at 10 locations in each city before and after the speed enforcement program implementation.

The study indicated that the radar-based speed enforcement program decreased the percentage of vehicles traveling more than five mph over the posted speed limit by about 20 percent. The laser-based speed program, however, did not have any effects in reducing the speeding in Council Bluffs. The absence of any speed reductions in Council Bluffs may be explained by the preexistence of a higher level of speed limit compliance in the community. The researchers concluded that laser-based speed measuring devices should supplement rather than replace the existing radar speed technology.

The lasting effects of police presence were evaluated in a recently increased speed limit zone in Michigan along Interstate 96 (24). The study indicated an average speed 
reduction of $5.5 \mathrm{mph}$ for the vehicles that approached a police car. Upon passing the police car, the vehicles, however, tended to speed up to their original speed or higher. The study reported no visible changes in speeds one, two, and three hours after the police presence. The study concluded that because of the limited resources of law enforcement agencies, this speed reduction strategy is less effective than others in enforcing highway speeding in general.

\section{Drone Radar}

Drone radar is an electronic radar system that transmits in the microwave-frequency band. Vehicles equipped with radar detection devices perceive transmitted radar signals from the drone as the presence of police enforcement. In response, believing that a police car is nearby, these vehicles reduce their speeds, which in turn causes other vehicles to slow down. The purpose of using drone radar in a speed reduction program is to reduce the 85th percentile speed, rather than the average speed, because it is assumed that the fastest group of drivers is more likely to possess radar detectors. Drone radar devices can be strategically attached to a variety of objects, including construction flashing arrow boards or barrels in work zones.

Benekohal, Resende, and Zhao studied the effectiveness of drone radar at a rural interstate work zone in Illinois (25). Three experiments were conducted with drone radar to determine the immediate, short-term, and lasting effects while using multiple radar guns. The first experiment was conducted for less than an hour, with one radar gun operating from a stationary vehicle near the merge area. This experiment was effective in reducing mean speeds by $8-10 \mathrm{mph}$. However, the second experiment, conducted for a few hours using one radar gun, indicated no speed reductions. The study team listened to $\mathrm{CB}$ radio conversations. They discovered that motorists were quickly able to determine that no police was present in the work zone, and that the radar emissions were drone radar. The motorists were even able to determine the location of the drone radar. In the third experiment, two radar guns were used from different locations for three hours. The study indicated that this modification increased the effectiveness of the radar, as motorists were unable to determine the location of the radar signals. In this case, speeds were reduced by 3-6 mph for trucks and by $3 \mathrm{mph}$ for cars.

Ullman also conducted an experiment on the effectiveness of using drone radar to reduce speeds in work zones (26). In this study, the radar effectiveness was examined at work zones on suburban and rural divided highways and on suburban interstates. Ullman performed the study in 30-45 minute segments throughout the day and compared the data with the next 30-45 minute period to provide comparison data for every portion of the day. Average speed reductions for all eight sites were reported to be only $0.2-1.6 \mathrm{mph}$ when the drone radar was active.

This study further analyzed the data to determine whether the fastest motorists were indeed the most likely to be affected by drone radar. The average speed reduction for vehicles traveling greater than $65 \mathrm{mph}$ at 3,000 feet upstream of the work zone was compared with that of all vehicles. The speed reduction for this speeding group of motorists was determined to be $0.2-2.6 \mathrm{mph}$ greater than the average speed reduction for all vehicles once inside the work zone.

Furthermore, Streff, Kostyniuk, and Christoff extensively examined the effectiveness of drone radar with and without patrol car presence on high-speed freeway locations and in freeway construction zones (27). The percentage of vehicles using radar detectors was estimated at about five percent for cars and more than sixteen percent for trucks. 
The study found the speed reduction effects of the drone radar, the police presence, and the combination of these measures to be statistically significant almost in all cases. The large number of observations resulted in a high statistical power. In many cases, the differences in mean speeds of about one mph were reported to be statistically significant. Speed reductions of this magnitude are rarely noticeable in a traffic stream and have minimal practical effects.

The study indicated that drone radar and police presence have practical effects on the behavior of high-speed trucks. Speed reductions were recorded for 30-70 percent of trucks in the passing lane exceeding the speed limit by at least $10 \mathrm{mph}$. No similar reduction in the speed of high-speed trucks was observed at the work zones. The study concluded that the combination of drone radar and police presence is a good countermeasure at locations where speeding trucks are a problem.

Drone radar was also used to slow motorists as they approached high-risk crash locations on both rural and urban interstates in Missouri (28). These high-risk crash sites were determined by identifying locations where roadway alignment, road surface, and traffic conditions have contributed to high crash rates.

This study indicated that at rural locations, mean speeds were reduced by 0.2 and $1.8 \mathrm{mph}$ for passenger cars and trucks, respectively. At urban locations, mean passenger car speeds were almost unchanged. However, trucks experienced one-to-two-mph speed reductions when the drone radar was active. It should be noted that the mean speeds of passenger cars and trucks exceeded the speed limit whether the drone radar was active or inactive.

For the drone radar to be effective, motorists must be kept guessing about the source of the radar emissions. Also, overusing such a technique may well reduce its usefulness, as motorists might then come to understand that radar emissions are rarely from police.

\section{Speed Monitoring Display}

Speed monitoring displays, also known as mobile radar trailers, were developed in the late 1980s (29). Speed displays use a radar device to determine speeds of approaching vehicles and display the detected speeds. The display boards are not generally used to enforce the speed limits and issue citations. The assumption is that motorists will drive slower once they are aware of their speed. These speed reductions occur in two ways. First, drivers will read the display, realize that they are speeding, and choose to slow down. Second, motorists with radar detectors will be likely to slow down when their detectors are activated by the radar signals.

McCoy, Bonneson, and Kollbaum examined the effectiveness of speed displays at a rural interstate work zone in South Dakota (30). The speed monitoring display evaluated in this study was placed on a trailer. The trailer was augmented with a "WORK ZONE" warning sign, an advisory 45-mph speed limit sign, and a "YOUR SPEED" plate. The trailer was placed in the median next to the left traffic lane at the beginning of the merge-area taper. As motorists approached the merge area, their speeds were displayed on the speed monitoring display.

The study indicated that the speed monitoring display reduced mean vehicle speeds by four $\mathrm{mph}$ (i.e., from 60.5 to $56.5 \mathrm{mph}$ ). The study also indicated a reduction in the percentage of vehicles that were exceeding the speed limit through the work zone. The percentage of passenger cars speeding through the work zone was reduced by 20-25 percent. The percentage of speeding trucks was reduced by about 40 percent. There are a 
number of factors that may play a role in improving the effectiveness of the speed display. These include the placement, size, and design of the display trailer.

In a similar study, Garber and Fontaine used changeable message signs with a radar unit to examine speed reductions at rural interstate work zones in Virginia (31). In this study, the radar and CMS system were set up approximately 300-600 feet upstream from the merge area. The radar was carefully placed to detect only one vehicle at a time. Vehicles that drove above a selected threshold speed activated the CMS system, which in turn displayed a "YOU ARE SPEEDING, SLOW DOWN" message. The speeding motorists were videotaped as they passed through the work zones to capture any changes in speeds of the vehicles.

This study found that the mean speed of all traffic was reduced by only approximately 0.7 $\mathrm{mph}$ at the CMS location. Once inside the work zone, however, this reduction increased to approximately $1.4 \mathrm{mph}$. The 85 th percentile speed reduction of about eight mph led to the conclusion that the CMS system, coupled with a radar unit, has an impact on reducing speeds of the fastest segment of the driving population.

Furthermore, the South Dakota DOT conducted a research study to identify and evaluate a speed monitoring display suitable for use at interstate highway work zones (32). Among the candidate display alternatives, the South Dakota DOT selected a CMS with a laser radar unit. The default display's message was "RIGHT LANE CLOSED, KEEP LEFT," with flashing arrows below the text. This message changed to "YOU ARE SPEEDING, SLOW DOWN NOW" as soon as a speeding vehicle activated the laser radar.

A field test was conducted to evaluate the effectiveness of the selected device at a work zone. The laser speed threshold was set at $70 \mathrm{mph}$. The study indicated a 10 percent reduction in the number of vehicles traveling greater than $70 \mathrm{mph}$. Mean speeds decreased up to two mph. The 85 th percentile speeds decreased by one to four $\mathrm{mph}$. This study concluded that by reducing the number of speeding vehicles, this CMS unit provided added safety to the work zone.

In another study, Bloch compared the speed reduction effects of speed monitoring displays (with and without police enforcement) with those of photo-radar systems (29). A photo-radar system consists of a radar unit, a camera, a flash unit, and a computer. A speeding vehicle triggers the system, causing a photograph to be taken of the vehicle and its license plate. Photographs can be used to identify the registered owner, and a notice of violation can be issued to them.

The study was conducted on three comparable streets in Riverside, California, over four weeks. No work zones were involved. A speed display board with no enforcement, another one with intermittent enforcement, and a photo-radar system were placed at each site. Mean speeds were measured alongside, as well as downstream of, the devices.

The study indicated that photo-radar system and the speed monitoring display were both effective in reducing the mean speeds during their deployments. Photo radar reduced the mean speeds by 5.6 and $4.5 \mathrm{mph}$ alongside and downstream of the devices, respectively. Similarly, the display board was recorded to reduce the mean speeds by 6.4 and $3.2 \mathrm{mph}$ alongside and downstream of the devices, respectively. The speed data collected at the second site, where a police motorcycle officer was stationed across the street from the speed display trailer, indicated significantly greater speed reductions at the downstream location (i.e., $6.5 \mathrm{mph}$ ). The study concluded that the speed display board with no enforcement is the most cost-effective speed control treatment. 
In 1990, Benekohal and Linkenheld examined the speed reduction effects of an audible system at a work zone in Illinois (33). The system consisted of a radar unit, which activated a horn when approaching vehicles exceeded a speed threshold. Speed data were collected for 118 vehicles. The data indicated an average speed reduction of $9.7 \mathrm{mph}$ when vehicles traveling faster than $60 \mathrm{mph}$ activated the horn. The study indicated that the horn system may have some speed reduction effects; however, noise problems and human-factor considerations may limit application of this device to very special cases.

\section{Rumble Strips}

The purpose of rumble strips is to alert drivers of potential hazards (e.g., running off the traveling lane or approaching a controlled intersection on a high-speed highway). Rumble strips produce slight jolts and audible rumble effects when motorists drive over them. A typical shoulder rumble strip design may be as high as 0.75 inch or as deep as one inch (34). Temporary rumble strips, on the other hand, are designed to be easily placed and removed without damaging the pavement. They are intended to inform drivers of a work zone ahead, where they may be required to stop or merge.

The speed reduction effects of portable rumble strips (PRS) were examined at a flaggercontrolled lane closure on a rural roadway in Marion, Iowa (34). A portable rumble strip is a rubber mat (approximately 18 inches long, 10 feet wide, and 1.125 inches tall) designed to be durable, to be relatively lightweight (about 67 pounds), and to be resistant to shifting due to traffic.

The speed reduction effects of PRS were examined at different locations upstream from the flagger station for a month. The study indicated that PRS was most effective when placed about 500 feet upstream from the flagger station. The observed data indicated an average speed reduction of four mph at 25-50 feet downstream from the PRS.

McCoy and Bonneson conducted a study for the South Dakota DOT on the effectiveness of rumble strips at a bridge repair work zone on a two-lane highway (19). The work zone traffic control plan (TCP) required motorists to stop at the beginning of the work zone and move across the bridge one at a time, in alternating directions. Three sets of rumble strips were installed on the northbound approach at 2,000, 1,400, and 750 feet upstream of the work zone. The study found that mean speeds were reduced at each of the rumble strip stations. Mean speeds were reduced by $0.8,1.7$, and $2.9 \mathrm{mph}$ at each location as vehicles approached the work zone.

The study indicated that while the strips were effective in reducing mean speeds, they had a negative impact on the stop compliance of motorists at the work zone. The percentage of drivers who came to a complete stop at the work zone after the rumble strip installations dropped by 20 percent (from 67 to 47 percent).

In 1986, Pigman and Agent studied the effectiveness of rumble strips in conjunction with variable message signs and supplemental warning signs to encouraging motorists to merge to the proper lane at a work zone on Interstate 75 in Kentucky (35). Five rumble strip sets (eight strips in each set) were installed 1.5, 1.0,0.6,0.3, and 0.1 miles upstream of the taper in the closed lane with 24 inches of spacing between the strips. The strips were made of a hard plastic-vinyl material, with dimensions of 0.5 inches by 4 inches by 23.57 inches.

The study indicated that the number of vehicles traveling northbound on the closed lane were decreased from 21.9 to 11 percent when variable message signs and supplemental warning signs were in place. The percentage of vehicles on the closed lane further 
dropped down to 4.1 percent when rumble strips were added to the treatment setup. It was not clear whether the drop in the number of vehicles in the closed lane was entirely attributable to the rumble strip treatment. The study recommended the application of rumble strips if other countermeasures failed to reduce late merges at work zones.

Richards et al. examined the speed reduction effects of rumble strips at a rural work zone in Texas (15). Eight 0.5-inch-high, polycarbonate rumble strips with decreasing logarithmic spacing were installed across the traveling lane of the work zone. More than 120 speed data samples were collected upstream from the treatment. Speeds were calculated from travel times over a 200-foot "trap" section. With only a two-mph speed reduction, the study found the rumble strips an ineffective treatment for controlling work zone speeds.

In their reviews of the studies on work zone speed control techniques, Benekohal et al. reiterated the ineffectiveness of rumble strips in significantly reducing speeds at work zones (16). They indicated that the effectiveness of rumble strips is dependent upon quality and quantity of the strips, their layout patterns on pavement (e.g., spacing between strips), and how well they function under different traffic and weather conditions.

\section{Optical Speed Bars}

Optical speed bars, also known as transverse strips, are innovative pavement markings that have been used to reduce speeds on curves and other locations with high numbers of accidents. Optical bars affect drivers perceptions of their speeds. The gradually decreasing distances between the strips create an illusion that drivers are speeding, resulting in speed reductions.

Denton conducted early optical speed bar experiments on an approach to a roundabout in Scotland (36). Ninety two-foot-wide yellow stripes with exponentially decreasing spaces from 20 to 10 feet were applied to the approach. The study found significant reduction in both mean and 85th percentile speeds. It indicated that mean traffic speeds were reduced by 22.6 percent (from 35 to $27 \mathrm{mph}$ ), while 85 th percentile speeds were reduced by 29.8 percent (from 47 to $33 \mathrm{mph}$ ). There was also evidence that fewer accidents took place following the strips' installation.

Pyne et al. examined the speed reduction effects of traverse strips on sharply curved roads using a simulator (37). The simulated road consisted of an 800-meter roadway, followed by a 200-meter-long curve with a radius of 300 meters. One group of 17 subjects experienced different speed reduction measures through the simulator, such as different signs, traverse lines with reducing spacing, and chevrons with increasing angles. The traverse lines create an illusion of speeding, and the chevrons create an illusion of the lane narrowing.

The study indicated that the most effective speed reduction treatments on the simulated roads were traverse lines with reducing spacing and a series of chevrons with increasing angles but constant spacing. The study found a statistically significant reduction of seven mph in the 85th percentile speed, which could have an important effect on safety on sharp bends. These results indicate that combining these treatments with a "SLOW" or a triangular warning sign may produce further speed reductions.

The application of optical speed bars to highway work zones has not yet been investigated. Meyer is currently planning a series of tests to determine the effectiveness of optical speed bars at work zones in Kansas (38). To examine the strips' design 
parameters, such as the number of strips, the length of the pattern, and the spacing, interactive simulations have been developed to facilitate the key parameter evaluations. No results are yet available. Potential design parameters will be investigated in the upcoming construction projects in Kansas.

Earlier tests of the use of transverse strips at work zones indicated that it has little or no impact on work zone speed reduction (39). The installation and maintenance of optical speed bars could be time consuming, and thus optical speed bars might be more suitable to long-term applications. Until more research is performed on how optical speed bars perform at work zones, their speed reduction effects at work zones remain unknown.

\section{Concluding Remarks}

Of all reported fatality crashes in 1996, about 1.7 percent occurred at work zones (40). Although this seems to be a relatively low figure, this does not mean that the economic analysis of applying countermeasures is not justified. For example, in Minnesota alone, work zones crashes have generated losses of \$221,429,100 between 1993 and 1997 (41).

Studies have indicated that accident rates increase with deviation from the mean speed (42). To minimize the increase in accident rates and speed variance at work zones, a 10mph reduction from the prevailing speed limit in work zones has been recommended.

Maintaining such a speed reduction at work zones can be a difficult task. Almost every transportation agency posts regulatory and advisory speed signs to inform motorists of the reduced speed limit at work zones. A number of agencies engage police enforcement at their work zone. There are also a few agencies that place flaggers at work zones to motion motorists to slow down. Some agencies have experimented with lane narrowing and other advanced strategies such as using drone radar, speed monitoring displays, removable rumble strips, and optical bars to control speeds at work zones.

Police enforcement is perceived to be one of the most successful work zone speed reduction strategies. Placing flaggers at work areas is also effective in controlling speeds at work zones. Studies indicate that other speed reduction techniques have less significant impacts in reducing speeds at work zones.

Although flagging and police enforcement speed reduction strategies have had very positive impacts in reducing work zone speeds, they are labor intensive and can become costly with long-term use. Replacing these strategies with innovative technologies, such as robotic flaggers and photo-radar enforcement machines, may be a more cost-effective solution.

The speed reduction techniques described in this chapter have had some success in slowing motorists through work zones. However, none of the techniques individually is capable of reducing vehicle speeds to the desired level. The most effective speed reductions will probably involve some combination of the techniques described in this literature review. 


\section{TECHNOLOGY DESCRIPTION}

\section{Introduction}

Through the literature and other referrals, the Center for Transportation Research and Education identified several technology providers. This chapter includes a write-up for each identified speed control technique. The write-up includes a description, the results of any field tests, the benefits, and the costs of the technology or technique. The speed reduction products discussed in this chapter include those of the following technology providers:

- Cobra Electronics Corporation (safety alert system)

- MPH Industries, Inc. (safety warning system [SWS] and speed monitoring display)

- Stalker, a division of Applied Concepts, Inc. (SPEEDGUARD speed monitor display)

- $\quad$ TRAFCON Industries, Inc. (wizard work zone alert and information radio)

- Advance Traffic Markings (ATM), a division of Patch Rubber Company (removable rumble strips)

\section{Safety Alert System-Cobra Electronics Corporation}

The safety alert system is a warning system that alerts drivers of emergency vehicles, road hazards, and trains. The system provides drivers with the extra time necessary to take evasive action and avoid accidents.

The system consists of two components: a transmitter and a receiver. The transmitter produces $K$-band signals that indicate either emergency vehicle, road hazard, or train. It can be mounted on emergency vehicles, school buses, road construction vehicles, or locomotives or at grade crossing sites.

The receiver is a radar detector. When the safety alert transmitter is switched on, it broadcasts a low-power, microwave, $K$-band traffic radar signal up to one mile ahead of and behind the transmitting vehicle. Older or less sophisticated detectors give motorists the same alert when a $K$-band radar gun is detected. More sophisticated detectors feature the safety alert traffic warning system, which can provide special signals specifically warning of emergency vehicles, road hazards, or trains.

The system is in use nationwide by police, fire, ambulance, and work zone vehicles, and it can be easily adapted for railroad crossings. The following cities have a large concentration of transmitters installed in their police, fire, and ambulance vehicles: Dayton, Ohio; Indianapolis, Indiana; Hoffman Estates, Illinois; Orlando, Florida; Denver, Colorado; New Orleans (Lake Pontchartrain Causeway), Louisiana; Salt Lake City, Utah; and Las Vegas, Nevada. The system is FCC approved and carries a U.S. patent.

\section{System Evaluation}

The Illinois DOT is conducting a pilot study of advisory onboard vehicle warning systems at railroad grade crossings. The University of Illinois at Urbana-Champaign is the project evaluator. About 300 vehicles, including school buses, transit vehicles, and 
commercial vehicles, have been equipped with Cobra safety alert traffic warning system receivers (i.e., detectors). These in-vehicle receivers are being activated by the specially designed Cobra safety alert transmitters installed at five railroad grade crossings. The transmitter emits a coded radio-frequency signal for the duration of the grade crossing event. Drivers of vehicles approaching railroad grade crossings receive an onboard advisory warning of a train approaching or occupying the crossing. The object of the study is to evaluate the reactions and/or perceptions of drivers to the warning information. This study began in July 1999 and will continue for approximately one year.

Furthermore, Speed Measurement Laboratories, Inc., examined the effectiveness of the safety alert system at work zones of rural interstates in Texas and New Mexico. During the study, speed data were collected with a laser gun. CB conversations were concurrently taped to determine the effectiveness of the drone transmissions.

The study concluded that, after the transmitter placement, average car and truck speeds were reduced by 25 and 45 percent, respectively. The taped CB conversations indicated that truck drivers believed a police vehicle was stationed at the work zone. The significant decrease in trucks' speeds compared with cars may be attributed to the fact that 40 percent of truck drivers use radar detectors and 92 percent use CB radios.

\section{Safety Warning System-MPH Industries, Inc.}

The Radio Association Defending Airwave Rights (RADAR), Inc., conceived and developed the concept of the safety warning system. This system consists of a transmitter and a receiver (detector). MPH Industries, Inc., manufactures SWS transmitters. A number of companies, including Bel-Tronics, Sanyo, Uniden, and Whistler, manufacture the SWS detectors.

The transmitter can be mounted on the outside of a vehicle (e.g., inside the emergency light bar) or can be placed in a stationary outdoor location (e.g., on the flashing arrow board trailer at a work zone). The SWS transmitter sends warning messages concerning road hazards to drivers of vehicles equipped with SWS detectors. Any $K$-band radar detector will also sound a basic alarm when the SWS transmitter is sending a warning message.

When an SWS detector encounters a continuous wave signal on the frequency used by SWS transmitters, it stops scanning and waits for a message display code. The detector then displays the message category or one of the messages permanently stored in memory. Furthermore, the transmitter can follow its initial message with a second message. For instance, the first message might indicate a work zone ahead, and then the posted speed limit for the location might be displayed.

An SWS detector is capable of identifying over 60 messages. These messages fall into five categories: (1) highway construction/maintenance, (2) highway hazard-zone advisory, (3) weather-related hazards, (4) travel information/convenience, and (5) fast- or slow-moving vehicles. In all but the final category, the transmitter will be stationary. The following 12 messages are currently stored in the highway construction/maintenance category:

- work zone ahead

- road closed ahead, follow detour

- bridge closed ahead, follow detour 
- highway work crews ahead

- utility work crews ahead

- all traffic follow detour ahead

- all trucks follow detour ahead

- all traffic exit ahead

- right lane closed ahead

- center lane closed ahead

- left lane closed ahead

- $\quad$ stationary police vehicle ahead

The SWS transmitter features a narrow, bidirectional beam that warns only affected drivers, not the entire community. Depending on the operating conditions, it can send a signal up to two miles. The retail price of SWS stationary, which sends only one unidirectional message, is $\$ 375$. The price tag for the SWS moving (which sends one message when the vehicle is in transit and switches to a second message when the vehicle is stationary) is $\$ 850$.

\section{Speed Monitor Display-MPH Industries, Inc.}

Speed displays use a radar device to detect and display the speeds of approaching vehicles. Speed monitoring displays are not generally used to enforce speed limits and issue citations; rather, the assumption is that motorists will drive slower once they see their excessive speed on the display.

MPH Industries, Inc., manufactures three types of speed monitor displays: the speed monitor trailer, the speed monitor III, and speed monitor F. A discussion of each of these products follows.

The speed monitor trailer consists of a 48 inch by 75 inch trailer, a speed display box, a $K$-band radar, and rechargeable batteries. Its display box has two 18-inch LED characters, which are visible in direct sunlight up to 1,000 feet. The display box can be easily set up and folded onto the trailer for towing. The trailer has four adjustable jacks on the corners that accommodate full leveling of the trailer on a slanted roadside and offer superior stability during high-wind conditions. The $K$-band radar, mounted inside the display box, detects approaching traffic only while ignoring vehicles that are moving away from the radar. One fully charged battery provides at least four days of continuous use. The speed monitor alpha trailer has the additional feature of programmable text messages as well as the ability to display vehicle speeds. The prices for the speed monitor trailer and the speed monitor alpha trailer are \$7,599 and \$17,295, respectively.

The speed monitor III is a lightweight, portable, smaller size speed display device. It can be placed on almost anything sturdy enough to hold it (e.g., atop a vehicle's trunk). It only detects speeds of approaching vehicles and excludes receding vehicles. Suitable for temporary placement at school crossings, it is large enough to be visible to drivers so that 
they become aware of their speeds as they approach the crossing. MPH Industries, Inc., sells this product for $\$ 2,795$.

Speed monitor $\mathrm{F}$ is a fixed version of speed monitor and is intended for permanent installation. Consisting of a display box, $K$-band radar, and power source, it can be mounted atop a pole along the roadside. Its display box, which houses the $K$-band radar, is similar to that of the speed monitor trailer. It only senses the speed of those vehicles moving toward the device. It can be powered by $120 \mathrm{VAC}, 12 \mathrm{VDC}$, or solar panel and costs $\$ 4,795$.

The display boxes of the trailer and $\mathrm{F}$ types have space for an optional traffic counter, which can be connected to the communications line that provides speed information from the radar to the sign. This makes it possible to get time-stamped speed information from the radar without laying pneumatic tubes across the roadway. The system includes Windows-based software, which provides reports and graphical information on time of day, traffic volume, speed, and vehicle classifications. The traffic counting system with radar interface is $\$ 3,300$.

These display boxes also have an overspeed option, which flashes motorists' speeds when they exceed the speed limit. If, for example, the speed limit is $35 \mathrm{mph}$, all vehicles that are approaching the sign at $36 \mathrm{mph}$ and faster will see their displayed speed flash until they slow to $35 \mathrm{mph}$ or slower.

\section{SPEEDGUARD Speed Monitor Display-Stalker, a Division of Applied Concepts, Inc.}

SPEEDGUARD is a trailer-mounted radar system that displays the speeds of approaching vehicles on a high-intensity, 24-inch LED. The speed display trailer with its augmented regulatory/advisory speed limit sign is 8 feet and 4 inches high, 49 inches wide, and 38 inches long. The speed limit sign can be folded when in transport mode.

SPEEDGUARD operates in both stationary and moving modes. The device automatically senses the trailer's movement and adds its speed to that of the approaching vehicle to compensate. Operating in the Ka-band frequency, the radar system can easily be removed for traffic speed enforcement independent of the trailer if desired. It has the ability to display speeds in either English or metric units.

SPEEDGUARD offers a number of options. When the unit detects a target vehicle traveling over the speed limit, a strobe lamp flashes toward the offending driver to simulate photo radar. It also alerts work zone workers of approaching high-speed vehicles, which may be as much as a mile away, with a high-pitched, 130 decibel siren. This advance warning provides ample time for workers to scramble out of the way of oncoming traffic. The manufacturer also offers bulletproof panels, which can withstand a 0.357 magnum round at close range without penetration. This feature was added after motorists shot five of ten units sold in Kentucky.

The speed display box is powered by three rechargeable batteries, which provide a total of 16 eight-hour days of use under normal traffic conditions. An optional solar-power system is also available, which consists of a 75-Watt solar panel, solar panel controller, and cables. A video or 35 millimeter camera may also be placed inside the display box to record traffic movements. 
The speed display trailer is priced at $\$ 8,800$. Violator alert and work zone alert optional systems are $\$ 1,625$ and $\$ 1,980$, respectively. A solar panel costs $\$ 1,200$. The price tag for a bulletproof panel is $\$ 1,360$.

\section{System Evaluation}

Carl Fors, president of Speed Measurement Laboratories, examined the SPEEDGUARD system at a 3-mile construction zone on Loop 410 south of San Antonio, Texas. Fors noted that many vehicles on Loop 410 exceeded the posted speed limit of $60 \mathrm{mph}$ when they first approached the radar system, then slowed to 40-50 mph once they saw their speed displayed on the message board. Fors also monitored the CB-radio transmissions of truckers on Loop 410. He could hear them quickly spreading the word to others that their pictures had been taken.

\section{Wizard Work Zone Alert and Information Radio-TRAFCON Industries, Inc.}

The wizard work zone alert and information radio was designed and patented by Highway Technologies, Inc., and built and marketed by TRAFCON Industries, Inc. It is designed to give drivers of heavy trucks enough advance warning of delays at upcoming construction sites or incidents to enable them to stop safely before encountering lines of halted vehicles. This system was developed at the request of the Pennsylvania DOT.

The wizard unit automatically broadcasts an alert message over any CB channel (usually channel 19). The message can be set to repeat at appropriate intervals (e.g., every 30 or 60 seconds). Messages are typically seven to ten seconds and can be prerecorded or recorded on site. An example of a message that might be broadcast is, "This is the state police ... there is a traffic accident on bypass A . . expect delays northbound . . exit B is a suggested alternate route."

In addition to fixed sites such as work zones and low-bridge situations, the wizard is very useful for temporary situations such as incidents, pavement painting, or sweeping operations. If information pertaining to the warning changes, the on-site crew can instantaneously update the message.

The unit is relatively small and weighs approximately 15 pounds. It can be kept in a police cruiser, maintenance vehicle, or fire truck. It can also be mounted on variable message boards, flashing arrow boards, emergency call boxes, or crash attenuator trucks.

Wizard is powered by a 12-volt battery. The radio is capable of transmitting messages up to four miles away. Because it operates in CB frequency, it requires no federal licensing paperwork. Other wizard applications include railroad grade crossings, weather advisory, weigh stations, border crossings, and toll roads.

\section{Removable Rumble Strips-Advance Traffic Markings, a Division of Patch Rubber Company}

Removable rumble strips are designed for placement at construction sites to alert motorists of upcoming roadway conditions. As a vehicle crosses over the strips, the sound and tactile (vibrating) sensation of driving over the strips heightens the driver's attention.

The rumble strips are four inches wide and one-eighth of an inch thick. They come with polymeric tape treated with pre-applied adhesive; this simplifies application on both asphalt and concrete road surfaces. They can also easily be removed without the use of 
heat, solvent, or grinding at temperatures above 40 degrees Fahrenheit, methods that often damage road surfaces. Their orange color is similar to that of signs, barrels, and cones used at work zones.

The manufacturer suggests placing three sets of five rumble strips at the beginning of the construction site on the travel lane for speed control. The recommended spacing of the strips is as follows: first set, two feet apart; second set, one foot apart; and third set, six inches apart, with suggestions that additional sets be scattered throughout the construction area. Rumble strips can also be installed on the merge lane to force traffic out of the lane before it closes. 


\section{SURVEY}

\section{Introduction}

The Iowa Department of Transportation has made improving work zone safety a high priority. Managing vehicle speeds through work zones is perceived to be an important factor in achieving this goal. To learn more about other state policies regarding work zone speed reduction and management, the Center for Transportation Research and Education conducted a survey.

The survey consists of two sections with three multipart questions in each section. The first section (questions 1 to 3 ) inquires about the policies agencies have developed for work zone speed controls. The second section (questions 4 to 6 ) focuses on their engaging, innovative, or unique speed reduction systems. Copies of the survey and the cover letter are included in appendix A.

Every state DOT and a number of non-DOT transportation agencies in other states (e.g., state turnpike commissions) were contacted using DOT letterhead in the hope of improving the likelihood of a response. Surveys were sent to 63 state transportation agencies. Thirty-nine responses were received for a 62 percent response rate. Responses were entered into a database to allow queries to be conducted on each individual question. Responses, grouped under each question, are listed in detail in appendices B through $\mathrm{M}$.

The following sections provide summaries of the responses to each question. Responses received from state agencies surrounding the state of Iowa (i.e., Illinois, Kansas, Kansas Turnpike Authority, Minnesota, Missouri, Nebraska, and Wisconsin) ${ }^{1}$ are examined more closely to identify the commonality of their work zone speed limit reduction policies.

\section{Question 1: Work Zone Policy Description}

Questions 1 through 3 study speed limit policies and design issues at work zones. Specifically, question 1 inquires whether the state agency has policies, procedures, or standards for establishing and applying work zone speed limits. Out of 39 responses, 28 agencies (72 percent) indicated having such policies.

Twenty-one agencies indicated that they generally reduce work zone speed limits to 10 mph less than the normal posted speed for the facility. Nine agencies mentioned that they even consider lowering the speed limits up to $20 \mathrm{mph}$ below the posted speeds. The speed limit reductions greater than $10 \mathrm{mph}$, however, generally require special reviews by the agency management.

Four state agencies expressed their preference to avoid work zone speed limit reductions altogether. However, if the speed limits must be reduced because of physical constraints (e.g., close proximity of workers to traffic), their standard reductions are to $10 \mathrm{mph}$ below the normal posted speed. Furthermore, six agencies stated that they consider speed limit reductions on a case-by-case basis. These reductions are based on site conditions and the nature of work activities being conducted.

Among the 39 participating agencies, the Washington DOT is the only agency required to publish a notice of reduced speed limits in local newspapers in the areas where the construction takes place. The notice should be published at least three days in advance of

\footnotetext{
${ }^{1}$ No response was received from the South Dakota DOT.
} 
the project implementation. Moreover, statutes in six states allow the enforcement authorities to issue double-fine tickets for work zone speeding violations.

Although 11 state agencies indicated having no work zone speed limit policies, four reported following certain procedures in determining their work zone speed limits. The South Carolina DOT indicated reducing its speed limits to 45 and $35 \mathrm{mph}$ during work activities on interstates and on all other roadways, respectively. The Utah DOT pointed out that the decision to reduce the speed limit at work zones is left up to the designers, the project/contractor personnel, and the maintenance crew. The speed limit reduction is generally between 10 and $20 \mathrm{mph}$ below the posted speed limit. Moreover, the Pennsylvania DOT indicated that it considers reducing work zone speed limits on a project-by-project basis. These speed reductions are traditionally up to $15 \mathrm{mph}$ below the posted speed limits.

The Iowa DOT is among the 11 agencies with no written policies. According to its unwritten policy, however, 55-mph regulatory speed limit signs are used on interstate projects in Polk County as well as at locations where two-lane, two-way operations occur. All other state agencies surrounding the state of Iowa, except the Kansas Turnpike Authority, indicated having policies for speed limit reductions at work zones. These agencies generally reduce the speed limits at their work zones by $10 \mathrm{mph}$. Work zone speed limits could be lowered as much as $35 \mathrm{mph}$ in rural areas and $25 \mathrm{mph}$ in urban areas in Nebraska. Illinois, Missouri, and Wisconsin DOTs consider reducing speed limits up to $20 \mathrm{mph}$ below the posted speed.

There are no speed reductions on Illinois's freeways $(65 \mathrm{mph})$ and nonfreeways $(55 \mathrm{mph})$ if there are no lane closures and no pavement works. Requirement to reduce speed limits at work zones in Illinois must always be approved by a district operations engineer.

Furthermore, there are usually no speed limit reductions on Wisconsin's roadways with speed limits of $55 \mathrm{mph}$ or less unless the roadway geometry or surface conditions warrant, in which case a 10-mph speed reduction is made. Among the Midwest transportation agencies, Illinois and Nebraska have statutes to double-fine speeding violators in their work zones.

Appendix B includes the complete responses to this question.

\section{Question 2: Policy Development Procedure}

As a follow-up to question 1, question 2 inquires about the states' work zone speed limit policy developmental procedures. The 28 state agencies that reported having work zone speed limit policies described the steps taken in developing their policies. For example, six agencies indicated their policies were developed by engineering panels. Four others established their policies through management teams, and a few others developed their policies through different appointed committees.

The question further categorizes the work zone speed limit policies into two groups: "bottom-up" and "top-down." A "bottom-up" policy is, for example, a product of a work done by an engineering panel and/or a management committee. A "top-down" policy, on the other hand, is established as a result of a state legislative mandate. Twenty-two agencies consider their policies "bottom-up," while the remaining six regard theirs as "top-down" policies. ${ }^{2}$

\footnotetext{
${ }^{2}$ The assumed bottom-up and assumed top-down phrases, noted under the policy strategy column in appendix $\mathrm{C}$, are policy types assumed by the authors.
} 
The Iowa DOT indicated that its current work zone speed limit policy is based on decisions made at the engineering level. The policies of its surrounding state agencies, such as the Kansas and Wisconsin DOTs, were developed by engineering and management teams. The philosophy behind their policies is provided in the National Cooperative Highway Research Program (NCHRP) Report 3-41 and in part 6 of the MUTCD. These and other surrounding state agencies, including the Illinois and Missouri DOTs, have "bottom-up" policies. The Illinois policy is a product of a work zone subcommittee, which included several contractors and the department's personnel. The Minnesota DOT's policy was enacted by their legislation (i.e., "top-down"); however, more recently a "bottom-up" task force was set up to rework all the standards for work zone speed limits.

Appendix $\mathrm{C}$ includes the complete responses to question 2.

\section{Question 3: Speed Limit Assignment}

Question 3 consists of seven parts. Each part describes a work zone design layout (e.g., mobile, stationary, and lane closure with and without concrete barriers) in which the agencies were required to state their exiting and work zone speed limits. The work zone layouts (i.e., scenarios) are shown in the survey (see appendix A).

The following subsections present summaries of the responses provided for each scenario. Table 1 includes the statistics for each scenario. It is noted that the total number of entities in each row is 39, which is the total number of responding agencies. The "no information" and "not applicable" columns in Table 1 indicate the number of agencies that provided no information or indicated the inapplicability of such operations in their jurisdictions.

TABLE 1 Statistics for Scenarios 1-7

\begin{tabular}{|c|c|c|c|c|}
\hline & \multicolumn{2}{|c|}{ Speed Reduction } & \multirow{2}{*}{$\begin{array}{c}\text { No } \\
\text { Information }\end{array}$} & \multirow{2}{*}{$\begin{array}{c}\text { Not } \\
\text { Applicable }\end{array}$} \\
\hline & Yes & No & & \\
\hline Mobile (two-lane road) & 11 & 18 & 9 & 1 \\
\hline Mobile (multilane road) & 10 & 24 & 5 & 0 \\
\hline Lane closure (w/o barrier) & 32 & 2 & 5 & 0 \\
\hline Lane closure (w/ barrier) & 33 & 1 & 5 & 0 \\
\hline Lane closure on bridge & 33 & 0 & 6 & 0 \\
\hline Lane shift & 27 & 4 & 6 & 2 \\
\hline Median crossover & 30 & 0 & 9 & 0 \\
\hline
\end{tabular}

Appendices D through J include the responses to scenarios 1 through 7.

Scenario 1: Mobile Maintenance Operation (Two-lane Road)

This is a situation where, on a two-lane road, a moving work area is led and followed by two maintenance vehicles. Only 11 agencies ( 28 percent) indicated that they generally reduce speed limits during the specified operations. Of these 11 agencies, only the Arizona DOT uses regulatory speed limit signs in this work zone scenario. The remaining 10 agencies, however, use advisory speed limit signs. The Arizona DOT uses $35 \mathrm{mph}$ regulatory speed limits since the majority of two-lane rural roads in Arizona have shoulder widths of $0-2$ feet. 
The Iowa DOT indicated no speed limit reductions in this situation. Of Iowa's surrounding state agencies, only the Missouri DOT indicated any speed limit reductions during this mobile operation. The Missouri DOT indicated using 35-mph advisory speed limit signs. Moreover, the Nebraska Department of Roads (DOR) indicated that advisory signs might be used if work activities last more than a half day at one location. Nine agencies provided no information. The Kansas Turnpike Authority was the only agency that indicated the inapplicability of this work zone activity in its jurisdiction.

Appendix D includes the complete responses for scenario 1.

\section{Scenario 2: Mobile Maintenance Operation (Multilane Road)}

Similar to the two-lane work zone operation described in scenario 1, scenario 2 is a mobile maintenance operation on a multilane road. Ten state agencies (26 percent) indicated that they generally reduce speed limits during this type of work activity. Of these 10 agencies, only Arizona and North Dakota DOTs use regulatory speed limit signs in this type of work zone operation. The remaining eight use advisory speed limit signs. The Arizona DOT uses 45-mph regulatory speed limits on its interstates and major U.S. routes. In addition to 55-mph regulatory speed limits, the North Dakota DOT uses flaggers in this scenario.

Similar to scenario 1, the Iowa DOT and all of its surrounding state agencies except the Missouri DOT reported no speed limit reductions during this mobile operation. The Missouri DOT also indicated using 10- and 20-mph advisory speed limits below the posted speeds (65-70 $\mathrm{mph}$ in rural areas, $60 \mathrm{mph}$ in urban areas) in protected and unprotected work areas, respectively.

Appendix E includes the complete responses for scenario 2.

\section{Scenario 3: Lane Closure with No Concrete Barrier (Multilane Road)}

This scenario describes an unprotected (e.g., no concrete barriers) lane closure on a multilane roadway. The majority of the state agencies responding ( 32 agencies, or 82 percent) indicated that, in this case, they reduce the speed limits by $10 \mathrm{mph}$ below the normal posted speed. Four agencies reported reducing the speed limits even up to 20 mph. Maine's DOT policy dictates that 55-mph regulatory speed limits should be used in this and the next three scenarios only when workers are present.

Three agencies, the Massachusetts, Missouri, and Montana DOTs, only use advisory signs for speed limit reductions. The Montana DOT indicated using 35-mph advisory speed limits in addition to flaggers if many construction vehicles are coming and going from the work zone area.

In addition to posting regulatory speed limit signs, seven agencies indicated using advisory speed limits. Among these, the Maryland DOT uses the advisory speed limits in this and the next two scenarios for spot situations such as sharp alignment changes and short sections of narrow lanes.

Only the Kansas Turnpike Authority and the Iowa DOT indicated no speed limit reductions in this situation. However, all other state agencies surrounding Iowa indicated at least 10-mph speed limit reductions below the posted speeds. The Kansas Turnpike Authority does not consider slowing traffic on a short-term lane closure, as it found speed limit reductions in this situation ineffective. The Illinois DOT indicated using " $45 \mathrm{MPH}$ WHEN WORKERS PRESENT" signs, augmented with flashing amber strobes and "\$150 FINE FOR SPEEDING" plates, to further reduce speeds. 
Furthermore, the Kansas DOT engages flaggers in advance of the work areas whenever workers are adjacent to traffic. The Minnesota DOT uses 40-mph regulatory and 45-mph advisory speed limit signs on its posted 55-mph roadways. The Missouri DOT, however, only uses advisory signs with reduced speed limits of 10-20 mph below the posted speeds. Moreover, the Nebraska DOR reported posting 55-mph regulatory speed limits on its rural, 75-mph interstates.

Appendix F includes the complete responses for scenario 3.

\section{Scenario 4: Lane Closure with Concrete Barrier (Multilane Road)}

In contrast to the situation described in scenario 3, this scenario describes a protected lane closure on a multilane roadway. Similar to the scenario 3 response rate, 33 agencies $(85$ percent) indicated reducing the speed limit by $10 \mathrm{mph}$ below the normal posted speed. Five agencies reported reducing the speed limit even up to $20 \mathrm{mph}$. The Oregon DOT is the only agency that indicated normally (with some exceptions) having no speed reductions in this type of work zone operation.

In addition to posting regulatory speed limit signs, 11 agencies reported using advisory speed limits. Furthermore, there are five agencies, including the Iowa DOT, that only use advisory signs for speed limit reductions. The Montana DOT indicated using 35-mph advisory speed limits.

The Iowa DOT indicated using 55-mph advisory speed limit reductions at some structure locations. Similarly, the Missouri DOT only uses advisory speed limit signs in this situation. The Illinois and Kansas DOTs reported only using regulatory speed limits with maximum speed limit reductions of $10 \mathrm{mph}$ below the normal posted speed. The Kansas DOT often uses temporary surfacing on shoulders to maintain a standard lane width, with advisory speed limits applied only to lateral shift-tapered areas.

The Kansas Turnpike Authority and the Minnesota and Wisconsin DOTs use both regulatory and advisory speed limit signs. The Kansas Turnpike Authority considers 10mph speed reductions if the lane width is less than 12 feet. The Minnesota DOT does not consider reducing speed limits if concrete barriers do not cross the centerline. If the described work zone space is short, the Wisconsin DOT indicated using a 55-mph advisory speed instead of a reduced regulatory speed limit sign. This advisory sign would be posted with the W4-2 (lane reduction transition or merge) warning sign. Moreover, the Nebraska DOR reported posting 55-mph regulatory speed limits on its rural, $75-\mathrm{mph}$ interstates.

Appendix $\mathrm{G}$ includes the complete responses for scenario 4.

\section{Scenario 5: Lane Closure on a Structure with Concrete Barrier (Multilane Road)}

This scenario defines protected lane closures on a structure (e.g., a bridge). Except for the six state agencies that did not provide any information, the remaining agencies (33 agencies, or 85 percent) indicated 10-mph speed limit reductions in this situation. Four agencies reported reducing the speed limits even up to $20 \mathrm{mph}$.

In addition to posting regulatory speed limit signs, 12 agencies indicated using advisory speed limits. Furthermore, there are five agencies, including the Iowa DOT, that only use advisory signs for speed limit reductions. The Montana DOT indicated using $35-\mathrm{mph}$ advisory speed limits. It also detours all wide-load trucks before reaching the construction area. The Washington DOT considers the described work zone operations as a spot work activity; thus, only advisory speed limits are used. 
The Iowa DOT indicated using 55-mph speed limit reductions at some structure locations. Similarly, the Missouri DOT only uses advisory speed limit signs. The Illinois and Kansas DOTs only use regulatory speed limits with maximum speed limit reductions of $10 \mathrm{mph}$ below the normal posted speed. The Kansas DOT indicated the requirement of additional delineation on existing bridge rails whenever traffic is moved closer to the rails.

Furthermore, the Kansas Turnpike Authority and the Minnesota and Wisconsin DOTs use both regulatory and advisory speed limit signs. The Kansas Turnpike Authority considers 10 -mph speed reductions if the lane width is less than 12 feet. The Wisconsin DOT reported posting a 55-mph regulatory speed if the structure work is within a large project. Moreover, the Nebraska DOR indicated the possibility of using 45-mph advisory speeds in addition to 55-mph regulatory speed limits on its rural, 75-mph interstates.

Appendix $\mathrm{H}$ includes the complete responses for scenario 5.

\section{Scenario 6: Lane Shift (Multilane Road)}

This scenario describes a protected work area on a multilane road where all traveling lanes are shifted. Twenty-three agencies (59 percent) indicated 10-mph speed limit reductions in this situation, including two agencies that reported reducing the speed limit up to $20 \mathrm{mph}$. In addition to posting regulatory speed limit signs, six agencies reported using advisory speed limits.

Four agencies expressed the possibility of reducing speed limits if specific conditions warrant. For example, the Maryland and Oregon DOTs evaluate projects individually to determine whether reduced speed limits are appropriate. Moreover, the New York DOT indicated that reduced speed limits may not be warranted because workers are protected by barriers and all traffic lanes remain open. The Texas DOT indicated considering speed limit reductions in cases where barriers are within two feet of traveling lanes.

In addition to the four agencies that indicated having no speed limit reductions, six agencies did not provide information, and two others reported the inapplicability of such operations in their jurisdiction. The Montana DOT indicated that it does not consider using this lane-shift setup because it requires significant paving and striping in the shifted area, which is not economical for short-term work (e.g., less than 30 days). It would, however, consider using a single-lane closure instead.

The Iowa DOT considers speed reductions only at work zones located in Polk County, where 55-mph regulatory speed limits are being posted. The Kansas Turnpike Authority is one of two agencies that indicated the inapplicability of the lane shifting because median barriers do not allow such operations. Furthermore, the Kansas and Minnesota DOTs indicated posting advisory speed limit signs based on ball-bank readings of curves. The Nebraska DOR reported using the lane shift operations only on its 60-mph urban interstate, where 50-mph regulatory speed limits are being posted. The Wisconsin DOT indicated the possibility of using advisory speed limits instead of the regulatory speed signs in this situation.

Appendix I includes the complete responses for scenario 6.

\section{Scenario 7: Median Crossover (Multilane Road)}

This scenario describes work activities on a multilane road where the approaching traffic crosses over the median onto the opposite direction, forming a two-lane, two-way operation. Thirty state agencies (77 percent) reported reducing speed limits by $10 \mathrm{mph}$ 
below the normal posted speed. The Arizona and Louisiana DOTs are the only agencies that consider 20-mph-reduced regulatory speed limits. Moreover, 13 agencies reported posting regulatory speed limit signs as well as advisory speed limits.

The angle of the lane shift and length of the taper dictate the speed limit reductions at work zones in Georgia. The Massachusetts DOT uses post-mounted static signs or changeable message signs to gradually reduce speed through the crossover. The agency also recommended an additional 10-mph speed limit reduction (i.e., 30-mph advisory speed) because of the crossover operations. The South Carolina DOT, however, designs the crossover to minimize speed reductions to no more than $10 \mathrm{mph}$ below the normal posted speed.

Similar to the Iowa DOT, the Nebraska DOR and the Illinois, Kansas, and Minnesota DOTs indicated using 55-mph regulatory speed limits. The Kansas Turnpike Authority, the Minnesota DOT, and the Nebraska DOR reported posting advisory speed signs in addition to regulatory speed limits. The Kansas and Minnesota DOTs consider using advisory speed limit signs based on ball-bank readings on the crossover curve. Moreover, the Kansas Turnpike Authority and Wisconsin DOT indicated using 60-mph regulatory speed limits on their 70- and 75-mph interstates, respectively. The Wisconsin DOT considers posting 45-mph advisory speed limits on the warning sign approaching the crossover.

Appendix $\mathbf{J}$ includes the complete responses for scenario 7.

\section{Question 4: System Effectiveness}

Questions 4 through 6 study the speed reduction systems employed by state agencies. Question 1 inquires about the effectiveness of the work zone speed reduction strategies that are currently in use or that have been used in the past by an agency. Among the 39 agencies that responded, the Oklahoma Turnpike Authority and the Connecticut, Oregon, and Utah DOTs provided no information. The Iowa DOT indicated the inapplicability of the inquiry with respect to its jurisdiction. The remaining 34 agencies recognized 12 different speed reduction strategies, which are listed in Table 2.

Table 2 presents the statistics on the applicability and effectiveness of each strategy. The values in the second and third columns in each row add up to 34. The numbers listed in the third column are also sums of the values listed in each row of the last four columns. For example, 28 agencies (see Table 2, first row) indicated using regulatory speed limit signs as a strategy to reduce speeds at their work zones. Of these 28 agencies, two agencies perceived the strategy to be effective, seven indicated that it is ineffective, 10 reported that the strategy is partially effective in reducing speeds at work zones, and nine agencies provided no information on the system's effectiveness. The following subsections briefly describe the speed reduction strategies listed in Table 2. 
TABLE 2 Question 4 Speed Reduction Strategies and Effectiveness

\begin{tabular}{lcccccc}
\hline & \multicolumn{2}{c}{ Applicable } & Effective & Ineffective & $\begin{array}{c}\text { Partially } \\
\text { Effective }\end{array}$ & $\begin{array}{c}\text { No } \\
\text { Information }\end{array}$ \\
\cline { 2 - 4 } No & Yes & & 2 & 7 & 10 & 9 \\
\hline Regulatory signs & 6 & 28 & 2 & 0 & 3 & 3 \\
Advisory signs & 26 & 8 & 2 & 2 & 5 & 7 \\
CMS & 16 & 18 & 4 & 0 & 5 & 3 \\
Police enforcement & 8 & 26 & 18 & 0 & 1 & 0 \\
Ghost police car & 32 & 2 & 1 & 0 & 0 & 0 \\
Flaggers & 32 & 2 & 2 & 1 & 2 & 1 \\
Speed display & 28 & 6 & 2 & 1 & 2 & 1 \\
Drone radar & 28 & 6 & 2 & 0 & 1 & 0 \\
Rumble strips & 33 & 1 & 0 & 0 & 0 & 1 \\
Lane narrowing & 31 & 3 & 2 & 0 & 0 & 1 \\
Pavement markings & 33 & 1 & 0 & 0 & 1 & 1 \\
HAR & 32 & 2 & 0 & 0 & 0 \\
\hline
\end{tabular}

Appendix $\mathrm{K}$ includes the complete responses to question 4.

\section{Regulatory Speed Limit Signs}

Out of the 34 agencies that responded, 28 agencies included the use of regulatory speed signs among the strategies employed at their work zones. Only two agencies indicated that posting regulatory speed signs is effective in reducing work zone speeds. With an estimated 30-50 percent speed limit compliance, the Arizona DOT is among the 10 agencies indicating that the use of regulatory signs is partially effective. Moreover, the North Dakota DOT reported that posting 20-mph-reduced regulatory signs is ineffective. However, it indicated that the new policy of reducing speed limits $10 \mathrm{mph}$ below the normal posted speed seems slightly more effective.

Among the state agencies surrounding Iowa, the Kansas and Wisconsin DOTs reported that regulatory speed signs have a minor impact in reducing speed. The Illinois and Missouri DOTs did not provide information on the system's effectiveness. When workers are present, the Illinois DOT supplements the signs with flashing amber strobes and "\$150 FINE MINIMUM" plates. The Kansas Turnpike Authority and the Nebraska DOR do not use regulatory speed limit signs as speed reduction strategies. The Minnesota DOT indicated a speed reduction of 3-4 mph when using regulatory speed signs at its work zones.

The first section of appendix $\mathrm{K}$ includes the responses to strategy.

\section{Advisory Speed Limit Signs}

Only eight state agencies consider the use of advisory speed signs to be an effective work zone speed reduction strategy. The North Carolina DOT noted some noticeable speed drops when the signs are used to alert motorists of upcoming curves, lane closures, and lane shifts. 
The Wisconsin DOT is the only agency surrounding Iowa that included this strategy as one of its work zone speed reduction strategies. The agency indicated that the use of advisory speed signs has a minor impact in reducing speeds at work zones.

The first section of appendix $\mathrm{K}$ includes the responses to strategy.

\section{Changeable Message Signs}

More than half (18 agencies) reported using CMS in their work zones. Four agencies perceived the strategy to be effective. The North Carolina DOT recorded a 3-5 $\mathrm{mph}$ decrease in the 85 th percentile speed. Similar to the regulatory speed sign usage, the Arizona DOT reported an estimated 30-50 percent speed limit compliance when engaging the CMS system in its work zones.

Four agencies, including the Illinois DOT, indicated using the system with radar to detect the speed of approaching vehicles. No studies have been conducted to determine the system's effectiveness. The Kansas Turnpike Authority and Wisconsin DOT indicated that the system is somewhat effective. CMS was not listed among the work zone speed reduction strategies of the remaining state agencies surrounding Iowa.

The first section of appendix $\mathrm{K}$ includes the responses to strategy.

\section{Police Enforcement}

Police enforcement is perceived to be one of the most successful work zone speed reduction strategies. Of the 26 agencies that included police enforcement in their work zone speed control plans, 18 agencies (69 percent) expressed that the strategy is very effective in managing speed at work zones. Half (5) of the remaining agencies indicated that using police enforcement was partially effective. The other three agencies provided no information on the system's effectiveness.

With an estimated 90-95 percent work zone speed limit compliance, the Arizona DOT gave police enforcement engagement a high score. Montana indicated that the system is very effective when a police officer is present during work and for a short time afterward.

The New York DOT indicated engaging police enforcement under two programs: dedicated and cooperative. The dedicated program is an integral part of its capital projects. It insures full police enforcement coverage only for very difficult projects (e.g., construction at high-speed and high-volume areas). Under the cooperative program, state and local police are engaged on an as-needed basis when resources are available. The New York DOT provided no information on the effectiveness of these programs.

The Kansas DOT indicated engaging highway patrols in its work zone projects. It reported that the strategy is very effective in reducing speeds, but it is very costly. The Kansas Turnpike Authority indicated that posting additional "\$85 FINE FOR ILLEGAL PASSING" signs has somewhat helped speed limit compliance in locations where high average daily traffic (ADT) is observed. The Minnesota DOT perceived a 6-8 mph speed reduction using police enforcement in its work zones. Furthermore, the Missouri DOT reported using police enforcement in its work zones; however, no information was provided on its effectiveness. There was no indication that the Illinois DOT engages police enforcement in its work zones.

The second section of appendix $\mathrm{K}$ includes the responses to this strategy. 


\section{Ghost Police Vehicle}

Used like a scarecrow, a law enforcement vehicle placed in work zones is yet another strategy used to reduce speeds, though only two state agencies reported using this strategy. The North Carolina DOT indicated that it also puts a mannequin inside the police car. It reported reducing 85th percentile speeds by 3-5 mph in the first few weeks of deployment. The New York State Thruway Authority described the strategy as moderately effective.

The second section of appendix $\mathrm{K}$ includes the responses to this strategy.

\section{Flaggers}

Only two agencies indicated using flaggers in their work zones. The Kansas and Wisconsin DOTs indicated that flaggers with proper placement are very effective in reducing speeds at work zones.

The second section of appendix K includes the responses to this strategy.

\section{Speed Monitoring Display}

Speed displays use a radar device to detect and display the speeds of approaching vehicles. The assumption is that motorists will drive slower once they see their excessive speed on the display.

Six agencies reported using speed displays in their work zones. With perceived speed reductions estimated at 30-50 mph, the Arizona DOT described the system as partially effective. The Ohio Turnpike Authority reported that the system is ineffective. Moreover, the New York State Thruway Authority indicated that the system was initially effective; however, after an extended period of time, it became less effective.

The Minnesota DOT reported a 4-6 mph speed reduction using the display. The Wisconsin DOT indicated having limited use of the displays so far, with mixed comments on their effectiveness in reducing speeds at work zones.

The third section of appendix $\mathrm{K}$ includes the responses to this strategy.

\section{Drone Radar}

Drone radar is an electronic radar system that transmits in the microwave-frequency band. Vehicles equipped with radar detection devices perceive transmitted radar signals from the drone as the presence of police enforcement. In response, believing that a police car is nearby, these vehicles reduce their speeds, which in turn causes other vehicles to slow down.

Six state agencies indicated experience with this speed reduction strategy. The Montana DOT reported using a "SLOW DOWN NOW" sign in conjunction with the device. This strategy was perceived to be effective by causing a 10-mph speed reduction. However, the speed reduction will soon diminish once motorists discover that no police enforcement is present. Moreover, the North Carolina DOT reported 3- to 5-mph reductions in 85th percentile speeds during the first few weeks of the system deployment. The Pennsylvania DOT was the only agency that indicated the system was ineffective in reducing speeds at work zones.

The third section of appendix $\mathrm{K}$ includes the responses to this strategy. 


\section{Rumble Strips}

The purpose of rumble strips is to alert drivers of potential hazards (e.g., running off the traveling lane). Rumble strips produce slight jolts and audible rumble effects when motorists drive over them. The Wisconsin DOT was the only agency that reported having a limited experience with removable rumble strips and is no longer using them as the maintenance crew reported having trouble keeping them in place.

The third section of appendix $\mathrm{K}$ includes the responses to this strategy.

\section{Lane Narrowing}

Narrow lane widths are, to some extent, effective in reducing traffic speeds. In general, narrower lanes leave less lateral distance between vehicles in adjacent lanes or between vehicles and shoulder obstructions, demanding more of motorists' attention and influencing them to reduce speeds. Only three agencies indicated experiencing lane narrowing at the work zones in their jurisdiction. The Maryland DOT reported using both pavement markings and channeling devices to narrow lanes, which the Maryland DOT perceived to be effective strategies in speed reduction. The Minnesota DOT reported a 2to 3-mph speed reduction using drums to narrow lanes.

The last section of appendix $\mathrm{K}$ includes the responses to this strategy.

\section{Pavement Markings}

Transverse strips are innovative pavement markings used to reduce speeds on curves and other locations with high numbers of accidents. The gradually decreasing distances between the strips create an illusion that the driver is speeding, resulting in speed reduction. The Wisconsin DOT was the only agency that reported examining the transverse pavement markings, which it did for the first time on one of its projects in 1999. The evaluation results are not yet available.

The last section of appendix $\mathrm{K}$ includes the responses to this strategy.

\section{Highway Advisory Radio (HAR)}

HAR systems are designed to broadcast information on traffic conditions. Motorists are required to tune their radios to specific frequencies to obtain the information. The Florida DOT and the Kansas Turnpike Authority indicated engaging HAR in their work zones. The Florida DOT provided no information on the system's effectiveness, while the Kansas Turnpike Authority reported it to be somewhat effective.

The last section of appendix $\mathrm{K}$ includes the responses to this strategy.

\section{Question 5: System Evaluation}

As a follow up to question 4, question 5 inquires whether the state agencies have conducted field trials or research on those speed control systems reported in the previous question. Ten agencies responded positively to this question. Among them, the Florida DOT indicated currently conducting research on CMS, speed display, and HAR systems. The North and South Carolina DOTs have examined the effectiveness of drone radar. They observed 3- to 5-mph speed reductions while the radar system was active.

Twenty-three agencies reported conducting no research on any of the speed reduction strategies. The Missouri DOT and Nebraska DOR are among the six agencies that provided no information; however, they, along with the Kansas and Iowa DOTs, are participating in the Midwest States Smart Work Zone Deployment Initiative. This is an 
ongoing research project in which a number of speed reduction strategies, including speed monitoring display, safety warning system, wizard CB alert system, and rumble strips, have been evaluated by the participating agencies. No reports are available yet.

The Minnesota DOT observed speed reductions of 8, 5, and 3 mph upon evaluating police enforcement, speed display, and lane-narrowing strategies, respectively. Moreover, research on speed management strategies was conducted for the Illinois DOT through the University of Illinois, but no further information is provided on the research outcome. The Kansas Turnpike Authority provided no information in response to this question.

Appendix L includes the complete responses for question 5.

\section{Question 6: Most Effective System}

In this last question, the state agencies were asked to describe the most effective system or process used in their organizations to reduce or manage work zone speeds. Of the 25 agencies that responded to this question, 17 indicated police enforcement as the most effective speed reduction treatment in work zone speed reductions. The Massachusetts DOT was the only agency that recognized the drone radar as its most effective speed reduction strategy. The drone radar is the only device used on all Massachusetts National Highway Roadway systems since July 1996. Fourteen agencies provided no information in response to this question.

The use of off-duty highway patrol officers has been mandated on all Arizona construction projects located on high-speed, high-traffic roadways for more than three years. The enforcement strategy has virtually eliminated speed violations in construction areas since its implementation. Moreover, a contract between Caltrans and the California Highway Patrol has allowed Caltrans to engage troopers in its construction projects. The police presence is reported to be very effective in enforcing speed limit compliance. Furthermore, the Hawaii DOT reported having police presence at its work zones only sparingly when speed reduction is critical. The use of highway patrol in Montana and a number of other agencies is budgeted through project funds.

The Colorado, Illinois, and Washington DOTs pointed out that the best policy for obtaining compliance with posted speed limits is to maintain realistic speed limits. The Washington DOT indicated that if the speed limits are appropriate for driving conditions, drivers' compliance will be observed. The Colorado DOT suggested that work zones should be designed so that speed limit reductions can be avoided as much as possible.

The Kansas Turnpike Authority indicated using HAR, CMS, and warning signs with flashing lights to control speeds at its high-volume work zones for more than three years. The Minnesota DOT has extensively used police enforcement on 20 percent of its construction projects per year for the past five years. Police enforcement has also been used in Wisconsin's work zones (about 10 projects per year) for approximately 12 years. The Nebraska DOR and the Iowa, Kansas, and Missouri DOTs are among the 14 agencies that provided no information in response to this question.

Appendix $\mathrm{M}$ includes the complete responses to question 6.

\section{Concluding Remarks}

A survey with a response rate of 62 percent was conducted during the summer of 1999 . This report is the result of a comprehensive examination of the work zone speed 
reduction polices or procedures reported by more than 30 state transportation agencies throughout the county.

Most participating state agencies reported reducing speed limits by $10 \mathrm{mph}$ below the normal posted speed during construction activities. There are a few agencies that even consider reducing speed limits by $20 \mathrm{mph}$. The additional $10-\mathrm{mph}$ speed limit reduction, however, generally requires reviews and recommendations by the appropriate engineering personnel. The majority of agencies use regulatory (black on white), rather than advisory (black on orange), signs to post reduced speed limits at their work zones.

A few state agencies indicated that speed limit reductions at work zones are being considered on a case-by-case basis. This process requires a careful examination of each construction project to determine whether speed reduction is warranted. A few comments suggest that work zones should be designed so that no speed limit reductions are imposed. However, if conditions warrant, realistic speed limit reductions should be maintained throughout the work zones.

Of the 12 identified speed reduction strategies, the use of regulatory speed limit signs and police enforcement are the most common practices reported by the agencies. However, only seven percent of the participating agencies consider the use of regulatory signs to be an effective speed reduction strategy. This may be compared with 70 percent of agencies that consider police enforcement engagement to be very effective in imposing speed limit compliance at work zones.

Although the use of police enforcement is a very effective speed reduction strategy, it is costly. Due to limited resources, the use of police officers at work zones is infrequent by many agencies. The impracticality of the extensive use of law enforcement at work zones may result in a short-term impact on motorists. As the Kentucky DOT points out, "speeds increase when officers leave the area."

The use of the CMS system by 18 out of 34 (see Table 2) agencies might be an indication of its potential in reducing work zone speeds. A number of these agencies use CMS in conjunction with radar to detect and display speeds of approaching vehicles. Four agencies indicated that CMS is effective in reducing work zone speeds. The other five perceived the system as somewhat effective.

The Iowa DOT and six other Midwest state agencies are among the small group of agencies (a total of 12) that have conducted research to study the effects of speed reduction strategies at work zones. It is expected that through the Midwest States Smart Work Zone Deployment Initiative and other research projects an innovative technology at least as effective as police enforcement will be identified to assist state agencies to better manage speed limits at work zones. 


\section{ACKNOWLEDGMENTS}

The project was funded in part by the Iowa Department of Transportation through its management agreement with Iowa State University. The authors would like to thank the Project Development Division of the Iowa DOT for sponsoring the project. 


\section{REFERENCES}

1. Migletz, J., and J.L. Graham. Work Zone Speed Control Procedures: Proceedings of the Symposium on Work Zone Traffic Control. Report FHWA-TS-91-003. TurnerFairbank Highway Research Center, Mclean, VA, 1991.

2. Manual on Uniform Traffic Control Devices. American Traffic Safety Services Association, Fredericksburg, VA, 1995, part 6.

3. Ullman, G.L., and D.R. Riesland. Catalog of Work Zone Speed Control Methods. Report FHWA-TX-90/1161-2. Texas Transportation Institute, College Station, TX, 1990.

4. Kuennen, T. "Minnesota Work Zone Signs Get New Muscle," Roads and Bridges, January 1988, pp. 108-109.

5. Prescott, P., Hall, R.D., and K.S. Rutley. An Assessment of the Effect of $70 \mathrm{mph}$ Repeater Signs on the M1 Motorway. Report CR206/SA. Transport and Road Research Laboratory, Crowthorne, Berkshire, England, 1990.

6. Graham, J.L., Paulsen, R.J., and J.C. Glennon. Accident and Speed Studies in Construction Zones. Report FHWA-RD-77-80. Midwest Research Institute, Kansas City, MO, 1977.

7. Jarvis, J.R. "The Effectiveness of Road Work Speed Limit Signs." Australian Road Research, Vol. 13, No. 3, September 1983, pp. 185-194.

8. Sisiopiku V.P., Lyles, R.W., Krunz, M., Yang, Q., Akin, D., and M. Abbasi. Study of Speed Patterns in Work Zones. Presented at the Transportation Research Board 1999 Annual Meeting, Washington DC, January 1999.

9. Lyles, R.W. "Alternative Sign Sequences for Work Zones on Rural Highways." Transportation Research Record, No. 833, 1981, pp. 13-17.

10. Benekohal, R.F., and J. Shu. Evaluation of Work Zone Speed Limit Signs with Strobe Lights. Report FHWA-IL-UI-242. Illinois Department of Transportation, June 1992.

11. Special Report 209: Highway Capacity Manual. Transportation Research Board, National Research Council, Washington DC, 1994.

12. Van Der Horst, R., and W. Hoeskstra. "Testing Speed Reduction Designs for 80 Kilometer per Hour Reads with Simulator." Transportation Research Record, No. 1464, 1994, pp. 63-68.

13. Richards, S.H., Faulkner, M.J.S., and C.L. Dudek. Traffic Management during Freeway Reconstruction and in Rural Work Zones. Report FHWA-TX-82/49+2637F. Texas Transportation Institute, College Station, TX, 1982.

14. Kuo, N.M., and J.M. Mounce. "Operational and Safety Impacts on Freeway Traffic of High-Occupancy Vehicle Lane Construction in a Median.” Transportation Research Record, No. 1035, 1985, pp. 58-65. 
15. Richards, S.H., Wunderlich, R.C., and C.L. Dudek. "Field Evaluation of Work Zone Speed Control Techniques." Transportation Research Record, No. 1035, 1985, pp. 66-78.

16. Benekohal, R.F., Kastel, L.M., and M. Suhale. Evaluation and Summary of Studies in Speed Control Methods in Work Zones. Report FHWA-IL-UI-237. Illinois

Department of Transportation, 1992.

17. Richards, S.H., R.C. Wunderlich, R.C., and C.L. Dudek. Controlling Speeds in Highway Work Zones. Report FHWA-TX-84/58+292-2. Texas Transportation Institute, College Station, TX, 1984.

18. Benekohal, R.F., and L.M. Kastel. "Evaluation of Flagger Training Session on Speed Control in Rural Interstate Construction Zones." Transportation Research Record, No. 1304, 1991, pp. 270-291.

19. McCoy, P.T., and J.A. Bonneson. Work Zone Safety Device Evaluation. Report SD92-10F. Center for Infrastructure Research, Lincoln, NE, 1993.

20. Noel, E.C., Dudek, C.L., Pendleton, O.J., and Z.A. Sabra. "Speed Control through Freeway Work Zones: Techniques Evaluation." Transportation Research Record, No. 1163,1988 , pp. 31-42.

21. Benekohal, R.F., Resende, P.T.V., and R.L. Orloski. Effects of Police Presence on Speed in a Highway Work Zone: Circulating Marked Police Car Experiment. Report FHWA-IL/UI-240. University of Illinois, Urbana, IL, 1992.

22. Effectiveness of Law Enforcement in Reducing Vehicle Speeds in Work Zones. Office of Construction, Construction Programs Section, Minnesota Department of Transportation, January 1999. http://www.atssa.com/mndot.htm.

23. Jones, R.K., and J.H. Lacey. The Effectiveness of Laser- and Radar-based Enforcement Programs for Deterrence of Speeding, Final Report. Report DOT-HS808-530. National Highway Traffic Safety Administration, U.S. Department of Transportation, 1997.

24. Sisiopiku, V.P., and H. Patel. Study of the Impact of Police Enforcement on Motorists Speeds. Presented at the Transportation Research Board 1999 Annual Meeting, Washington, DC, January 1999.

25. Benekohal, R.F., Resende, P.T.V., and W. Zhao. Speed Reduction Effects of Drone Radar in Rural Interstate Work Zones. Report FHWA-IL-238. University of Illinois, Urbana, IL, 1992.

26. Ullman, G.L. "Effect of Radar Transmission on Traffic Operations at Highway Work Zones." Transportation Research Record, No. 1304, 1991, pp. 261-269.

27. Streff, F.M., Kostyniuk, L.P., and C. Christoff. Effects of Drone Radar and Police Enforcement on Travel Speeds: Test on 65 mph Freeway and 55 mph Construction Zone. Transportation Research Institute, University of Michigan, 1995.

28. Freedman, M., Teed, N., and J. Migletz. "Effect of Radar Drone Operations on Speeds at High Crash Risk Locations." Transportation Research Record, No. 1464, 1994, pp. 69-80. 
29. Bloch, S.A. "Comparative Study of Speed Reduction Effects of Photo-Radar and Speed Display Boards." Transportation Research Record, No. 1640, 1998, pp. 27-36.

30. McCoy, P.T., Bonneson, J.A., and J.A. Kollbaum. "Speed Reduction Effects of Speed Monitoring Displays with Radar in Work Zones on Interstate Highways."

Transportation Research Record, No. 1509, 1995, pp. 65-72.

31. Garber, N.J., and M.D. Fontaine. Controlling Vehicle Speeds in Work Zones: Effectiveness of Changeable Message Signs with Radar. Report UVA-529242/CE96102. Prepared for Mid-Atlantic Universities Transportation Center for U.S. Department of Transportation and Virginia Department of Transportation; Department of Civil Engineering, University of Virginia, Charlottesville, VA, 1996.

32. Wertjes, J.M. Use of Speed Monitoring and Communication Display for Traffic Control, Final Report. Report SD-95-10F. Office of Research, South Dakota Department of Transportation; prepared by Benshoof \& Associates, Inc., Edina, MN, 1996.

33. Benekohal, R.F., and J.S. Linkenheld. Evaluation of Radar Activated Horn System for Speed Control in Highway Maintenance Operations. Report FHWA-IL-UI-235. University of Illinois, Urbana, IL, 1990.

34. Stout, D., Graham, J., Migletz, J., Fish, J., and F. Hanscom. Maintenance Work Zone Safety Devices Development and Evaluation. Report SHRP-H-371. Strategic Highway Research Program, National Research Council, Washington, DC, 1993.

35. Pigman, J.G., and K.R. Agent. "Evaluation of I-75 Lane Closures." Transportation Research Record, No. 1163, 1988, pp. 22-30.

36. Denton, G.G. The Influence of Visual Pattern on Perceived Speed. Report LR-409. Transport and Road Research Laboratory, Crowthorne, Berkshire, England, 1971.

37. Pyne, H.C., Doughery, M.S., Carsten, O.M.J., and M.R. Tight. A Simulator-based Evaluation of Speed Reduction Measures for Rural Arterial Roads, Working Paper. Report 434. Institute For Transport Studies, University of Leeds, England, 1995.

38. Meyer, E. Applications of Optical Speed Bars to Highway Work Zones. Presented at the Transportation Research Board 1999 Annual Meeting, Washington DC, January 1999.

39. Graham, J.L., Paulsen, R.J., and J.C. Glennon. Accident and Speed Studies in Construction Zones. Report FHWA-RD77-80. Midwest Research Institute, Kansas City, MO, 1977.

40. Fatalities by Work Zone and Large Truck Involvement (Fatality Analysis Reporting System). Federal Highway Administration, U.S. Department of Transportation, 1996. http://www.ohs.fhwa.dot.gov/work zone/1996work.htm. Accessed on Aug. 19, 1999.

41. In the Last Five Years (1993-1997) 64 People Have Died in Minnesota Work Zones . . 63 Were Motorists. Metro Division, Minnesota Department of Transportation, 1999. http://www.channel4000.com/partners/metro/workzone.html. Accessed on May $17,1999$. 
42. Migletz, J., Graham, J.L., Anderson, I.B., Harwood, D.W., and K.M. Bauer. Work Zone Speed Limit Procedure. Presented at the Transportation Research Board 1999 Annual Meeting, Washington DC, January 1999. 


\section{APPENDIX A}

\section{COVER LETTER AND SURVEY FORM}

June 11, 1999

«First_Name» «Last_Name»

«Title»

«Company»

«Address_1»

«Address_2»

«City», «State» «Zip»

Dear

The Iowa Department of Transportation has made improving work zone safety a high priority, and sees managing vehicle speeds through work zones as an important step in achieving this goal. We are reviewing our policies regarding work zone speed reduction and management and are researching innovative systems to assist us. The Iowa Department of Transportation is funding a study of Speed Reduction Measures in Work Zones, in order to learn what methods are available to reduce or manage speeds. We have contracted with the Center for Transportation Research and Education (CTRE) at Iowa State University, to manage this research project.

We want to better understand what your agency is doing to reduce or manage work zone vehicle speeds. We would appreciate your cooperation in completing the enclosed survey and returning it to us by July 9, 1999. We have enclosed a postage-paid, self-addressed envelope for your convenience.

We have organized the survey into two parts. The first section deals with the policies your agency has developed for work zone speed controls. The second section focuses on innovative or unique speed reducing systems your agency is using or has used in the past, with room to comment on their perceived effectiveness. This section also allows you to detail what your agency considers its most successful systems to reduce or manage work zone speeds.

We appreciate any help you can provide us on this important issue. Please direct all questions to Tom Maze, Director of CTRE, at (515) 294-8103, or email him at tmaze@iastate.edu.

Thank you,

Timothy D. Crouch, P.E.

State Traffic Engineer

Iowa Department of Transportation 


\section{Work Zone Speed Reduction Survey}

The Iowa Department of Transportation (Iowa DOT) is interested in learning about the practices and policies used by other state transportation agencies to reduce or manage vehicle speeds in work zones on their primary highway system. To assist the Iowa DOT, the Center for Transportation Research and Education (CTRE) at Iowa State University has been contracted to conduct this survey. Your agency's responses to the survey will help Iowa establish new work zone traffic control policies and operational procedures. CTRE will prepare a report based on the survey results, and copies will be provided to respondents who request one (see below). Thank you in advance for your assistance in this important project.

Please distribute the survey to the appropriate staff member(s) to complete. This survey would probably be best completed by personnel in your organization's Traffic Engineer's Office, or equivalent. The Iowa DOT is interested in speed management in both construction work zones and maintenance work zones. If your organization is structured so that construction and maintenance are different divisions, it may be appropriate to have personnel from both divisions complete the survey. The perspectives of the different groups are of interest to the Iowa DOT.

Please provide the following information for our records of survey respondents:

State:

Organization:

Name of person(s) completing the survey:

Title:

Address:

Telephone number:

Fax number:

E-mail address:

O Check here if you want a copy of CTRE's final report based on this survey.

Please return

the completed survey

by July 9, 1999,

using the enclosed

envelope, to:
Dr. Tom Maze

Center for Transportation Research and Education

2901 S. Loop Drive, Suite 3100

Ames, IA 50010-8632

Phone: (515) 294-8103

Fax: (515) 294-0467 


\section{Section 1: Policy and Design Issues}

This section of the survey deals with your organization's policies for establishing and applying work zone speed limits. What we refer to as a "policy," you may call a "procedure" or "standard." Any automatic process governing the decision to reduce or manage work zone speed is considered a "policy" for the purposes of this survey.

If it is easier for you, copy appropriate pages from your written policy, highlight pertinent sections, and return them with this survey.

$------------------------------------$ Question 1: Does your state have an established policy on reducing or managing traffic speeds in work zones on the state primary system? If you have such a policy:

- Describe the policy.

- Explain how this policy is generally applied in different settings (e.g., rural vs. urban, multilane vs. two-lane, reconstruction vs. maintenance, etc.). 


\section{Question 2: How was this policy established?}

- Explain the steps taken in developing the policy, such as focus groups or scientific studies, or if the policy came in the form of a legislative requirement.

- If a management team or engineering panel established the policy, please state that, along with any criteria used in the decision-making process.

- It would be helpful for us to know if the policy was "bottom-up" (engineeringlevel) or "top-down" (such as a legislative mandate) in nature.

\section{Question 3: Based on the policy of your organization, what speed limit would be} used for traffic in the following scenarios? Seven scenarios (all rural sections of primary highway) are shown on the following pages. Direction arrows indicate traffic flow. For simplicity, posted signs like "WORK ZONE AHEAD," "LEFT LANE CLOSED AHEAD," etc., are not portrayed in these figures, but are assumed to be present. For each scenario:

- State the existing non-work zone speed limit and both the work zone regulatory and advisory speeds.

- Note on the drawing where and what type of speed limit sign (regulatory or advisory speed limit signs, changeable message signs, etc.) would be used in each scenario.

Again, if it is easier for you, feel free to attach standard plan sheets or design details that your organization might use to address a work zone of each type, and highlight the speed limits shown on the plans. 


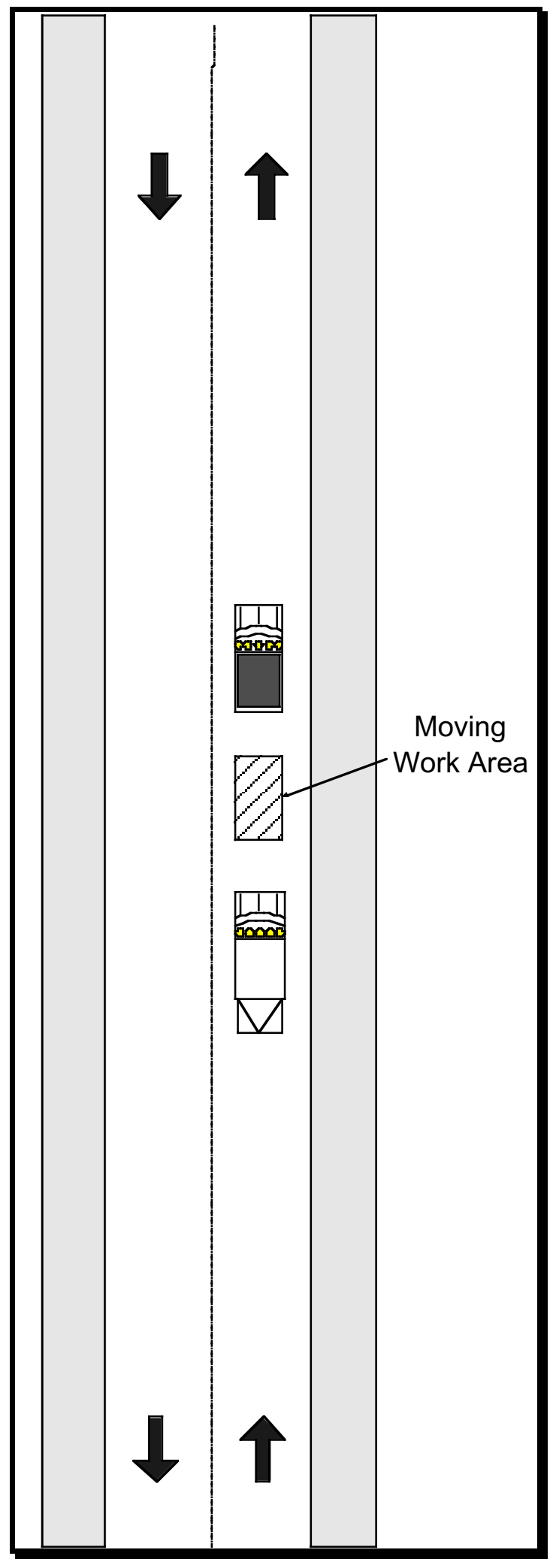

Scenario 1 - Mobile Maintenance Operation (Two-lane road)

Existing Non-Work Zone Speed Limit:

Regulatory Work Zone Speed Limit:

Advisory Work Zone Speed Limit:

Additional Comments: 


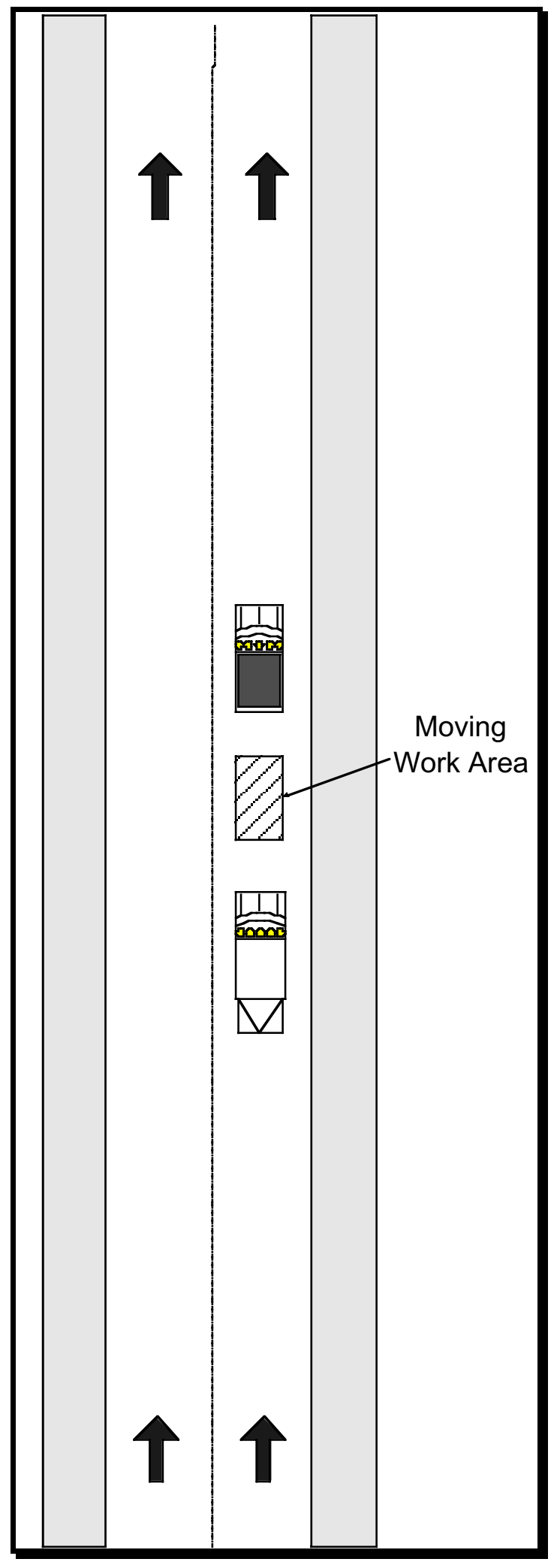

Scenario 2 - Mobile Maintenance Operation (Multilane road)

Existing Non-Work Zone Speed Limit:

Regulatory Work Zone Speed Limit:

Advisory Work Zone Speed Limit:

Additional Comments: 


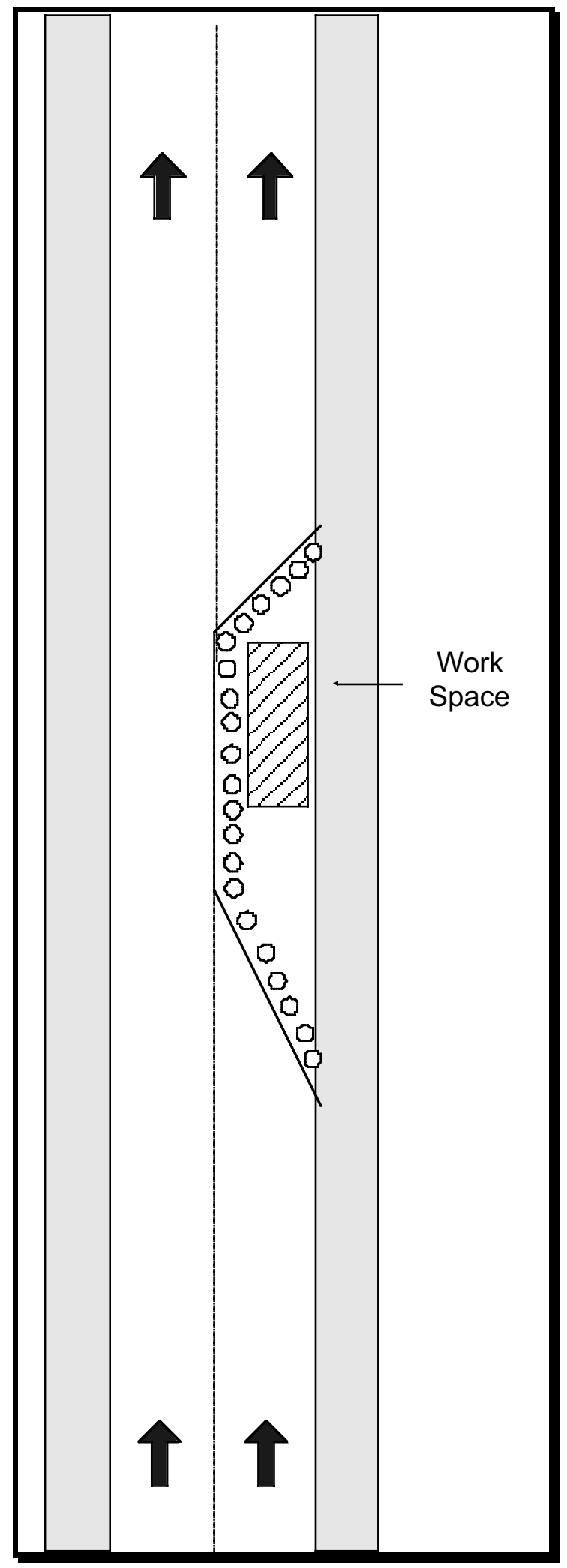

Scenario 3 - Lane closure, no concrete barrier (Multilane road)

Existing Non-Work Zone Speed Limit:

Regulatory Work Zone Speed Limit:

Advisory Work Zone Speed Limit:

Additional Comments: 


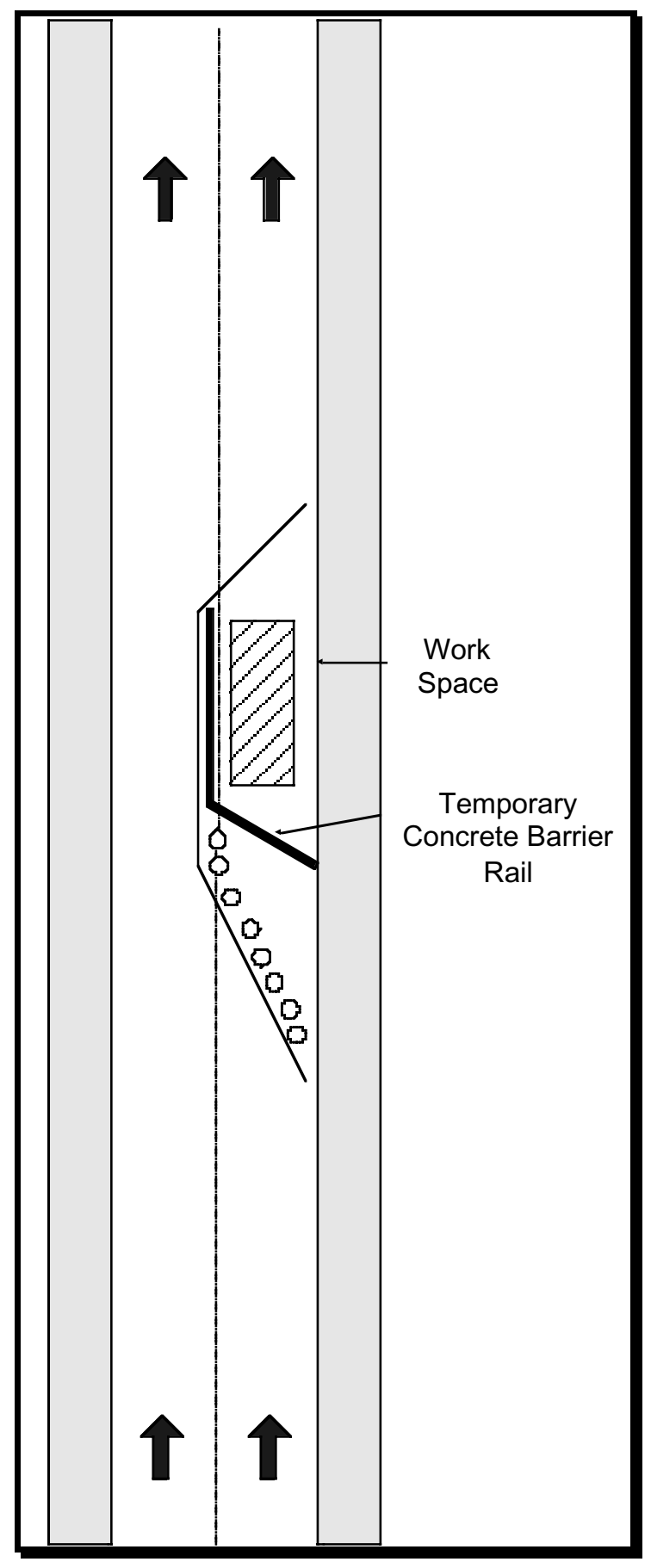

Scenario 4 - Lane closure, with concrete barrier (Multilane road)

Existing Non-Work Zone Speed Limit:

Regulatory Work Zone Speed Limit:

Advisory Work Zone Speed Limit:

Additional Comments: 


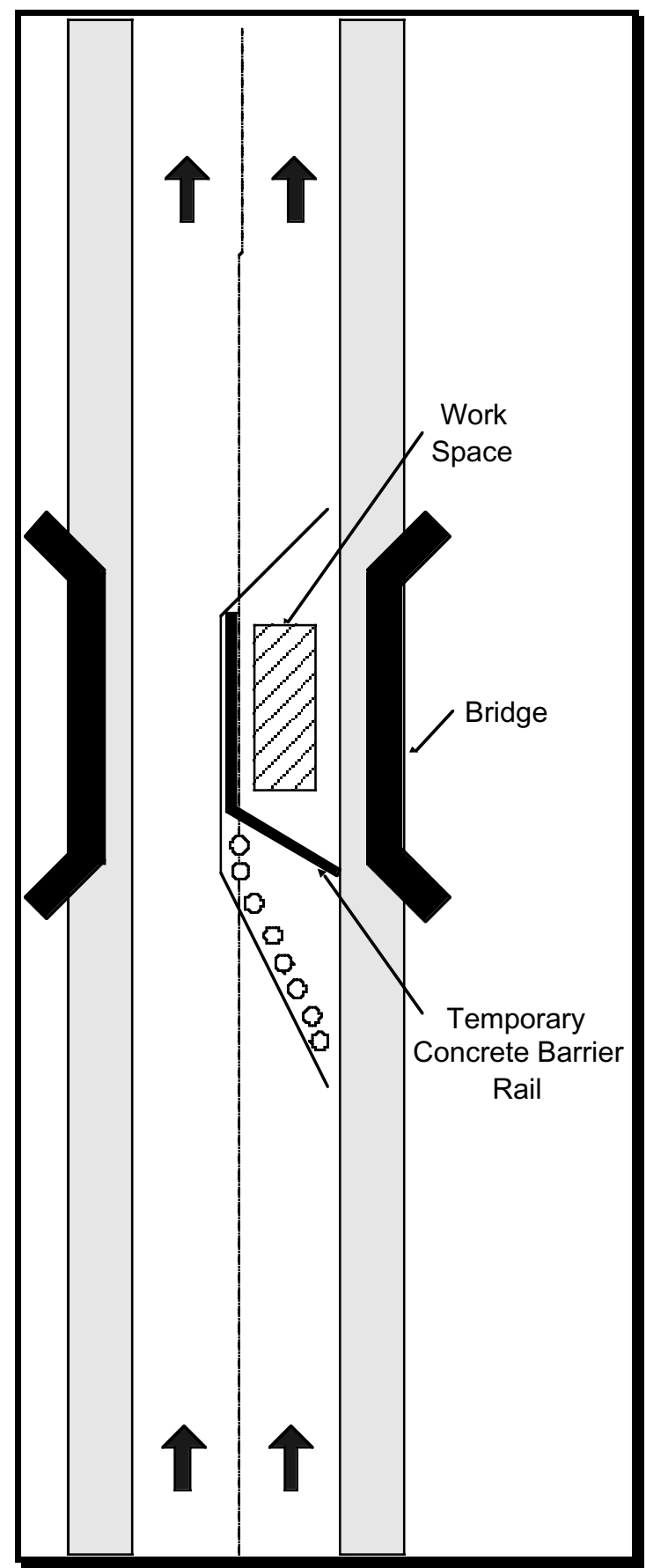

Scenario 5 - Lane closure on a structure, with concrete barrier (Multilane road)

Existing Non-Work Zone Speed Limit:

Regulatory Work Zone Speed Limit:

Advisory Work Zone Speed Limit:

Additional Comments: 


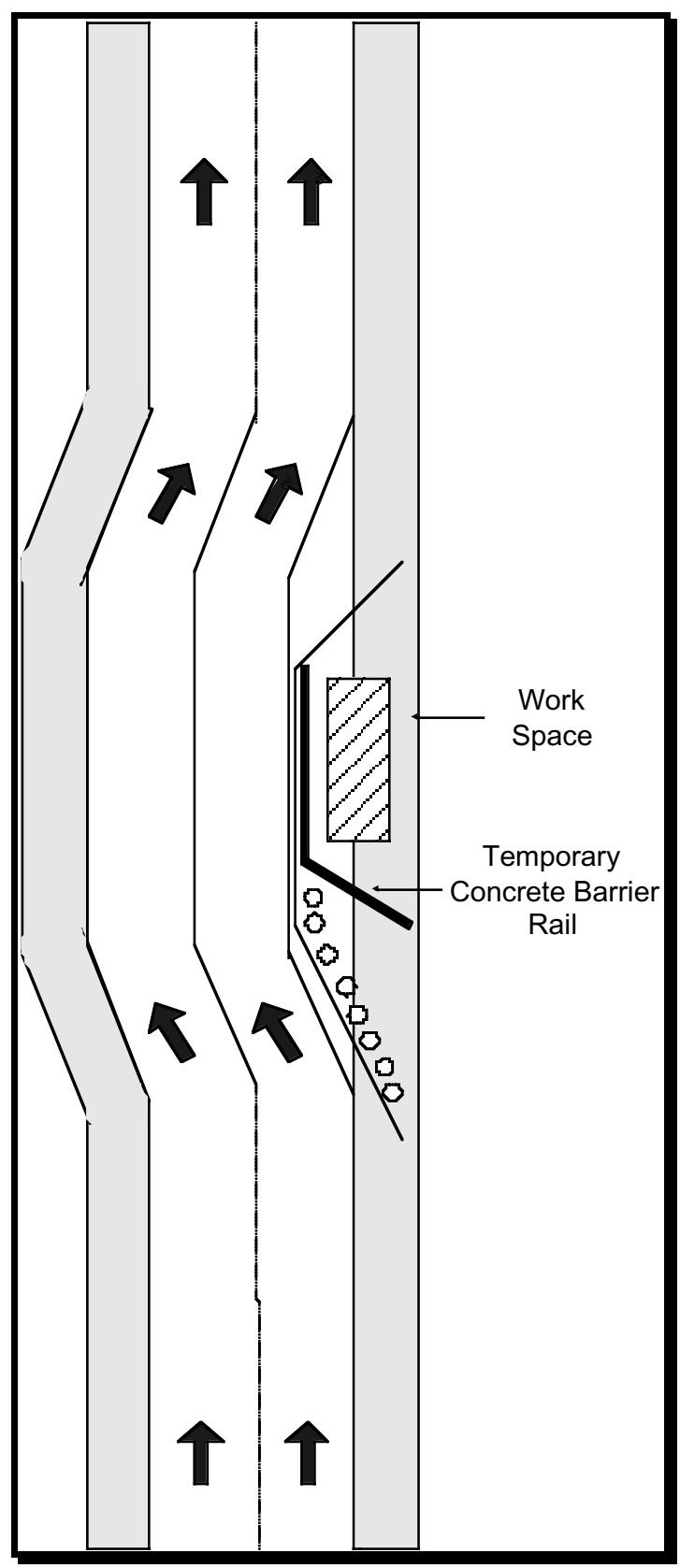

Scenario 6 - Lane Shift (Multilane road)

Existing Non-Work Zone Speed Limit:

Regulatory Work Zone Speed Limit:

Advisory Work Zone Speed Limit:

Additional Comments: 


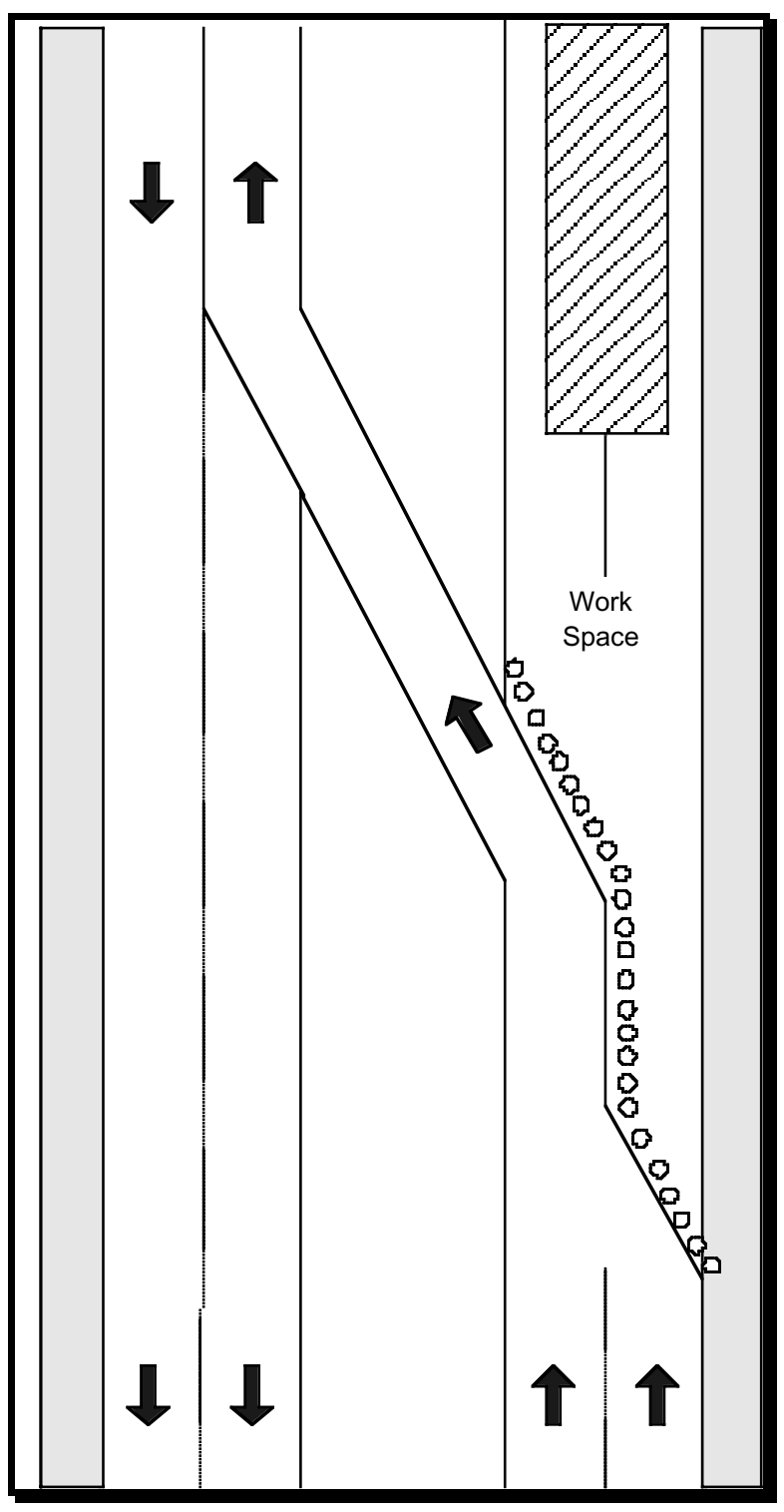

Scenario 7 - Median Crossover (Multilane road)

Existing Non-Work Zone Speed Limit:

Regulatory Work Zone Speed Limit:

Advisory Work Zone Speed Limit:

Additional Comments: 


\section{Section 2: Speed Reduction Systems and Their Implementation}

The following questions are designed to learn more about the speed reduction systems with which your organization is experienced, as well as your evaluation of those systems. In short, what system(s) do you use, and what do you think of it (them)?

If it is easier for you, we encourage you to copy and attach pages of your written policy, highlighting pertinent sections.

Question 4: What systems does your organization use to manage the speed of vehicles through work zones?

- List all methods that are currently in use or have been used in the past. This list should include everything from fixed regulatory signs up to the most advanced components of your traffic control plan.

- Describe each method's performance/effectiveness. Try to use a quantitative response, such as the amount of observed speed reduction in mph, if possible. If a system does not appear to have a quantitative impact, state that, with possible reasons why.

\section{System}

Perceived Effectiveness 
Question 5: Has your organization conducted field trials or in-house research for these or other speed management systems? If so:

- Explain what method or technology was evaluated, and the results of the trials.

- List the titles of any research report resulting from the evaluation.

- If possible, we would appreciate your including one copy of each of these reports when you return this survey. Additional postage may be required.

Method Evaluated Results Title of Research Report Enclosed (Y/N)

Question 6: Describe the most effective system or process used by your

organization to reduce or manage work zone speeds. Feel free to sketch a diagram to help us understand the system. Then answer these questions about the process:

- On what basis do you characterize it as the most effective system? Quantify your answer, if possible.

- How long has this procedure been used in your state?

- How often is it used, on average, each year? 
For more information or clarifications concerning this survey, please contact Tom Maze at (515) 294-8103, or tmaze@iastate.edu

Center for Transportation Research and Education Iowa State University

2625 North Loop Drive, Suite 2100

Ames, IA 50010-8615

Phone: (515) 294-8103

Fax: (515) 294-0467 


\section{APPENDIX B}

\section{QUESTION 1: POLICY DESCRIPTION}

\section{State Agencies with Policies}

\section{State Policy Policy Description}

Alabama

California

Yes

Yes
It is generally implemented on a project by project basis and is generally applied based on type facility, design speed, type work, proximity of the work zone to traffic, etc. Advisory speed limits are applied in most work zones.

ADOT follows the guidelines of part 6 of the MUTCD.

The decision is normally made for construction projects during design by consensus of the design engineer, resident engineer, and regional traffic engineer and stated in the plans.

Maintenance zones are controlled by the regional traffic engineer. Temporary traffic control should be based on the design speed of the facility whenever possible. When this is not possible, the off-peak 85th percentile speed or the posted speed limit prior to construction should govern the design. The necessary speed reduction shall be established in the interest of public safety and convenience and for the protection of workers and equipment. When a speed reduction greater than $10 \mathrm{mph}$ is considered appropriate, the transition to the lower speed limit should be make in steps or not more than $10 \mathrm{mph}$.

Construction speed zones are established on roads under construction where reduced speed is necessary to limit the risk of an accident to workers and the traveling public during all hours of the day and night. Use other means to slow drivers, if possible. Speed limit and end zone signs will be installed at locations jointly agreed upon by the traffic engineer and the construction engineer. The speed zone will be verified by an engineering and traffic survey.

\section{Attachments}

No

Yes

Yes 

standard reduction is $10 \mathrm{mph}$ from the preexistence non-work zone speed. WZ designs that retain the prevailing speed limit should be considered whenever practical. No speed limit reduction is recommended when the distance to the work is greater than 10 feet. from the edge of the traveled way or when the work area is protected by concrete barrier and lane widths are not reduced. No reduction recommended in posted speed limits of $40 \mathrm{mph}$ or less. Establish minimum WZ speed limits in accordance with provided tables. On roadways having three or more lanes normally available for a given direction of travel, the tables provided should be used to determine the WZ speed limit if the minimum width in the traffic lane available to traffic directly adjacent to the work is 10 feet or more. WZ speeds for unusual conditions shall be determined by the Region Traffic Engineer or Staff Traffic Engineer. Standard traffic engineering techniques shall be used to establish all WZ speed limits.

Florida Yes

All TCPs must include specific regulatory speeds (either posted or reduced) for each phase of work. Regulatory speeds must be uniformly established through each phase, and should not be reduced more than $10 \mathrm{mph}$ below the posted speed and never below the minimum statutory speed. When a reduction greater than $10 \mathrm{mph}$ is imposed, the reduction should be in $10 \mathrm{mph}$ per 150 -meter increments. All regulatory speeds must be established on the basis of a traffic and engineering investigation. Designers should only reduce speed when the temporary geometry requires it. When field conditions warrant speed reductions different from those shown in the TCP, the contractor may submit to the project engineer for approval by the department, a signed and sealed study to justify the need for further reducing the posted speed, or the engineer may request the district traffic operations engineer (DTOE) to investigate the need. Florida statute states that fines shall be doubled when speeding in work zones. It also gives FDOT the authority to regulate speed limits in work zones. Policy described in attached documents: (1) Plans Preparation Manual (PPM), (2) Construction Project Administration Manual (CPAM), (3) Roadway and Traffic Design Standards, (4) Florida Status 318.18, 316.0745, (5) Motorist Awareness System (MAS).

Georgia Yes

Typically, speed reduction policy is applied to rural and urban interstate projects. Representatives from the Office of Construction determine which projects have the Speed Reduction Special Provision added to the contract. 
Speeds at work zones are dropped in increments of $10 \mathrm{mph}$, but not in excess of $20 \mathrm{mph}$ below the posted speed limit. Reductions over $10 \mathrm{mph}$ must be supported by engineering study. Requirements to reduce speed limits must always be approved by a district operations engineer. The types of roads addressed are divided into freeways $(65 \mathrm{mph})$ and nonfreeways $(55 \mathrm{mph})$. For these types, the speed limit will not be lowered if there is no lane closure or apparent hazard on the freeway, or no work on pavement and no apparent hazard on nonfreeways. Decision of when to reduce speeds in work zones is based on whether following conditions exist: (for freeway 10 mph decrease): lane closures, traffic crossovers; (for freeway 20 mph decrease): proximity of unprotected workers, engineering speed study indicating the need. For nonfreeways $(10 \mathrm{mph}$ decrease): unprotected workers, narrow lane, high volumes, inadequate sight distance, workers are on the shoulder or in closed lane adjacent to open lane. Traffic fines are doubled in work zones. The policy also details methods for posting work zone speed signs.

Kansas

Kentucky Yes

Louisiana

Yes
Kansas policy is to reduce work zone speed limits as little as necessary. Kansas DOT tries to design all traffic control as the pre-existing speeds, but routinely use 10-mph reductions due to physical constraints. The actual speed (regulatory or advisory) is determined by the engineer in the field.

Policy provides three options for speed management: (1) Engineer can apply a 10-mph reduction in regulatory speed limit, (2) a reduction greater than $10 \mathrm{mph}$ must be supported by an engineering or traffic investigation, and (3) no change at all. Any of the three alternatives can be supplemented with a "double-fine" zone.

In an area where construction or maintenance work has degraded the condition of the original highway, where work is in progress in the immediate vicinity of the travel way, or where workers are in close proximity to traffic, a reduced speed limit of $10 \mathrm{mph}$ less than the preexisting speed limit may be used. Speeds can be further reduced if the geometrics or work conditions warrant a reduction. Preexisting speeds of $35 \mathrm{mph}$ or less generally do not warrant further reduction. 
The maximum reduction shall be $10 \mathrm{mph}$ from existing speed limit. Reductions greater than this require special review and recommendations by the appropriate division traffic engineer or engineer of traffic. Reduced speed zones should be at least 1,500 feet. long. Fines double for speeding violations in WZs. There are three types of reduced speed zones: (1) Advisory-should be first consideration when establishing WZ speed reduction. Used where a potential hazard exists and to alert drivers of conditions which may require a speed reduction. A speed limit authorization from the Commissioner of Transportation is not required to select an advisory speed. The resident engineer, DTE, or designated crew leader is authorized to determine the appropriate advisory speed limit. Engineering judgment is sometimes the only indicator of the reasonable speed to be installed. A $10 \mathrm{mph}$ advisory speed reduction is suggested. (2) Short-term/work-hour speed enforceable under the double-fine law-may be used only when workers are present, and they and the work area are adjacent to traffic. Intended for use in short-term stationary construction or maintenance WZs, not mobile or moving operations. Short-term speed limit signs are posted in the traffic control zone only during those hours when work activity occurs. Existing speed limit can be lowered up to $10 \mathrm{mph}$ with $10 \mathrm{mph}$ being a good starting point. The short-term/work-hour speed limit shall be between 25 and 55 mph. Speed limit reductions less than these must be reviewed and recommended by the DTE or other appropriate traffic personnel. (3) Temporary construction zone speed-regulatory speed limit enforceable under the double-fine law, may be used for long-term projects where altered travel paths and/or unsafe travel conditions warrant reduced speeds 24 hours per day. May be used only when the condition exists; for example, crossovers, lane closures, drop-offs, narrow lanes, etc. The existing regulatory speed limit can be lowered up to $10 \mathrm{mph}$ as long as the WZ speed limit is between 25 and $55 \mathrm{mph}$. Speed limit reductions greater than these must be reviewed and recommended by the appropriate DTE or other appropriate traffic personnel. This policy comes with tables and charts to aid users in making appropriate choice of reduction method. 
State Policy Policy Description

Attachments

Maryland $\quad$ Yes The State Highway Administration may reduce estimated speed

Yes limits in a highway WZ upon determination that the change is necessary to ensure public safety. The reduced speed limit should usually be $5 \mathrm{mph}$ less than normally posted speed, but no more than $10 \mathrm{mph}$. For speed limits less than or equal to 55 $\mathrm{mph}$, reduced speeds suggested when: full width shoulder has been converted to travel lane; reduced lane width; lane closed for extended period; major work activities adjacent to travel lanes; new road alignments along freeways having a design speed significantly less than design speed of roadway. For roadways with posted speed greater or equal $60 \mathrm{mph}$ : when $\mathrm{WZ}$ activities remain stationary for more than 1 hour on travel portion of roadway, speed limit must be reduced from 65/60 to $55 \mathrm{mph}$ for the following: shoulder converted to travel lane; reduced lane width; closed lane; new alignment w/ design speed less than that of roadway. Other work activities on or near the roadway should be evaluated individually by assistant district engineer. Advisory speed limits used for spot situations like sharp alignment changes, short sections of narrow lanes.

Minnesota $\quad$ Yes Speed limits are generally reduced by $10 \mathrm{mph}$ below the posted Yes speed limit. The $10 \mathrm{mph}$ speed limit reduction is a guideline, not a rigid policy. Maintenance supervisors have discretion to use the reduced work zone speed limit as they deem necessary. 99\% of work zone speed limits are used on multi-lane facilities. The complete work zone speed limit policy is described in attached booklet (pp. 4 and 5).

Mississippi Yes Speeds on interstate and four-lane divided highways are reduced by $10 \mathrm{mph}$ where construction is in progress.

In general, a 10-mph reduction is made. For speed reductions greater than $20 \mathrm{mph}$ it is done in two stages. On divided highways, the reduced speed is applicable to the affected direction of travel. When local ordinance provides for lower speeds, the lower speed is used. Reduced speeds shall not be below $35 \mathrm{mph}$. If the geometrics of the roadway during the work activity requires a lower speed than the speed indicated in the "work zone speed limit" chart (i.e., temporary bypasses, narrow lanes, etc.), then the speed limit will be based on the roadway geometrics.

Montana Yes

Sign for $35 \mathrm{mph}$ when construction activity is within 30 feet of active roadway. $35 \mathrm{mph}$ sign must be placed within 500 feet of activity to implement double fine. The MDOT uses a lot of flagger and pilot car operations when single lane is closed. Use more signs (on both sides of roadway), also use $10 \mathrm{mph}$ step-down speed limit signs on multilane. Policy is the same Rural and urban settings, but lower for urban areas (15-25 mph). 
Maintenance work: Rural areas- for work activity in driving lanes: freeways, $55 \mathrm{mph}$; other state highways, $35 \mathrm{mph}$. If work activity is on shoulder and does not encroach on driving lane: freeways, $55 \mathrm{mph}$, other state highways, $40 \mathrm{mph}$. If work is off shoulder, no change to statutory limit. Urban areas- freeways, use guidelines for rural areas. Other state highways- $35 \mathrm{mph}$ if statutory speed greater or equal to $50 \mathrm{mph}, 25 \mathrm{mph}$ if statutory speed less than or equal to $45 \mathrm{mph}$. Special conditions or work activities may occur where speed limits higher or lower than those described above may be appropriate; but limits cannot be lower than $35 \mathrm{mph}$, rural, $25 \mathrm{mph}$, urban. Exceptions to these speeds for maintenance jobs can be made if work is short duration, takes place off of shoulder, or is a fast moving operation. The director-state engineer may raise the $35 \mathrm{mph}$ in rural areas and $25 \mathrm{mph}$ in urban areas, or may delegate this authority to Department of Roads supervisory personnel. Limits can be raised by $5 \mathrm{mph}$ increments, but cannot exceed statutory speed limits. The difference between adjacent speed limits may not exceed $20 \mathrm{mph}$; in this case, a transitional speed limit must be provided to reduce speed. A "FINES FOR SPEEDING DOUBLE IN WORK ZONES" sign must be posted at the beginning of each work zone. Construction work: Speeds must be determined by Lincoln office, and will be included in the contract provisions so that a contractor will be aware of a construction speed limit while preparing his bid. Director-state engineer may delegate power to change established construction WZ speeds to designated individuals. 
At this time, NVDOT reviews reduced speed requests, for work zones, on a case-by-case basis. The request must include the reason for the request, such as reduced lane widths, tight geometrics on lane shifts, proximity to workers, and so on. However, due in part to the number of projects that are putting out for construction and the number of requests for speed reductions, NVDOT is working on a work zone speed limit policy and have it in draft form. The policy will formalize the speed reduction procedure. The draft policy looks at two basic speed zones, one for highways with posted speed limits of $65 \mathrm{mph}$ or higher which would temporarily reduce the regulatory speed limit to $55 \mathrm{mph}$. The other covers highways with a posted speed limit of $55 \mathrm{mph}$, which would temporarily reduce the regulatory speed limit to $45 \mathrm{mph}$. Highways with speed limits of $45 \mathrm{mph}$ or less will only have advisory speeds. The temporary speed reductions would take place only in an active work zone, after all work zone signs have been placed. Whenever the work zone is removed, the temporary speed limit signs would also be removed. If the work zone remains in effect during nonworking hours, due to hazardous conditions, "channelizing" devices, and so on, the temporary speed reduction will remain in effect during nonworking hours. Reduced regulatory speed limits will be (and currently are) allowed only in a work zone, and never for the entire project length. The idea is that by having regulatory speed reductions only in active work zones, higher compliance of the speed limit by motorists will be achieved. Speed limits are currently being reduced, within construction zones, on about 75 construction projects per year. After implementing the new policy this will go up to around 125 per year. 
New York Yes Agency having jurisdiction over the affected street or highway has the authority to establish a reduced speed limit in construction or maintenance work areas. WZ speed limits cannot be no greater than $20 \mathrm{mph}$ below the normally posted speed limits, and lower than $25 \mathrm{mph}$. First goal in designing a WZ is to include physical features and traffic controls that will permit flow close to normal approach speed. Need for reduced speed limits should be considered during design, included in project traffic control plan. Plan must include areas for police to stop motorists for enforcement operations. If need for speed reduction is noted after work starts, Regional construction personnel are responsible both for selecting speed limit and ensuring enough area for police enforcement activities. Conditions indicating need for reduced speed include: unprotected workers or equipment in open or closed lanes, shoulders, or median adjacent to open travel lanes; construction vehicles or equipment entering or crossing the travel lanes on a frequent basis in a way that may interrupt, slow or stop traffic flow; alternate one-way traffic controlled by flaggers or signal; closure of lanes that restrict flow on those remaining open; narrowed or diverted traffic lanes; sight distance restrictions; any other restrictions caused by construction which reduce safety. Work zone traffic controls should be designed to permit safe traffic flow at speeds as close to the approach speeds as practicable. (Described in attached Instruction 95-032.)

New York Thruway were signed for $45 \mathrm{mph}$. However, the New York State Thruway Authority is in the process of changing that policy to post those work zones where workers are protected by concrete barrier and the geometrics allow (no lane drops, gradual lane shifts and minimal narrowing of the lanes) at $55 \mathrm{mph}$. No reduced speed limit is posted in conjunction with movable work areas. This policy applies to all areas of the Thruway and to all types of work. In an effort to encourage compliance with the posted speed limit, state police intermittently park in work zones for brief periods (15-30 minutes) with their lights flashing. This is normally done during their regular tours. In addition, recently started posting signs as part of the advance series of signs informing motorists that fines for speeding are doubled in work zones. Although not on a regular basis, the Thruway has also employed radar activated VMS's displaying speeds, drone radar, and "ghost" cars (recycled state police cars). 
North Dakota Yes Policy is based on the NCHRP Report 3-41. Procedure is based

Yes upon considering a speed limit on a site-by-site basis and factors relating to the actual work zone conditions. For WZ speed determination purposes, ND divides its highway types into (1) Interstates/four-lane divided and (2) two-lane highways. Parameters used to evaluate the conditions at the WZ before determining WZ speed: proximity of work activities to edge of roadway; location of construction equipment with regards to roadway; truck traffic entering work site; distance between workers and traveled way; presence/absence of detour. $10 \mathrm{mph}$ speed limit reduction is most common. Flow chart diagram is provided to aid decision makings.

Ohio Turnpike Yes Normal speed limits are $65 \mathrm{mph}$ for cars, $55 \mathrm{mph}$ for vehicles over four tons empty weight and noncommercial buses. One policy: $50 \mathrm{mph}$ regulatory speed limit for all stationary work zones.

Oregon $\quad$ Yes $\quad$ Reductions are granted by the state traffic engineer by written order for long term (greater than one day) construction or shorter if emergency. Oregon does not reduce speeds for routine maintenance or utility work. Criteria are analyzed on a case-by-case basis. Reductions can be requested as part of project design or during construction. Preferred alternative is no reduction needed. The attached worksheet is used to determine if a speed reduction is required.

Tennessee Yes TNDOT has no automatic process for reducing speed limits in work zones. Speed zone reductions are considered in work zones based on site conditions and the nature of work or activity. The general procedure is as follows: if, in the design phase, the design speed of the roadway cannot be consistently maintained, then a regulatory speed limit would be considered for the duration of the project. Generally, it would be attempted to reduce speed no more than $10 \mathrm{mph}$. Once a project starts, the project engineer can request a speed limit reduction. The request is reviewed and if conditions warrant, the speed limit reduction is granted. 

work activity and not throughout the entire project. Minimum length of a speed zone is $0.2 \mathrm{mi}$. In determining best reduced speed for construction, consider factors such as safe stopping sight distances, construction equipment crossings, nature of the construction project, any other factors that affect safety of traveling public and workers. Only speed limits authorized by Transportation Commission minute order, city or county ordinance are legal. Advisory speed plates in conjunction with construction warning signs can often be used more appropriately than construction regulatory speed signs. Advisory speeds can be altered as needed by project conditions, and several different advisory speeds can be used for varying conditions throughout the project. Regulatory construction speed limits should be used only for sections of construction projects where speed control is of major importance and enforcement is available. When a district desires construction speed zoning for projects or portions of a project outside the limits of incorporated cities, the district should prepare and submit applicable TXDOT form, plans, specifications and estimates to the state Design Division; Design Division then forwards form to Traffic Operations Division for review, processing, commission action. Cities have authority to establish construction speed zones within their corporate limits if they desire. Speed limit may be reduced by 10 $\mathrm{mph}$ if the following conditions exist: work encroaches on the area closer than 10 feet (shoulder activity); work requires a temporary detour; etc. No reduction needed for work greater than 10 feet from edge of traveled way (roadside activity) or if work requires intermittent or moving operation on shoulder. 
State

Washington

Wisconsin

Wyoming
Policy Policy Description

Attachments

Yes The policy for speed limits and speed advisories is the same for

Yes all highways. Speed limits and speed advisories are only used when drivers should reduce speed for their safety. When speed restrictions are necessary, Project engineer shall submit a request to the regional traffic engineer in advance of need. Regional administrator may reduce regulatory speed limit where changes to roadway environment dictate reduced speeds. Publish notice of the reduced speed in newspaper in area where the reduction takes place at least 3 days in advance of reduction; in emergencies or for up to 12-hour reduction periods, publish 1 day in advance. District administrators have authority to establish reduced regulatory speed limits if: personnel and equipment are working on, or immediately adjacent to travel lanes; lane widths have been decreased. The need is determined by an engineering and traffic investigation. The Maintenance and Operations Office and state patrol must be advised of regulatory reduced speed areas. Within a construction area, short sections of roadway may have curves or rough sections which may require reduced speeds. An advisory sign (in increments of $5 \mathrm{mph}$, determined by Regional Traffic Engineer) must be used in these areas in conjunction with proper warning signs.

Yes If the work or traffic control devices are within 6 feet of the open lane, speed is reduced from 65 to 55 . This speed reduction is not done when the work area is short in length and duration. 45 limit is considered where workers are close to traffic. On 55 -mph or less roadways regulatory speed reductions are usually not done. However, if the geometry or roadway surface conditions warrant, a 10-mph reduction is made. This policy is based on experience of other states with similar practices.

Yes Wyoming uses a "standard plan" to lower speeds through typical work zones. If conditions vary, traffic engineers in the field evaluate the conditions and modify the speed limits to fit the situation. In theory, it is supposed to work this way. It is, however, assumed that the speed limit can get lowered upon a speed reduction request from a contractor or someone in the Wyoming Highway Department. There is a common philosophy that if $50 \mathrm{mph}$ is desired, a $40 \mathrm{mph}$ speed limit should be posted. 


\section{State Agencies without Policies}

\section{State Policy Policy Description}

Attachments

Connecticut No

No

Hawaii No No

Iowa No No written policy. The current unwritten policy is to use $55 \mathrm{mph}$

No regulatory speed limit signs on projects on Interstate in Polk County and where TLTWO (2-lane, 2-way operation) occurs (head-to-head).

Kansas Turnpike No

Massachusetts No

No

North Carolina No

NCDOT has a policy for establishing speed limits, but not

No for work zones. Any detour curve or alignment is based on AASHTO guidelines.

Oklahoma

Turnpike

No

No

Pennsylvania No

Work zone speed limits are set on a project-by-project basis.

No The decision is made by the project designer or maintenance foreman based on experience and perceived hazard. If used, speed limits are traditionally set at $15 \mathrm{mph}$ below normal speed limits.

Rhode Island No No

South Carolina No The only standardized speed reduction is during lane closures on multilane facilities; $45 \mathrm{mph}$ for interstate routes and $35 \mathrm{mph}$ for all other roadways.

Utah No Sent a letter stating that UDOT does not have a policy. The decision to reduce the speed limit is left up to the designers, project/contractor personnel, and the maintenance crew. Speed reduction is subject to review and approval by area traffic engineer. The amount of speed reduction is generally 10-20 mph below the posted speed limit based upon the impact the work activity has on traffic and the type of facility interstate highways, surface highways etc. 


\section{APPENDIX C \\ QUESTION 2: POLICY DEVELOPMENT PROCEDURE}

\section{State Agencies with Policies}

\section{State}

Alabama

Arizona

California

Colorado

Florida

Georgia

Illinois

Kansas

\section{Policy Development Procedure}

Departmental policies govern the location of regulatory speed limit signs, reduction in $10 \mathrm{mph}$ increments, etc.

This unwritten policy was developed by practice from engineering staff. In 1996, a Traffic Control Supplement to the MUTCD, chapter 6, was issued and adopted by statute (prepared by consultant on-call contract).

CADOT policies were developed by task groups, which included different agencies throughout California.

Policy was developed at an engineering level by staff Traffic Office personnel and reviewed by construction, maintenance, and traffic operations personnel.

Florida has a statewide Maintenance of Traffic Committee (MOTC). This committee helps establishing policies and procedures for reducing speed limits in work zones.

GADOT Commissioner initiated the policy. Construction Office representatives were responsible for writing the policy.

Policy was a product of a subcommittee of IDOT's Work Zone Safety Committee. It included contractors and IDOT personnel. Although it was a bottom-up approach, the passage of the double fines in work zone law prompted the development of the policy.

Policy philosophy comes from the NCHRP Report 3-41 (2) "Effectiveness \& Implementability of Procedures for Setting Work Zone Speed Limits" and section 6B, paragraph 2 (p. 13 of small and p. 3 of large 1993 part 6 MUTCD). The policy was developed by a management team between design and traffic engineering.

\section{Policy Strategy}

Assumed "bottom-up"

"Bottom-up"

Assumed "bottom-up"

Assumed "bottom-up"

Assumed "bottom-up"

Assumed "bottom-up"

"Bottom-up"

"Bottom-up" 
State

Kentucky

Louisiana

Maine

Maryland

Minnesota

Mississippi

Missouri

\section{Policy Development Procedure}

A cooperative effort between the Transportation Cabinet, the Legislature, and groups representing highway contractors.

The policy was reviewed by the state traffic engineer at the request of the Louisiana DOT and Development General Council. Developed at a management level.

This policy was established as a result of the state legislature doubling fines for speeding violations in a work zone. A DOT task force was established to amend this and other actions to enhance work zone safety. Developed by an engineering panel.

With the increase in speed limits to $65 \mathrm{mph}$ on some of our highways, it was felt that speeds in work zones have to be reduced to ensure safe work zones. Contractors also expressed similar concerns. The central Office of Traffic and Safety developed a policy for reducing or managing traffic speeds in work zones. The legislature also gave the authority to use "double-fine" signs in work zones.

Legislation was enacted to implement the first work zone speed limit. MnDOT then conducted numerous studies on sign sequences and developed a policy on what signs to use to implement a WZ speed limit legally. Recently, a "bottom-up" task force was set up to rework all the standards for work zone speed limits. This includes engineers, law enforcement, contractors, and safety inspectors. It is still a guideline, not a rigid policy.

Adapted as a policy by Mississippi Transportation Commission based on recommendations from professional staff.

MODOT has a work zone standards Quality Circle.

\section{Policy Strategy}

Assumed "bottom-up"

Assumed "bottom-up"

“Top-down”

"Top-down"

"Top-down" at first; more recently "bottom-up"

Assumed "bottom-up"

Assumed "bottom-up" 
State

Montana

Nebraska

Nevada

New York

New York Thruway

North Dakota

Ohio Turnpike

Oregon

\section{Policy Development Procedure}

State law established $35 \mathrm{mph}$ speed limit in construction zones. This can be changed by engineering studies. Speed limit established by legislative mandate. Montana did not have a speed limit in the 1950s. Just recently passed its first non-FHWA mandated speed limit.

The statutes were from the legislature, resulting in guidelines. The guidelines were established by the Traffic Engineering Division, the Maintenance Division, and the Director's Office.

The policy (being developed) is the result of numerous discussions within our (traffic engineering) division. The policy is based on what we do now on a case-by-case basis.

Developed by the engineering staff.

The system-wide $45 \mathrm{mph}$ speed limit in stationary WZs was initiated in conjunction with the increase in the general speed limit from 55 to $65 \mathrm{mph}$ on the thruway. The decision was made by a management team with input from the AGC and thruway highway maintenance crews. The use of police in work zones was a joint decision between thruway management and the state police, again with input from the AGC and thruway maintenance forces. The recent decision to sign some WZs at $55 \mathrm{mph}$ was made by management and is consistent with NYSDOT practice.

Based on NCHRP Report 3-41. Adopted by our Traffic Control Review Team, approved by Chief Engineer.

Developed by a management team.

Procedure is engineering level plus from research plus MUTCD.

\section{Policy Strategy}

Assumed "top-down"

Assumed "top-down"

"bottom-up"

"Bottom-up"

Assumed "bottom-up"

Assumed "bottom-up"

Assumed "bottom-up"

"Top-down" from

legislature 
State

Tennessee

Texas

Washington

Wisconsin

Wyoming

\section{Policy Development Procedure}

There was no formal procedural development. The process is engineering level. TN has statute which allows the fine for speeding to increase if the violation is in a work zone with workers present and flashing lights activated.

Transportation Code gives the Texas

Transportation Commission the authority to alter maximum speed limits on highway routes both within and outside of cities, provided the procedures for establishing speed zones are followed. Basic speed law developed through the Transportation Code.

Almost all of the studies that support WADOT policy come from the highway itself.

Developed by engineers and management by considering the principles of the MUTCD and NCHRP Report 3-41.

Districts have responsibility for implementing temporary speed limits. This was done at the request of district engineers.

\section{Policy Strategy}

Assumed "bottom-up"

"Top-down"

"Bottom-up"

"Bottom-up"

Assumed "bottom-up" 


\section{State Agencies without Policies}

State

Connecticut

Hawaii

Iowa

Kansas Turnpike

Massachusetts

North Carolina

Oklahoma Turnpike

Pennsylvania

Rhode Island

South Carolina

Utah
Policy Development Procedure

Policy Strategy

No policy.

No policy.

No written policy. However, the current unwritten policy is based on decisions made at the engineering level. It is the engineering decision to use 55-mph speed limit signs, since TLTWO acts like 2-lane primary roads (which is $55 \mathrm{mph}$ currently) and not like 4-lane divided interstate at $65 \mathrm{mph}$.

No policy.

No policy.

No policy.

No policy.

No policy.

No policy.

No policy. Standard (NOT policy) developed by Traffic Engineering office.

No policy.
"Bottom-up" 


\section{APPENDIX D}

SCENARIO 1: MOBILE MAINTENANCE OPERATION (TWO-LANE ROAD)

\section{Speed Reduction}

$\begin{array}{llll}\text { State } & \text { Existing SL } & \text { Reg. SL } & \text { Adv. } \\ \text { Alabama } & 55 & 55 & 35-45 \\ \text { Arizona } & 65 & 35 & \end{array}$

Two-way traffic is maintained through flagging/coning operation or pilot car operation (dependent on length and geometry of roadway and terrain). Majority of two-lane rural roads in Arizona have shoulders $0-2$ feet width.

May be used Use advanced warning signs on trailing vehicles (e.g., "SLOW TRAFFIC AHEAD" and "DO NOT PASS").

$\begin{array}{lr}\text { Florida } & 55 \\ \text { Georgia } & 55 \\ \text { Maine } & 55\end{array}$

55

55

55

45

45

45

Massachusetts

40

40

30

35

$40-60$

Nevada

Tennessee
$55-75$

$55-65$

55
An advisory speed would only be considered if conditions were site or route specific, such as numerous vertical and horizontal curves. This decision would be made by the signing and marking supervisor using judgment and prevailing conditions. 
State

Washington
Existing SL

Up to 70 on

certain

highways
Reg. SL Adv. SL Comments

Warning signs are needed for the work area but a recommended speed cannot be determined without stating specific roadway conditions. 


\section{No Speed Reduction}

State Existing SL Reg. SL Adv. SL Comments

Colorado

No speed reduction. Work zone speed limits are not normally used for mobile operations. This would apply to both regulatory $\&$ advisory posting. However, procedures would allow posting if conditions warrant.

Illinois

Iowa

Kansas

$55-65$

Kentucky

Louisiana

55

Minnesota

Mississippi

Montana

$65-75$

Nebraska

$55-65$

New York

North Dakota

55

55

55

55
55

No speed reduction.

No speed reduction.

No speed reduction. Operations restricted to off-peak traffic periods.

No speed reduction.

No speed reduction. The work vehicle is followed by one or two protection vehicles equipped with TMA and two high-intensity flashing lights.

No speed reduction. MnDOT does not use a fixed numeric value speed limit on any moving operation.

No speed reduction.

No speed reduction. Would have shadow vehicle 500-1000 feet behind mobile operation with TMA and arrow board just flashing in its four corners. The vehicle may carry a sign (e.g., Wet Paint Ahead).

May be used No speed reduction if work lasts less than a half day at one location.

No speed reduction. NYSDOT rarely, if ever, uses speed limits for mobile operations.

No speed reduction. Use advanced Signing-flaggers with advisory speed plates. 
State

Oregon

Pennsylvania

South Carolina

Texas

Wisconsin

Wyoming
55

55

55

55

55

Existing SL Reg. SL

65

\section{Adv. SL Comments}

No speed reduction. Currently, regulatory speeds in Oregon cannot be posted using VMS.

No speed reduction.

No speed reduction.

No speed reduction.

No speed reduction. Reduced speed limit would usually not be posted during mobile operations.

No speed reduction. This situation would either have flaggers or advance warning prior to the work zone. Typically, we do not lower speeds for short-term mobile operations. 


\section{No Information}

$\begin{array}{llll}\text { State } & \text { Existing SL } & \text { Reg. SL Adv. SL Comments }\end{array}$

Connecticut

Hawaii

Maryland

New York

North Carolina

Ohio Turnpike

Oklahoma

Rhode Island

Utah
No information.

No information.

No information.

No information.

No information.

No information.

No information.

No information.

No information. 


\section{Not Applicable}

\section{$\begin{array}{llll}\text { State } & \text { Existing SL } & \text { Reg. SL } & \text { Adv. SL }\end{array}$}

Kansas Turnpike

Not applicable. 
APPENDIX E

SCENARIO 2: MOBILE MAINTENANCE OPERATION (MULTILANE ROAD)

\section{Speed Reduction}

\begin{tabular}{|c|c|c|c|c|}
\hline State & Existing SL & Reg. SL & Adv. SL & Comments \\
\hline Arizona & $65-75$ & 45 & & $\begin{array}{l}\text { This is an interstate or a } \\
\text { major U.S. route. Controlled } \\
\text { by cones and highway patrol } \\
\text { officer at rear of operations. }\end{array}$ \\
\hline California & $65-70$ & May be used & May be used & $\begin{array}{l}\text { Advanced warning signs on } \\
\text { trailing vehicles (e.g., "LANE } \\
\text { CLOSED AHEAD," "ROAD } \\
\text { WORK AHEAD," and CMS). }\end{array}$ \\
\hline Florida & 65 & 65 & 55 & \\
\hline Maine & 65 & 65 & 55 & $\begin{array}{l}\text { Maine has no specific policy } \\
\text { for this situation, but } \\
\text { advisory speed limit would } \\
\text { probably be used. }\end{array}$ \\
\hline Massachusetts & 50 & 50 & 40 & $\begin{array}{l}\text { Would recommend a portable } \\
\text { CMS to be able to move } \\
\text { along with the work area. }\end{array}$ \\
\hline Missouri & $\begin{array}{l}65-70 \text { rural, } 60 \\
\text { urban }\end{array}$ & & $\begin{array}{l}10-20 \mathrm{mph} \\
\text { reduction }\end{array}$ & $\begin{array}{l}10 \text { and } 20 \mathrm{mph} \text { speed } \\
\text { reduction in protected (e.g., } \\
\text { concrete barriers, crash } \\
\text { worthy devices, etc.) and } \\
\text { unprotected work areas, } \\
\text { respectively. }\end{array}$ \\
\hline Nevada & $45-75$ & & $30-60$ & $\begin{array}{l}\text { Try to limit the advisory } \\
\text { speed reduction to no more } \\
\text { than } 15 \text { mph below the } \\
\text { posted speed limit. }\end{array}$ \\
\hline North Dakota & 65 & 55 & & Flaggers used. \\
\hline
\end{tabular}


State

Tennessee

Washington
$55-70$

Existing SL

Up to 70

\section{Reg. SL Adv. SL Comments}

An advisory speed would only be considered if conditions were site or route specific, such as numerous vertical and horizontal curves. This decision would be made by the signing and marking supervisor using judgment and prevailing conditions.

Warning signs are needed for the work area but a recommended speed cannot be determined without stating specific roadway conditions. 


\section{No Speed Reduction}

\begin{tabular}{|c|c|c|c|c|}
\hline State & Existing SL & Reg. SL & Adv. SL & Comments \\
\hline Alabama & $65-70$ & $65-70$ & $65-70$ & No speed reduction. \\
\hline Colorado & & & & $\begin{array}{l}\text { No speed reduction. Work } \\
\text { zone speed limits are not } \\
\text { normally used for mobile } \\
\text { operations. This would } \\
\text { apply to both regulatory \& } \\
\text { advisory posting. However, } \\
\text { procedures would allow } \\
\text { posting if conditions warrant. }\end{array}$ \\
\hline Georgia & $55-70$ & $55-70$ & & No speed reduction. \\
\hline Illinois & $55-65$ & $55-65$ & & $\begin{array}{l}\text { No speed reduction for } \\
\text { moving operations. }\end{array}$ \\
\hline Iowa & 65 & 65 & 65 & No speed reduction. \\
\hline Kansas & $55-70$ & No change & No change & $\begin{array}{l}\text { No speed reduction. } \\
\text { Operations restricted to } \\
\text { off-peak traffic periods. }\end{array}$ \\
\hline Kansas Turnpike & 70 & 70 & 70 & $\begin{array}{l}\text { No speed reduction. } \\
\text { Additional Truck } 1500 \text { feet } \\
\text { behind work zone advising of } \\
\text { work zone. Possible } \\
\text { additional truck } 1500 \text { feet } \\
\text { behind the protection truck } \\
\text { depending on area and sight } \\
\text { restrictions. }\end{array}$ \\
\hline Kentucky & Varies & & & No speed reduction. \\
\hline Louisiana & 65 & & & $\begin{array}{l}\text { No speed reduction. } \\
\text { Protection vehicle } 1 \text { equipped } \\
\text { with arrow display and lane } \\
\text { closure sign moves on } \\
\text { shoulder. If there is no } \\
\text { shoulder vehicle } 1 \text { should be } \\
\text { eliminated. Protection vehicle } 2 \\
\text { equipped with arrow and TMA } \\
\text { moves on closed lane. Protection } \\
\text { vehicle } 3 \text { be used on closed lane on } \\
\text { high-speed roads. }\end{array}$ \\
\hline
\end{tabular}




\begin{tabular}{|c|c|c|c|c|}
\hline State & Existing SL & Reg. SL & Adv. SL & Comments \\
\hline Maryland & & & & No speed reduction. \\
\hline Minnesota & & & & $\begin{array}{l}\text { No speed reduction. } \\
\text { MnDOT do not use a fixed } \\
\text { numeric value speed limit on } \\
\text { any moving operation. }\end{array}$ \\
\hline Mississippi & & & & No speed reduction. \\
\hline Montana & $65-75$ & & & $\begin{array}{l}\text { No speed reduction. We } \\
\text { would have a shadow vehicle } \\
500-1000 \text { feet behind the mobile } \\
\text { operation with a TMA and } \\
\text { arrow board with sequencing } \\
\text { arrows directing traffic to the } \\
\text { left. }\end{array}$ \\
\hline Nebraska & $65-75$ & & May be used & $\begin{array}{l}\text { No speed reduction if work } \\
\text { lasts less than a half day at one } \\
\text { location. }\end{array}$ \\
\hline New York & & & & $\begin{array}{l}\text { No speed reduction. } \\
\text { NYSDOT rarely, if ever, uses } \\
\text { speed limits for mobile } \\
\text { operations. }\end{array}$ \\
\hline New York & $55-65$ & $55-65$ & & No speed reduction. \\
\hline Ohio Turnpike & $55-65$ & $55-65$ & & No speed reduction. \\
\hline Oklahoma & 75 & & & No speed reduction. \\
\hline Oregon & $55-65$ & & & No speed reduction. \\
\hline Pennsylvania & $55-65$ & & & No speed reduction. \\
\hline South Carolina & & & & No speed reduction. \\
\hline Texas & 65 & & & $\begin{array}{l}\text { No speed limit reduction } \\
\text { recommended except in } \\
\text { unusual circumstances. }\end{array}$ \\
\hline Wisconsin & 65 & 65 & & No speed reduction. \\
\hline Wyoming & 75 & 75 & & $\begin{array}{l}\text { No speed reduction. On a } \\
\text { multilane facility, a shadow } \\
\text { vehicle would use a } \\
\text { sequential chevron to move } \\
\text { traffic to the left lane. }\end{array}$ \\
\hline
\end{tabular}




\section{No Information}

$\begin{array}{llll}\text { State } & \text { Existing SL } & \text { Reg. SL } & \text { Adv. SL }\end{array}$

Connecticut

No information.

Hawaii

North Carolina

No information

No information.

Rhode Island

No information.

Utah

No information. 


\section{APPENDIX F}

\section{SCENARIO 3: LANE CLOSURE WITH NO CONCRETE BARRIER (MULTILANE ROAD)}

\section{Speed Reduction}

\begin{tabular}{|c|c|c|c|c|}
\hline State & Existing SL & Reg. SL & Adv. SL & Comments \\
\hline Alabama & $65-70$ & $50-60$ & 45 & \\
\hline Arizona & $65-75$ & 45 & & $\begin{array}{l}\text { Assuming this is an } \\
\text { interstate or major U.S. } \\
\text { route. }\end{array}$ \\
\hline California & $65-70$ & May be used & May be used & $\begin{array}{l}\text { Advisory speed limits may } \\
\text { be implemented at any speed } \\
\text { increment of } 5 \mathrm{mph} \text { below } \\
\text { posted speed limit down to } \\
25 \mathrm{mph} \text {. }\end{array}$ \\
\hline Colorado & $55-70$ & & & $\begin{array}{l}\text { Speeds may be reduced as } \\
\text { much as } 10 \text { mph below the } \\
\text { posted limits. Posting would } \\
\text { depend on the design of the } \\
\text { work zone, original posting, } \\
\text { location of the workers and } \\
\text { hazards and operation of the } \\
\text { work activity (i.e., flaggers, } \\
\text { etc.). }\end{array}$ \\
\hline Florida & 65 & 55 & & $\begin{array}{l}\text { Existing speed limits may be } \\
\text { reduced by } 10 \mathrm{mph} \text { (only } \\
\text { during lane closure). }\end{array}$ \\
\hline Georgia & $55-70$ & $\begin{array}{l}10 \mathrm{mph} \\
\text { reduction }\end{array}$ & & $\begin{array}{l}\text { The contractor may elect to } \\
\text { lower the posted speed in } 10 \\
\text { mph increments. }\end{array}$ \\
\hline Illinois & $55-65$ & $45-55$ & & $\begin{array}{l}45-55 \text { regulatory posted } \\
\text { through lane closure ( } 10 \\
\text { mph reduction). } \\
\text { Additionally, " } 45 \mathrm{MPH} \text { WHEN } \\
\text { WORKERS PRESENT" signs } \\
\text { posted with flashing amber } \\
\text { strobes to further reduce } \\
\text { speed. " } \$ 150 \text { fine for } \\
\text { speeding" also is on sign. }\end{array}$ \\
\hline
\end{tabular}




\begin{tabular}{|c|c|c|c|c|}
\hline State & Existing SL & Reg. SL & Adv. SL & Comments \\
\hline Kansas & $55-70$ & $\begin{array}{l}\text { Maximum } 10 \\
\text { mph reduction }\end{array}$ & & $\begin{array}{l}\text { On interstates, a flagger is } \\
\text { required in advance of the } \\
\text { work area whenever workers } \\
\text { are adjacent to traffic } \\
\text { without a barrier protection. }\end{array}$ \\
\hline Kentucky & Varies & $\begin{array}{l}10 \mathrm{mph} \\
\text { reduction }\end{array}$ & $\begin{array}{l}10 \mathrm{mph} \\
\text { reduction }\end{array}$ & \\
\hline Louisiana & 65 & 45 & & $\begin{array}{l}\text { This procedure also applies } \\
\text { when work is being } \\
\text { performed in the lane } \\
\text { adjacent to the median on a } \\
\text { divided highway. Under } \\
\text { these conditions, "LEFT } \\
\text { LANE CLOSED" signs and } \\
\text { the corresponding lane } \\
\text { reduction symbol signs } \\
\text { shall be used. }\end{array}$ \\
\hline Maine & 65 & 55 & & $\begin{array}{l}\text { Regulatory speed limit signs } \\
\text { are shown only when } \\
\text { workers are present. }\end{array}$ \\
\hline Maryland & $60-65$ & 55 & $45-50$ & $\begin{array}{l}\text { Advisory speed limits } \\
\text { should be used for spot } \\
\text { situations such as sharp } \\
\text { alignment changes, or short } \\
\text { sections of narrow lanes, } \\
\text { etc. The reduced work zone } \\
\text { speed limit is to be displayed } \\
\text { only at those times it is } \\
\text { needed and removed when } \\
\text { no longer needed. }\end{array}$ \\
\hline Massachusetts & 50 & 50 & 40 & $\begin{array}{l}\text { Would use post-mounted } \\
\text { static lane closure signs. }\end{array}$ \\
\hline Minnesota & $55-70$ & $\begin{array}{l}40 \text { at activity } \\
\text { areas }\end{array}$ & $\begin{array}{l}10 \mathrm{mph} \\
\text { reduction }\end{array}$ & $\begin{array}{l}\text { By law, work zone speeds } \\
\text { may be reduced } 15 \mathrm{mph} \\
\text { below posted speeds (when } \\
\text { existing speed limit is } 55 \text { or } \\
\text { less) to as low as } 20 \mathrm{mph} \text {. }\end{array}$ \\
\hline
\end{tabular}

Mississippi $\quad$ Up to $70 \quad 10 \mathrm{mph}$

reduction 


\begin{tabular}{|c|c|c|c|c|}
\hline State & Existing SL & Reg. SL & Adv. SL & Comments \\
\hline Missouri & $\begin{array}{l}65-70 \text { rural, } 60 \\
\text { urban }\end{array}$ & & $\begin{array}{l}10-20 \mathrm{mph} \\
\text { reduction }\end{array}$ & $\begin{array}{l}10 \text { and } 20 \mathrm{mph} \text { speed } \\
\text { reduction in protected (e.g., } \\
\text { concrete barriers, crash } \\
\text { worthy devices, etc.) and } \\
\text { unprotected work areas, } \\
\text { respectively. }\end{array}$ \\
\hline Montana & $65-75$ & & 35 & $\begin{array}{l}\text { Would use flagger if many } \\
\text { construction vehicles } \\
\text { leaving work zone, such as } \\
\text { for a paving operation. } \\
\text { Would use no flagger for } \\
\text { stationary operations like } \\
\text { bridge work. }\end{array}$ \\
\hline Nebraska & 75 & 55 & & $\begin{array}{l}\text { Assuming this is a rural } \\
\text { interstate. Reduced speed } \\
\text { limit signs are posted } 500 \text { feet } \\
\text { prior the taper area. } \\
\text { "REDUCED SPEED AHEAD" } \\
\text { warning signs are placed } \\
1000 \text { feet upstream of the } \\
\text { speed signs. }\end{array}$ \\
\hline Nevada & $45-75$ & $\begin{array}{l}55 \text { for } 65-75, \\
45 \text { for } 55, \text { no } \\
\text { reduction for } \\
45\end{array}$ & $\begin{array}{l}40-45 \text { for } \\
\text { temp speed } \\
\text { reduction of } \\
55,30-35 \\
\text { for } 45\end{array}$ & $\begin{array}{l}\text { Work zones are designed for } \\
\text { the speeds that will be } \\
\text { posted for the temporary } \\
\text { regulatory speed reductions. }\end{array}$ \\
\hline New York & 55 & $40-45$ & & $\begin{array}{l}\text { Maximum } 15 \text { mph speed limit } \\
\text { drop is considered. } \\
\text { Depending on conditions, a } \\
\text { speed drop may not be } \\
\text { needed. }\end{array}$ \\
\hline New York & $55-65$ & 45 & & \\
\hline North Dakota & 65 & 55 & & $\begin{array}{l}\text { Use flaggers and advisory } \\
\text { speed plate. }\end{array}$ \\
\hline Ohio Turnpike & $55-65$ & 50 & & \\
\hline Oklahoma & 75 & $45-75$ & & \\
\hline Oregon & $55-65$ & $\begin{array}{l}10 \mathrm{mph} \\
\text { reduction }\end{array}$ & & \\
\hline Pennsylvania & $55-65$ & $\begin{array}{l}15 \mathrm{mph} \\
\text { reduction }\end{array}$ & & \\
\hline
\end{tabular}


State

South Carolina

Tennessee

$55-70$

65

Up to 70

Wisconsin

Wyoming

$40-55$

Washington

Wisconsin

65

75
Existing SL

Texas

55

35

55

\section{Reg. SL Adv. SL Comments} $\begin{array}{ll}\text { Would } & 10 \mathrm{mph} \text { less } \\ \text { consider } 10 & \text { than posted } \\ \text { mph reduction } & \text { speed limit }\end{array}$

A 10-mph reduction would be considered based on the lane closure, and nature of construction work. Decision would be based on request from project engineer documenting need such as difference in elevation, work-site conditions, and workers.

Taper lengths for lane closures are set according to the speed limit. In this example there is no reason to reduce the driver's speed.

On some projects, especially short in length or duration, the speed limit might not be reduced or a $55 \mathrm{mph}$ advisory speed might be used instead of a regulatory. Signs would be placed between the WZ advance warning signs (posted 2k' prior to lane closure).

The speed limit would be set based upon the width restriction and the degree of hazard. 


\section{No Speed Reduction}

$\begin{array}{lllll}\text { State } & \text { Existing SL } & \text { Reg. SL } & \text { Adv. SL } & \text { Comments } \\ \text { Iowa } & 65 & 65 & 65 & \text { No speed reduction. } \\ \text { Kansas Turnpike } & 70 & 70 & 70 & \begin{array}{l}\text { No speed reduction. Kansas } \\ \text { Turnpike does not slow traffic down } \\ \text { on a short-term closure as it } \\ \text { is found limiting speed to be } \\ \text { ineffective. }\end{array}\end{array}$




\section{No Information}

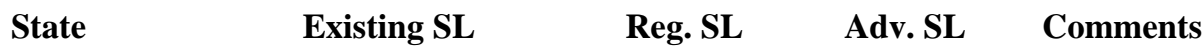

Connecticut

Hawaii

North Carolina

Rhode Island

Utah
No information.

No information.

No information.

No information.

No information. 
APPENDIX G

SCENARIO 4: LANE CLOSURE WITH CONCRETE BARRIER (MULTILANE ROAD)

\section{Speed Reduction}

\begin{tabular}{|c|c|c|c|c|}
\hline State & Existing SL & Reg. SL & Adv. SL & Comments \\
\hline Alabama & $65-70$ & $50-60$ & 45 & \\
\hline Arizona & $65-75$ & 45 & & $\begin{array}{l}\text { This kind of work zone } \\
\text { would not normally be used } \\
\text { in rural condition but may } \\
\text { be used in urban condition } \\
\text { at much lower speeds. }\end{array}$ \\
\hline California & $65-70$ & May be used & May be used & $\begin{array}{l}\text { Advisory speeds may be } \\
\text { implemented at any speed } \\
\text { increment of } 5 \mathrm{mph} \text { below } \\
\text { posted speed limit down to } \\
25 \mathrm{mph} \text {. }\end{array}$ \\
\hline
\end{tabular}

Colorado $\quad 55-75$

Florida

65

55

Speeds may be reduced as much as $10 \mathrm{mph}$ below the posted limits. Posting would depend on the design of the work zone, original posting, location of the workers and hazards and operation of the work activity (i.e., flaggers, etc.).

Existing speed limits may be reduced by $10 \mathrm{mph}$ (until construction activity is completed).

$\begin{array}{lll}\text { Georgia } & \text { Up to } 70 & \begin{array}{l}10 \mathrm{mph} \\ \text { reduction }\end{array} \\ \text { Illinois } & 55-65 & 45-55 \\ \text { Iowa } & 65 & 65\end{array}$

The contractor may elect to lower the posted speed in $10 \mathrm{mph}$ increments.

If barrier present, no further reduction from $10 \mathrm{mph}$ below posted is used.

The advisory $55 \mathrm{mph}$ speed limit is used at some structure locations. 


\begin{tabular}{|c|c|c|c|c|}
\hline State & Existing SL & Reg. SL & Adv. SL & Comments \\
\hline Kansas & 70 & \multicolumn{2}{|c|}{$\begin{array}{l}\text { Max. reduction } \\
\text { of } 10 \text { to fit } \\
\text { physical } \\
\text { constraints }\end{array}$} & $\begin{array}{l}\text { Often use temporary } \\
\text { surfacing on shoulder to } \\
\text { maintain standard lane } \\
\text { width. Advisory speed } \\
\text { would then apply only to } \\
\text { lateral shift taper rates. }\end{array}$ \\
\hline Kansas Turnpike & 70 & 60 & 60 & $\begin{array}{l}\text { If lane width is restricted } \\
\text { below } 12 \text { feet, speed is } \\
\text { reduced to } 60 \mathrm{mph} \text {. }\end{array}$ \\
\hline Kentucky & Varies & $\begin{array}{l}10 \mathrm{mph} \\
\text { reduction }\end{array}$ & $\begin{array}{l}10 \mathrm{mph} \\
\text { reduction }\end{array}$ & \\
\hline Louisiana & 65 & 45 & 45 & $\begin{array}{l}\text { The use of a barrier should } \\
\text { be based on the need } \\
\text { determined by an } \\
\text { engineering analysis. To } \\
\text { prevent vehicles from } \\
\text { impacting the ends of the } \\
\text { barrier, the taper and end } \\
\text { should be treated as given } \\
\text { in chapter } 9 \text { of the AASHTO } \\
\text { RDG. }\end{array}$ \\
\hline Maine & 65 & 55 & & $\begin{array}{l}\text { Regulatory speed limit } \\
\text { signs are shown only when } \\
\text { workers are present. }\end{array}$ \\
\hline Maryland & $60-65$ & 55 & $45-50$ & $\begin{array}{l}\text { Advisory speed limits } \\
\text { should be used for spot } \\
\text { situations such as sharp } \\
\text { alignment changes, or short } \\
\text { sections of narrow lanes, } \\
\text { etc. The reduced work zone } \\
\text { speed limit is to be } \\
\text { displayed only at those } \\
\text { times it is needed and } \\
\text { removed when no longer } \\
\text { needed. }\end{array}$ \\
\hline Massachusetts & 50 & 50 & 40 & $\begin{array}{l}\text { Would use post-mounted } \\
\text { static lane closure signs. }\end{array}$ \\
\hline Minnesota & $55-70$ & $\begin{array}{l}10 \mathrm{mph} \\
\text { reduction }\end{array}$ & $\begin{array}{l}10 \mathrm{mph} \\
\text { reduction }\end{array}$ & $\begin{array}{l}\text { Would not reduce speed as } \\
\text { barrier does not cross } \\
\text { center line. }\end{array}$ \\
\hline Mississippi & Up to 70 & $\begin{array}{l}10 \mathrm{mph} \\
\text { reduction }\end{array}$ & & \\
\hline
\end{tabular}




\begin{tabular}{|c|c|c|c|c|}
\hline State & Existing SL & Reg. SL & Adv. SL & Comments \\
\hline Missouri & $\begin{array}{l}65-70 \text { rural, } 60 \\
\text { urban }\end{array}$ & & $\begin{array}{l}10-20 \mathrm{mph} \\
\text { reduction }\end{array}$ & $\begin{array}{l}10 \text { and } 20 \mathrm{mph} \text { speed } \\
\text { reduction in protected (e.g., } \\
\text { concrete barriers, crash } \\
\text { worthy devices, etc.) and } \\
\text { unprotected work areas, } \\
\text { respectively. }\end{array}$ \\
\hline Montana & $65-75$ & & 35 & $\begin{array}{l}\text { Use concrete barrier to } \\
\text { protect workers and public } \\
\text { from dangerous situations. } \\
\text { If concrete barrier could not } \\
\text { be tapered due to the site } \\
\text { conditions, would use } \\
\text { temporary crash cushion } \\
\text { like quad-guard. }\end{array}$ \\
\hline
\end{tabular}

Nebraska $\quad 75$

Nevada

45-75

New York

55

$40-45$

New York

$55-65$

North Dakota

65

Ohio Turnpike

$55-65$

Oklahoma

75

Pennsylvania

$55-65$

South Carolina

$40-55$

Tennessee

$55-70$

55 45

35
55 for $65-75, \quad 40-45$ for Work zones are designed 45 for 55 , no temp speed for the speeds that will be reduction for reduction of posted for the temporary $55,30-35$ regulatory speed for 45 reductions.

Need to consider volumes, restricted flow, narrow lanes. A speed drop may not be needed. reduction

$\begin{array}{ll}\text { Would } & 10 \mathrm{mph} \text { less } \\ \text { consider } 10 & \text { than posted } \\ \text { mph reduction } & \text { speed limit }\end{array}$

A 10-mph reduction would be considered based on the lane closure, and nature of construction work. The addition of barrier would strengthen consideration of speed limit reduction. 
State

Texas

65

Washington

Up to 70

Wisconsin

65

$55-65$

Wyoming

75

$65-75$
55

Adv. SL Comments

No lower In this drawing, which has than 55 no scale, the concrete barrier is encroaching into the open lane. We would post "ROAD NARROWS" after the taper with a speed advisory no slower than 15 mph below the legal speed. No such lane encroachment allowed on interstates.

If the work zone space is short, a 55-mph advisory speed might be used instead of a reduced regulatory speed. Advisory speed would be posted with the W4-2 (lane reduction transition or merge) warning sign.

Signing would be similar to scenario 3.

The speed limit would be set based upon the width restriction, the degree of hazard, and the roadway geometry. 
No Speed Reduction

$\begin{array}{lllll}\text { State } & \text { Existing SL } & \text { Reg. SL } & \text { Adv. SL } & \text { Comments }\end{array}$

Oregon $\quad 55-65$

Normally no speed

reduction, but there are some exceptions. 


\section{No Information}

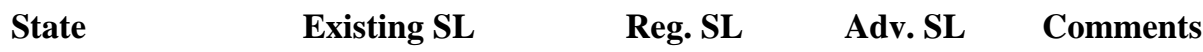

Connecticut

Hawaii

North Carolina

Rhode Island

Utah
No information.

No information.

No information.

No information.

No information. 


\section{APPENDIX H \\ SCENARIO 5: LANE CLOSURE ON A STRUCTURE WITH CONCRETE BARRIER (MULTILANE ROAD)}

\section{Speed Reduction}

\begin{tabular}{|c|c|c|c|c|}
\hline State & Existing SL & Reg. SL & Adv. SL & Comments \\
\hline Alabama & $65-70$ & $50-60$ & 45 & \\
\hline Arizona & $65-75$ & 45 & & $\begin{array}{l}\text { Temporary concrete } \\
\text { barriers are not normally } \\
\text { used for this situation unless } \\
\text { it is long term ( } 3 \text { days or } \\
\text { more) operation. }\end{array}$ \\
\hline California & $65-70$ & May be used & May be used & $\begin{array}{l}\text { Advisory speeds may be } \\
\text { implemented at any speed } \\
\text { increment of } 5 \mathrm{mph} \text { below } \\
\text { posted speed limit down to } \\
25 \mathrm{mph} \text {. }\end{array}$ \\
\hline Florida & 65 & 55 & & $\begin{array}{l}\text { Existing speed limits may be } \\
\text { reduced by } 10 \mathrm{mph} \text { (until } \\
\text { construction activity is } \\
\text { completed). }\end{array}$ \\
\hline Georgia & Up to 70 & $\begin{array}{l}10 \mathrm{mph} \\
\text { reduction }\end{array}$ & & $\begin{array}{l}\text { The contractor may elect to } \\
\text { lower the posted speed in } \\
10 \text { mph increments. }\end{array}$ \\
\hline Illinois & $55-65$ & $45-55$ & & $\begin{array}{l}\text { If no barrier present, no } \\
\text { further reduction from } 10 \\
\text { mph below posted is used. }\end{array}$ \\
\hline Iowa & 65 & 65 & 55 & $\begin{array}{l}\text { The advisory } 55 \mathrm{mph} \text { speed } \\
\text { limit is used at some } \\
\text { structure locations. }\end{array}$ \\
\hline Kansas & 70 & \multicolumn{2}{|l|}{$\begin{array}{l}\text { Max. reduction } \\
\text { of } 10 \text { to fit } \\
\text { actual } \\
\text { constraints }\end{array}$} & $\begin{array}{l}\text { Additional delineation is } \\
\text { required on existing bridge } \\
\text { rail whenever traffic is } \\
\text { moved closer to the rail. }\end{array}$ \\
\hline Kansas Turnpike & 70 & 60 & 60 & $\begin{array}{l}\text { If lane width is restricted } \\
\text { below } 12 \text { feet, speed is } \\
\text { reduced to } 60 \mathrm{mph} \text {. }\end{array}$ \\
\hline Kentucky & Varies & $\begin{array}{l}10 \mathrm{mph} \\
\text { reduction }\end{array}$ & $\begin{array}{l}10 \mathrm{mph} \\
\text { reduction }\end{array}$ & \\
\hline
\end{tabular}


State

Louisiana

65

Reg. SL

65
45

45

55

55

$45-50$

40

$10 \mathrm{mph}$

reduction

$10 \mathrm{mph}$

reduction

The use of a barrier should be based on the need determined by an engineering analysis. To prevent vehicles from impacting the ends of the barrier, the taper and end should be treated as given in chapter 9 of the AASHTO RDG.

Regulatory speed limit signs are shown only when workers are present.

Advisory speed limits should be used for spot situations such as sharp alignment changes, or short sections of narrow lanes, etc. The reduced work zone speed limit is to be displayed only at those times it is needed and removed when no longer needed.

Would use post-mounted static lane closure signs.

By law, work zone speed may be reduced $15 \mathrm{mph}$ below existing. Every structure is different, so there is no MnDOT policy on set speed.

$10 \mathrm{mph}$ reduction

Missouri

65-70 rural, 60

10-20 mph

10- and 20-mph speed urban

reduction in protected (e.g., concrete barriers, crash worthy devices, etc.) and unprotected work areas, respectively. 
State

Montana

$65-75$

Nebraska

75

65-75

Nevada

New York

55

55-65

65

North Dakota

$55-65$

75

55-65

Oregon

Pennsylvania

55-65

40-55 15-mph reduction 35
45

55 for $65-75$, 45 for 55 , no reduction for 45

55

Reg. SL

35

This restricted travel way means all wide loads will need to be detoured before the hit construction area. If concrete barrier could not be tapered due to the site conditions, would use temporary crash cushion like quad-guard.

45-may be used

$\begin{array}{ll}40-45 \text { for } & \text { Work zones are designed } \\ \text { temp. speed } & \text { for the speeds that will be } \\ \text { reduction of } & \text { posted for the temporary } \\ 55,30-35 & \text { regulatory speed } \\ \text { for } 45 & \text { reductions. }\end{array}$

A reduced speed may not be needed. A 15-mph speed drop is the maximum allowable in extreme conditions.
Reduction is based on a worksheet that must be signed off by traffic control plans designer, region traffic manager, and project manager. 
State

Tennessee

$55-70$

Texas

Washington

Wisconsin

65

Up to 70
Reg. SL

Would

consider 10

mph reduction speed limit

$10 \mathrm{mph}$ less

than posted

A 10-mph reduction would be considered based on the lane closure, and nature of construction work.

Construction activity on a structure with barrier would further strengthen consideration of speed limit reduction.

55

Perhaps 55 Same comments as 4. Also a short work area such as this must be recognized as a spot location. For these areas a reduced SL is ineffective, but an advisory speed can be much more effective, as it will be in conjunction with a warning sign explaining "why."

$55 \mathrm{mph}$ regulatory limit would only be posted if the structure work was within a larger/longer project. Signs would be placed between the WZ advance warning signs (posted 2k' prior to lane closure).

The speed limit would be set based upon the width restriction, the degree of hazard, and the roadway geometry. 


\section{No Information}

$\begin{array}{llll}\text { State } & \text { Existing SL } & \text { Reg. SL } & \text { Adv. SL }\end{array}$

Colorado

No information.

Connecticut

No information.

Hawaii

No information.

North Carolina

No information.

Rhode Island

No information.

Utah

No information. 


\section{APPENDIX I}

\section{SCENARIO 6: LANE SHIFT (MULTILANE ROAD)}

\section{Speed Reduction}

\begin{tabular}{|c|c|c|c|c|}
\hline State & Existing SL & Reg. SL & Adv. SL & Comments \\
\hline Alabama & $65-70$ & $50-60$ & & \\
\hline Arizona & $65-75$ & 55 & & $\begin{array}{l}\text { Lane tapers are critical to } \\
\text { maintain } 55 \mathrm{mph} \text { speed } \\
\text { limits. }\end{array}$ \\
\hline California & $65-70$ & May be used & May be used & $\begin{array}{l}\text { Advisory speeds may be } \\
\text { implemented at any speed } \\
\text { increment of } 5 \mathrm{mph} \text { below } \\
\text { posted speed limit down to } \\
25 \mathrm{mph} \text {. }\end{array}$ \\
\hline Georgia & Up to 70 & 55 & & $\begin{array}{l}\text { Tapers should be long } \\
\text { enough to accommodate } \\
\text { posted speed limits. }\end{array}$ \\
\hline Illinois & $55-65$ & $45-55$ & & $\begin{array}{l}\text { Speed reduction optional } \\
\text { depending on the } \\
\text { geometrics of the lane shift. }\end{array}$ \\
\hline Iowa & 65 & $\begin{array}{l}65(55 \mathrm{mph} \text { in } \\
\text { Polk County } \\
\text { work zones) }\end{array}$ & 65 & \\
\hline Kansas & 70 & $\begin{array}{l}\text { Max. 10-mph } \\
\text { reduction }\end{array}$ & & $\begin{array}{l}\text { Posting advisory speed } \\
\text { limit signs will be based on } \\
\text { ball-bank reading of curves. }\end{array}$ \\
\hline Kentucky & Varies & $\begin{array}{l}10 \mathrm{mph} \\
\text { reduction }\end{array}$ & $\begin{array}{l}10 \mathrm{mph} \\
\text { reduction }\end{array}$ & \\
\hline Louisiana & 65 & 45 & $\begin{array}{l}\text { Speed limit } \\
\text { to be } \\
\text { field- } \\
\text { determined }\end{array}$ & $\begin{array}{l}\text { Where shifted section is } \\
\text { long, one set of "REVERSE } \\
\text { CURVE" signs show initial } \\
\text { shift and a } 2 \mathrm{~d} \text { set shows the } \\
\text { return to normal alignment. } \\
\text { An ALL LANES THRU may } \\
\text { be used to emphasize that } \\
\text { no lanes are closed. Use of } \\
\text { a barrier is based on need } \\
\text { determined by engineers. }\end{array}$ \\
\hline
\end{tabular}




\begin{tabular}{|c|c|c|c|c|}
\hline State & Existing SL & Reg. SL & Adv. SL & Comments \\
\hline Maine & 65 & 55 & & $\begin{array}{l}\text { Regulatory speed limit } \\
\text { signs are shown only when } \\
\text { workers are present. }\end{array}$ \\
\hline Maryland & $60-65$ & & & $\begin{array}{l}\text { Would be evaluated } \\
\text { individually by the } \\
\text { assistant district engineer } \\
\text { - Traffic to determine if a } \\
\text { reduced speed limit is } \\
\text { appropriate. }\end{array}$ \\
\hline Minnesota & $55-70$ & $\begin{array}{l}\text { 10-mph } \\
\text { reduction }\end{array}$ & $\begin{array}{l}10-\mathrm{mph} \\
\text { reduction }\end{array}$ & $\begin{array}{l}\text { Advisory speeds are used } \\
\text { at crossover curve based } \\
\text { upon ball-bank readings. }\end{array}$ \\
\hline Mississippi & Up to 70 & & & $\begin{array}{l}\text { Posting advisory speed } \\
\text { limit signs are based on the } \\
\text { curve characteristics. }\end{array}$ \\
\hline Missouri & $\begin{array}{l}65-70 \text { rural, } 60 \\
\text { urban }\end{array}$ & & $\begin{array}{l}10-20 \mathrm{mph} \\
\text { reduction }\end{array}$ & $\begin{array}{l}10-\text { and } 20-\text { mph speed } \\
\text { reduction in protected (e.g., } \\
\text { concrete barriers, crash } \\
\text { worthy devices) and } \\
\text { unprotected work areas, } \\
\text { respectively. }\end{array}$ \\
\hline Nebraska & 60 & 50 & & $\begin{array}{l}\text { Have not used this in rural } \\
\text { areas, so this example is for } \\
\text { an urban interstate. }\end{array}$ \\
\hline Nevada & $65-75$ & $\begin{array}{l}55 \text { for } 65-75, \\
45 \text { for } 55, \text { no } \\
\text { reduction for } \\
45\end{array}$ & $\begin{array}{l}40-45 \text { for } \\
\text { temp. speed } \\
\text { reduction of } \\
55,30-35 \\
\text { for } 45\end{array}$ & $\begin{array}{l}\text { Work zones are designed } \\
\text { for the speeds that will be } \\
\text { posted for the temporary } \\
\text { regulatory speed } \\
\text { reductions. }\end{array}$ \\
\hline New York & 65 & 55 & & $\begin{array}{l}\text { If } 45 \text { mph is desired, step } \\
\text { down to } 55 \text { prior to work } \\
\text { zone, then reduce to } 45 \text { at } \\
\text { the work area. Reduced SL } \\
\text { may not be warranted } \\
\text { because workers are } \\
\text { protected by barriers and all } \\
\text { traffic lanes remain open. } \\
\text { Traffic volume may dictate } \\
\text { whether SL is needed. }\end{array}$ \\
\hline
\end{tabular}




\begin{tabular}{|c|c|c|c|c|}
\hline State & Existing SL & Reg. SL & Adv. SL & Comments \\
\hline New York & $55-65$ & $45-55$ & & $\begin{array}{l}\text { Work zone speed limit } \\
\text { would depend on amount of } \\
\text { lane shift and width of } \\
\text { lanes. }\end{array}$ \\
\hline North Dakota & 65 & 55 & & $\begin{array}{l}\text { Use flaggers and advisory } \\
\text { speed plates. }\end{array}$ \\
\hline Ohio Turnpike & $55-65$ & 50 & & \\
\hline Oklahoma & 75 & $45-75$ & & \\
\hline Oregon & $55-65$ & & & $\begin{array}{l}\text { Reduction is based on a } \\
\text { worksheet that must be } \\
\text { signed off by Traffic } \\
\text { Control Plans Designer, } \\
\text { Region Traffic Manager, } \\
\text { and Project Manager. }\end{array}$ \\
\hline Pennsylvania & $55-65$ & 55 & & \\
\hline Tennessee & $55-70$ & $\begin{array}{l}\text { Based on } \\
\text { design speed } \\
\text { of diversion }\end{array}$ & $\begin{array}{l}10 \text { mph less } \\
\text { than } \\
\text { regulatory } \\
\text { speed }\end{array}$ & $\begin{array}{l}\text { Would try to design } \\
\text { diversion no less than } 10 \\
\text { mph below the roadway's } \\
\text { design speed. However, the } \\
\text { regulatory speed would be } \\
\text { based on the design speed } \\
\text { of the diversion. }\end{array}$ \\
\hline Texas & 65 & 55 & & $\begin{array}{l}\text { Reduced speed only used } \\
\text { in cases where barrier is } \\
\text { within two feet of traveled } \\
\text { way. }\end{array}$ \\
\hline Wisconsin & 65 & $55-65$ & $45-55$ & $\begin{array}{l}\text { If the work space is short, } \\
\text { the advisory speed might } \\
\text { be used instead of the } \\
\text { reduced regulatory speed. } \\
\text { Advisory speed would be } \\
\text { posted before the lane shift } \\
\text { warning sign. }\end{array}$ \\
\hline Wyoming & 75 & $65-75$ & & $\begin{array}{l}\text { The speed limit would be } \\
\text { set based upon the width } \\
\text { restriction, the degree of } \\
\text { hazard, and the roadway } \\
\text { geometry. }\end{array}$ \\
\hline
\end{tabular}




\section{No Speed Reduction}

\begin{tabular}{|c|c|c|c|c|}
\hline State & Existing SL & Reg. SL & Adv. SL & Comments \\
\hline Florida & 65 & 65 & & $\begin{array}{l}\text { No speed reduction. } \\
\text { Existing speed limit to } \\
\text { remain. Lane shift to be } \\
\text { designed for existing speed } \\
\text { limit. }\end{array}$ \\
\hline Massachusetts & 50 & 50 & 50 & $\begin{array}{l}\text { No speed reduction. } \\
\text { Would try to avoid speed } \\
\text { reduction since both lanes } \\
\text { are to remain open and the } \\
\text { shift is not that severe. }\end{array}$ \\
\hline South Carolina & $45-55$ & $45-55$ & & $\begin{array}{l}\text { No speed reduction. } \\
\text { SCDOT practice is to } \\
\text { design the lane shifts to } \\
\text { maintain current speed } \\
\text { limits during these types of } \\
\text { scenarios. }\end{array}$ \\
\hline Washington & Up to 70 & & & $\begin{array}{l}\text { No speed reduction. The } \\
\text { taper rate is set in } \\
\text { accordance with the speed } \\
\text { limit. The barrier is closer to } \\
\text { the lane than the approach } \\
\text { shoulder width, so it must } \\
\text { be identified with an object } \\
\text { marker type } 3 \text {. }\end{array}$ \\
\hline
\end{tabular}




\section{No Information}

$\begin{array}{llll}\text { State } & \text { Existing SL } & \text { Reg. SL } & \text { Adv. SL }\end{array}$

Colorado

No information.

Connecticut

No information.

Hawaii

No information

North Carolina

No information.

Rhode Island

No information.

Utah

No information. 


\section{Not Applicable}

\section{State \\ Existing SL \\ Reg. SL \\ Adv. SL Comments}

Kansas Turnpike

Not applicable. Median barrier does not allow doing this type of closure.

Montana

Not applicable. This setup is not being used because it needs a lot of paving and striping the shifted area which is no good for a short-term work (i.e., less than 30 days). Would probably use a single lane closure instead. 


\section{APPENDIX J}

\section{SCENARIO 7: MEDIAN CROSSOVER (MULTILANE ROAD)}

\section{Speed Reduction}

\begin{tabular}{|c|c|c|c|c|}
\hline State & Existing SL & Reg. SL & Adv. SL & Comments \\
\hline Alabama & $65-70$ & $50-60$ & 45 & \\
\hline Arizona & $65-75$ & 45 & & $\begin{array}{l}\text { Currently, ADOT is working } \\
\text { on standards for the } \\
\text { Interstate median crossover } \\
\text { work zone. To date, it was } \\
\text { done by details inserted in } \\
\text { plans. }\end{array}$ \\
\hline California & $65-70$ & May be used & May be used & $\begin{array}{l}\text { Will use temporary concrete } \\
\text { barrier (k-rail) to separate the } \\
\text { opposing traffic except on } \\
\text { urban-type facilities where } \\
\text { operating speeds are low. } \\
\text { Advisory speeds may be } \\
\text { implemented at any speed } \\
\text { increment of } 5 \text { mph below } \\
\text { posted speed limit down to } \\
25 \text { mph. }\end{array}$ \\
\hline Florida & 55 & 45 & & $\begin{array}{l}\text { Existing speed limit reduced } \\
\text { by } 10 \mathrm{mph} \text { for detours. }\end{array}$ \\
\hline Georgia & Up to 70 & & & $\begin{array}{l}\text { The speed reduction will be } \\
\text { dictated by the angle of the } \\
\text { lane shift and length of the } \\
\text { tapers. }\end{array}$ \\
\hline Illinois & $55-65$ & 55 & & $\begin{array}{l}\text { Regulatory full-time posting } \\
\text { to } 55 \mathrm{mph} \text {. }\end{array}$ \\
\hline Iowa & 65 & 55 & & $\begin{array}{l}\text { Use } 55 \text {-mph regulatory } \\
\text { speed limit based policy on } \\
\text { TLTWO. }\end{array}$ \\
\hline Kansas & 70 & $\begin{array}{l}\text { Max. 10-mph } \\
\text { reduction }\end{array}$ & & $\begin{array}{l}\text { Posting advisory speed limit } \\
\text { signs will be based on } \\
\text { ball-bank reading on the } \\
\text { crossover curve. }\end{array}$ \\
\hline Kansas Turnpike & 70 & 60 & 60 & \\
\hline Kentucky & Varies & $\begin{array}{l}\text { 10-mph } \\
\text { reduction }\end{array}$ & $\begin{array}{l}10-\mathrm{mph} \\
\text { reduction }\end{array}$ & \\
\hline
\end{tabular}




\begin{tabular}{|c|c|c|c|c|}
\hline State & Existing SL & Reg. SL & Adv. SL & Comments \\
\hline Louisiana & 65 & 45 & $\begin{array}{l}\text { Speed to be } \\
\text { field- } \\
\text { determined }\end{array}$ & \\
\hline Maine & 65 & 55 & & $\begin{array}{l}\text { The regulatory speed limit } \\
\text { signs would be posted and } \\
\text { enforced } 24 \text { hours a day. }\end{array}$ \\
\hline Maryland & $60-65$ & 55 & $45-50$ & $\begin{array}{l}\text { Have not specifically sited in } \\
\text { the attachment, but } \\
\text { assumed speed reductions } \\
\text { would be based on traffic } \\
\text { control guidelines. }\end{array}$ \\
\hline Massachusetts & 50 & 50 & $30-40$ & $\begin{array}{l}\text { Would use post-mounted } \\
\text { static signs or CMS to } \\
\text { gradually reduce speed } \\
\text { through the crossover. } \\
\text { Recommend using a double } \\
\text { speed reduction because of } \\
\text { the crossover. }\end{array}$ \\
\hline Minnesota & $55-70$ & $\begin{array}{l}10-\mathrm{mph} \\
\text { reduction }\end{array}$ & $\begin{array}{l}10-\mathrm{mph} \\
\text { reduction }\end{array}$ & $\begin{array}{l}\text { Advisory speed used at the } \\
\text { crossover curve based upon } \\
\text { ball-bank readings. }\end{array}$ \\
\hline Mississippi & Up to 70 & $\begin{array}{l}10-\mathrm{mph} \\
\text { reduction }\end{array}$ & & $\begin{array}{l}\text { Posting advisory speed } \\
\text { limits is based on the } \\
\text { curvature. }\end{array}$ \\
\hline Nebraska & 75 & 55 & 45 & \\
\hline Nevada & $65-75$ & $\begin{array}{l}55 \text { for } 65-75, \\
45 \text { for } 55, \text { no } \\
\text { reduction for } \\
45\end{array}$ & $\begin{array}{l}40-45 \text { for } \\
\text { temp. speed } \\
\text { reduction of } \\
55,30-35 \\
\text { for } 45\end{array}$ & $\begin{array}{l}\text { Work zones are designed for } \\
\text { the speeds that will be } \\
\text { posted for the temporary } \\
\text { regulatory speed reductions. }\end{array}$ \\
\hline New York & 55 & $40-45$ & Do not use & $\begin{array}{l}\text { If the mainline speed limit is } \\
65 \mathrm{mph} \text {, step down to } 55 \text {, } \\
\text { then again to } 45 \text {. Volumes, } \\
\text { geometrics, etc. bear upon } \\
\text { final speed limit reduction. }\end{array}$ \\
\hline North Dakota & 65 & & & $\begin{array}{l}\text { Speed is reduced in } \\
\text { increments of } 20 \text { mph until } \\
\text { reach the speed of the } \\
\text { median crossover. }\end{array}$ \\
\hline
\end{tabular}


State

Oklahoma

75

$55-65$

Oregon

Pennsylvania

$55-65$

South Carolina

$40-55$

$55-70$

Tennessee

Texas

65

55

Based on design speed of diversion

Design speed of crossover or $55 \mathrm{mph}$

45

10 mph less Would try to design than regulatory speed

Reduction is based on a worksheet that must be plans designer, region manager.

Design the crossover to minimize the speed $10 \mathrm{mph}$ when possible.

diversion no less than 10 mph below the roadway's of the diversion.

Detour and transition signed off by traffic control traffic manager, and project reductions to no more than design speed. However, the regulatory speed would be based on the design speed geometry with a design speed equal to or greater than the existing posted speed limit should be provided whenever possible.

Here is an example of an extended work zone where the speed limit could practically be reduced over a section of highway. With the reduced SL would come NO PASSING signs as well as other signing needed for vehicles being shifted to the oncoming lanes. 
State

Wisconsin 65

55

Wyoming

75

60
Reg. SL Adv. SL Comments

$45 \mathrm{mph}$ advisory speed might be used on the warning sign approaching the crossover. Signs would be placed between the WZ advance warning signs (posted 2k' prior to lane closure).

Use a $60 \mathrm{mph}$ on two-way traffic situations, but the crossover is signed for the existing geometrics. Again, field people tend to be conservative. Speed limits through the crossover and advisory speeds are lower than necessary for the geometrics. 


\section{No Information}

State

Colorado

Connecticut

Hawaii

Missouri

Montana

New York

North Carolina

Rhode Island

Utah

\section{Existing SL}

65-70 rural, 60 urban

$65-75$
Reg. SL Adv. SL Comments

No information.

No information.

No information.

No information.

No information.

No information.

No information.

No information

No information. 


\section{APPENDIX K}

\section{QUESTION 4: SYSTEM EFFECTIVENESS}

\section{Regulatory Speed Limit Signs, Advisory Speed Limit Signs, and Changeable Message Signs}

State

Alabama

Arizona

Colorado

Connecticut

Florida

Georgia

Hawaii

Illinois

\section{Regulatory SL Signs}

Ineffective.

Partially effective (i.e., estimated 30 to 50 percent compliance).

No information on the system effectiveness. Formal studies have not been conducted. However, it is perceived that artificially low speed limits do not affect speeds that much.

\section{Advisory SL Signs}

Changeable Message Signs

Ineffective.

Partially effective (i.e., estimated 30 to 50 percent compliance).

No information on the system effectiveness. Have used this at two tunnels only. Formal studies have not been conducted. However, it is perceived that artificially low speed limits do not affect speeds that much.

No information on the system effectiveness. CMS with safety warning radar system (i.e., A MAS task to be completed by end of 1999).

within the WZ. FDOT has a task Team working on the MAS. Studies will be done on the indicated systems.

Moderate.

Minor.

Moderate.

No information on the More effective than standard construction signs.

No studies were done to determine the system effectiveness. Used CMS with radar. 


\section{State}

Iowa

Kansas

Kansas Turnpike

Kentucky

Louisiana

Maryland

Massachusetts

Minnesota

Mississippi

Missouri

Montana

Nebraska

Nevada

New York

\section{Regulatory SL Signs}

Very little effect without heavy police enforcement.

\section{Advisory SL Signs}

Changeable Message Signs
Somewhat effective.

Ineffective.

No information on the system effectiveness.

No information on the system effectiveness. system effectiveness.

Effective.

Generally ineffective.

A 3-4 mph speed reduction.

Ineffective.

No information on the system effectiveness.

No information on the system effectiveness.
No information on the system effectiveness. Do not have quantitative field data, only observations.

Good when coupled with police enforcement.
No information on the system effectiveness. CMS displays "HIGHER TRAFFIC FINES IN WORK ZONES."

Effective. Used in conjunction with regulatory signs.

Vehicles appear to slow down to read these signs.
No information on the system effectiveness. Do not have quantitative field data, only observations.

No information on the system effectiveness. Has had limited use so far. Used CMS with radar. 
State

New York Thruway Generally ineffective.

North Carolina

North Dakota

Old Method (20 mph reduction): ineffective. First year of a new method (10 mph reduction) seems slightly more effective.

Ohio Turnpike

Oklahoma Turnpike

Oregon

Pennsylvania Ineffective.

Rhode Island Ineffective.

South Carolina Poor.

Tennessee Minor. Minor.

Texas No information on the system effectiveness.

No information on the system effectiveness.

A 3-5 mph decrease in the 85th percentile speed. Used CMS with radar.

Changeable Message Signs

Used when a motorist has to alter his/her driving path, such as curves, lane closures, lane shifts.

Some noticeable speed drops depending on the sharpness of the curve.

Advisory SL Signs
Ineffective. Used CMS with radar.

Fair. Used CMS with radar.

No information on the system effectiveness. Use CMS if construction plans call for it.

Utah

Washington Effective only if warranted by driving conditions.

Effective if warranted by driving conditions and when warning signs warn drivers about a specific hazard.

Wisconsin Minor impact on speed reductions.

Minor impact on speed reductions.
Minor impact on speed reductions. 
State

Wyoming

\section{Regulatory SL Signs}

No information on the system effectiveness. Sometimes used with flashing beacons.

\section{Advisory SL Signs}

\section{Changeable Message Signs}


Police Enforcement, Ghost Police Car, and Flaggers

State

Alabama

Arizona

California

Colorado

\section{Connecticut}

Florida

Georgia

Hawaii

Illinois

Iowa

Kansas

Highway Patrol assigned to project: very effective when present, but costly. Fines doubled in work zones: effective with enforcement.

Kansas Turnpike

Kentucky

Continuous police

enforcement very effective.

90 to 95 percent

compliance).

No information on the system effectiveness.

No information on the system effectiveness. Enforcement by personnel hired for project monitoring as well as posting doublefines signs. Formal studies have not been conducted. However, it is perceived that artificially low speed limits do not affect speeds that much.

Most effective. Hired off-duty police.

Very effective.

Enforcement in form of additional signings, such as "\$85 FINE FOR ILLEGAL PASSING." Has helped somewhat in high ADT locations.

Very effective.
Police Enforcement

Ghost Police Car

Flaggers

Very effective (i.e., estimated
Very effective with proper placement. 
State

Louisiana

Maine

Maryland

Massachusetts

Minnesota

Mississippi

Missouri

Montana

Nebraska

Nevada

New York

New York Thruway

\section{Police Enforcement}

No information on the system effectiveness.

Very effective.

A 6-8 mph speed reduction.

No information on the system effectiveness.

Very effective while the police officer was present and for a short time after the enforcement ends.

Good.

Seems to be working the best. Do not have quantitative field data, only observations. Added enforcement from NV highway patrol will be requested when having difficult time in getting the speed down. Also, have a double-fine statute when workers are present.

No information on the system effectiveness. (1) Dedicated: It is an integral portion of the capital project. It insures full coverage for just very difficult projects, e.g. WZ at high speed \& vol. (2) Cooperative: arranged with state $\&$ local police on a need basis when police resources are available.

Very effective.

Moderately effective. 
State

North Carolina

North Dakota

Ohio Turnpike

Oklahoma Turnpike

Oregon

Pennsylvania

Rhode Island

South Carolina

Tennessee

Texas

Utah

Washington

Wisconsin

Wyoming
Police Enforcement

Increased law enforcement with increased fines for speeding in work zones.

Resulted in compliance with posted speed limits.

\section{Ghost Police Car Flaggers}

Used Law enforcement vehicles with a mannequin. Reduced 85th

percentile speeds by 3-5 mph in the initial weeks of deployment.

Police enforcement: moderate. Double fine: ineffective.

Effective when violators are ticketed.

Good.

Effective, but expensive.

Effective.

Seems to be the most effective measure.

Seems to be the most effective system.
Can be effective at the work area. 
Speed Monitoring Display, Drone Radar, and Rumble Strips

State

Alabama

Arizona

California

Colorado

Connecticut

Florida

Georgia

Hawaii

Illinois

Iowa

Kansas

Kansas Turnpike

Kentucky

Louisiana

Maine

Maryland

Massachusetts

Minnesota
Speed Display

Drone Radar

Rumble Strips
Partially effective (i.e., estimated 30 to 50 percent compliance).

No information on the system effectiveness. Radar speed display trailer with variable message capability ( A MAS task to be completed by the end of 1999).

When those vehicles with radar slow down it is like a chain reaction.

A 4-6 mph speed reduction. 
Mississippi

Missouri

Montana

Used a "SLOW DOWN

NOW" flashing sign.

Effective for a short

duration (10-mph

reduction). Back to

normal after drivers

figured out no

enforcement is present.

Nebraska

Nevada

New York

No information on the system effectiveness. Currently planned for statewide use. Partial coverage planned for 1999, full coverage for 2000

New York Thruway Initially very effective; after Moderately effective. extended period moderately effective.

North Carolina

Reduced 85th percentile speeds by $3-5$ mph during the initial weeks of deployment.

North Dakota

Ohio Turnpike

Ineffective-trucks would see how high the numbers would go.

Oklahoma Turnpike

Oregon

Pennsylvania

Ineffective.

Rhode Island

South Carolina 
State

Tennessee

Texas

Utah

Washington

Wisconsin

Wyoming
Speed Display

Drone Radar

Have had limited use so far, Not enough experience. and mixed comments on their effectiveness.

\section{Rumble Strips}

sing them any more as we had trouble

keeping them in place. 
Lane Narrowing, Pavement Markings, and Highway Advisory Radio

State

Alabama

Arizona

California

Colorado

Connecticut

Florida

Georgia

Hawaii

Illinois

Iowa

Kansas

Kansas Turnpike

Kentucky

Louisiana

Maine

Maryland

Both lane narrowing and reducing the spacing with "channelizing" devices are effective.

Massachusetts

Minnesota
Lane Narrowing

Pavement Markings

Highway Advisory Radio
No information on the system effectiveness. (A MAS task to be

completed by the end of 1999).
Somewhat effective. It makes the traveler aware of the situation. 
Mississippi

Missouri

Montana

Nebraska

Nevada

New York

New York Thruway

North Carolina

North Dakota

Ohio Turnpike

Oklahoma

Oregon

Pennsylvania

Rhode Island

South Carolina

Tennessee

Texas

Utah

Washington

Wisconsin
No information on the system effectiveness. Transverse pavement markings being tried for the first time on a project in 1999. Results are not yet available. 
State

Lane Narrowing
No information on the system effectiveness.
Sometimes used, but "channelizing" devices
generally suffer.
Wyoming

Pavement Markings

Highway Advisory Radio 
APPENDIX L

\section{QUESTION 5: SYSTEM EVALUATION}

\section{Research}

\section{Florida}

Response

Yes

Regulatory Speed signs

Changeable Message Signs

Currently being studied. Results available as part of the MAS by the end of 1999 .

Enforcement

Speed Display

Currently being studied. Results available as part of the MAS by the end of 1999 .

Drone Radar

Narrow Lanes

Pavement Markings

Highway Advisory Radio

Currently being studied. Results available as part of the MAS by the end of 1999 .

\section{Illinois}

Response

Research was conducted by Dr. Benekohal at the University of Illinois.

Regulatory Speed signs

Changeable Message Signs

Enforcement

Speed Display

Drone Radar

Narrow Lanes

Pavement Markings

Highway Advisory Radio 
Iowa

Response

Research is being conducted by CTRE.

Regulatory Speed signs

Changeable Message Signs

Enforcement

Speed Display

Drone Radar

Narrow Lanes

Pavement Markings

Highway Advisory Radio

\section{Kansas}

Response

Research is being conducted by the Midwest States Smart Work Zone Deployment Initiative. No results yet available.

\section{Regulatory Speed signs}

Changeable Message Signs

Enforcement

Speed Display

Drone Radar

Narrow Lanes

Pavement Markings

Highway Advisory Radio 


\section{Minnesota}

Response

Yes

Regulatory Speed signs

Changeable Message Signs

Enforcement

Speed Display

Drone Radar

Narrow Lanes

Pavement Markings

Highway Advisory Radio

New York Thruway

Response

Regulatory Speed signs

Changeable Message Signs

Enforcement

Speed Display

Drone Radar

Narrow Lanes

Pavement Markings

Highway Advisory Radio 8-mph reduction.

5-mph reduction.

3-mph reduction.
Yes

A series of speed studies have been completed in WZs where the posting of regulatory 45-mph speed limit technique was used. These will be compared to speed studies in WZs where a variety of techniques (CMS with radar, drone radar, enforcement) will be tried. 
North Carolina

Response Yes

Regulatory Speed signs

Changeable Message Signs

Enforcement

Speed Display

Drone Radar

85th percentile speed studies using hand-held radar were performed at spot locations where 3- to 5-mph reduction observed. No reports available.

Narrow Lanes

Pavement Markings

Highway Advisory Radio

\section{South Carolina}

Response

Regulatory Speed signs

Changeable Message Signs

Enforcement

Speed Display

Drone Radar

Narrow Lanes

Pavement Markings

Highway Advisory Radio
Yes

Results have shown that a radar system reduces traffic by no more than 5 mph. 


\section{Washington}

\section{Response}

Regulatory Speed signs

Changeable Message Signs

Enforcement

Speed Display

Drone Radar

Narrow Lanes

Pavement Markings

Highway Advisory Radio

\section{Wisconsin}

Response

Regulatory Speed signs

Changeable Message Signs

Enforcement

Speed Display

Drone Radar

Narrow Lanes

Pavement Markings

Highway Advisory Radio
Research conducted by Graham-Migletz (816-254-1788).
Yes

Currently being tried on a project on the approach to a lane closure.

Before/after speed studies are being done, but results are not yet available. 


\section{No Research}

State

Alabama

Arizona

California

Colorado

Hawaii

Kansas Turnpike

Kentucky

Louisiana

Maine

Maryland

Massachusetts

Mississippi

Montana

Nevada

New York

Oklahoma Turnpike

Oregon

Pennsylvania

Rhode Island

Tennessee

Texas

Utah

Wyoming

\section{Response}

No research.

No research.

No research.

No research.

No research.

No research.

No research.

No research

No research.

No research

No research.

No research.

No research.

No research.

No research

No research

No research.

No research.

No research.

No research.

No research.

No research.

No research. 


\section{No Information}

$\begin{array}{ll}\text { State } & \text { Response } \\ \text { Connecticut } & \text { No information. } \\ \text { Georgia } & \text { No information. } \\ \text { Missouri } & \text { No information. } \\ \text { Nebraska } & \text { No information. } \\ \text { North Dakota } & \text { No information. } \\ \text { Ohio Turnpike } & \text { No information. }\end{array}$




\section{APPENDIX M}

\section{QUESTION 6: MOST EFFECTIVE SYSTEM}

\section{Information}

State

Alabama

Arizona

California
Enforcement

Drone Radar

Comments

Continuous police enforcement on a regular or daily basis is the only effective method we have found. However, this is only used on projects that allow to contract and is paid for as a line item in the contract from project funds.

Use of off-duty highway patrol officers with vehicles has been mandated on all construction projects with high speed traffic for three+ years.

The speed violations through construction have been virtually nil since. Start using on contract maintenance WZs and occasionally in urban WZs.

Caltrans has contracted with the California Highway Patrol (CHP). The CHP presence in work zones is very effective. Motorists respond to the CHP presence and generally obey posted speed limits. Caltrans implemented this program in 1992-1993. 
State

Colorado

Connecticut

Hawaii

Illinois

Kansas Turnpike

A state police vehicle parked in the advance sign pattern with lights flashing.

Standard lane closure with reduced speed limit sign and law enforcement.

Have police present at the construction zone. This method has been used only sparingly when speed reduction is critical.
Drone Radar

ork zone to avoid speed limit reductions.

When reduction is necessary, post realistic limits.

Trying to set and maintain realistic speed limits is the best policy for obtaining compliance. Reducing the speed limit where conditions warrant, but only during those times when these conditions exist.

Used combine highway advisory radio, variable message signs, warning signs, and flashing lights to control high volume WZs where backups occur. Have used the process for 3-4 years on Friday nights and other high traffic times.

Kentucky

The presence of police officers is very effective. However, there is no long-term effect. Speeds increase when officers leave the area. 
State

Louisiana

Maryland

Massachusetts

Minnesota

Montana
Enforcement

Law enforcement is the most effective system used by LADOT. This is based on the number of tickets issued, and has been used as a speed reduction tool for at least 50 years. It is used when roadway conditions and traffic warrant a need to reduce speed in WZs.

Enforcement in conjunction with regulatory (double-fine) signs. In use for 9 years.

At the present time, this is the only device we use. It has been used since July 1996. It is used on all National Highway Roadway systems.

Extraordinary

enforcement has been the most effective. This is based on speed studies conducted at various locations. This method is used extensively on construction projects, and has been used for about 5 years at about $20 \%$ of construction projects per year.

The use of Highway Patrol in work zone is funded through the increased work zone fines. Off-duty officers have been used for about 5 years. Project funds are used to pay for their time spent in construction zones. 
State

Nevada

New York

New York

North Carolina

Pennsylvania
Enforcement

Drone Radar

Police enforcement is simply the key, combined with realistic work zone speed limits. The two combined result in a successful work zone speed limit program.
NVDOT system evaluations have evolved by observing, in the field, what works, what doesn't. Field observers include department's construction personnel, traffic engineering personnel, as well as contractor's personnel. This procedure has been in use, on a case by case basis for about 2 years. As soon as the new policy is implemented, it will be used on all projects where the nonconstruction speed limit is $55 \mathrm{mph}$, or higher.
Study is underway. As yet to be determined.
Increased fines in the work zone with increased law enforcement resulted in increased compliance with the posted speed limit.

High-level police enforcement appears to be the only effective method of managing work zone speeds. Unfortunately, the state police have limited resources and therefore this is infrequently used. 
State

South Carolina

Tennessee

ashington

Wisconsin

Wyoming

\section{Enforcement}

The use of off-duty

highway troopers to

patrol the project was

found most effective.

The salaries of these

troopers are charged to

the public. Patrol cars

with flashing blue lights

appear to be the most

effective.

Have police present for about 4 years on most interstate projects.
Drone Radar

Comments
The best thing to do is to remember that the speed limits are for the driver. If the speed limits are appropriate for driving conditions, drivers' compliance will be observed.
Enforcement has been the most effective measure, based on comments from field engineers and worker observations. On some high-volume, high-speed roadways, overtime enforcement is funded during the project. This has been done for approx. 12 years, about 10 projects per year.

Patrol visibility seems to be the most effective. Their time is being charged to the projects. 


\section{No Information}

State

Georgia

Iowa

Kansas

Maine

Mississippi

Missouri

Nebraska

North Dakota

Ohio Turnpike

Oklahoma

Oregon

Rhode Island

Texas

Utah

\section{Enforcement}

Drone Radar

No information.

No information.

No information.

No information.

No information.

No information.

No information.

No information.

No information

No information.

No information.

No information.

No information. 